Prepared in cooperation with the Bureau of Reclamation

\title{
Emigration and Transportation Stress of Juvenile Chinook Salmon Relative to their Reintroduction Upriver of Shasta Dam, California, 2017-18
}

Open-File Report 2018-1144 



\section{Emigration and Transportation Stress of Juvenile Chinook Salmon Relative to their Reintroduction Upriver of Shasta Dam, California, 2017-18}

By Noah S. Adams, Theresa L. Liedtke, John M. Plumb, Lisa K. Weiland, Amy C. Hansen, and Scott D. Evans

Prepared in cooperation with the Bureau of Reclamation

Open-File Report 2018-1144

U.S. Department of the Interior

U.S. Geological Survey 


\title{
U.S. Department of the Interior \\ RYAN K. ZINKE, Secretary
}

\author{
U.S. Geological Survey \\ James F. Reilly II, Director
}

U.S. Geological Survey, Reston, Virginia: 2018

For more information on the USGS—-the Federal source for science about the Earth, its natural and living resources, natural hazards, and the environment-visit https://www.usgs.gov/ or call 1-888-ASK-USGS (1-888-275-8747).

For an overview of USGS information products, including maps, imagery, and publications, visit https:/store.usgs.gov.

Any use of trade, firm, or product names is for descriptive purposes only and does not imply endorsement by the U.S. Government.

Although this information product, for the most part, is in the public domain, it also may contain copyrighted materials as noted in the text. Permission to reproduce copyrighted items must be secured from the copyright owner.

Suggested citation:

Adams, N.S., Liedtke, T.L., Plumb, J.M., Hansen, A.C., Evans, S.D., and Weiland., L.K., 2018, Emigration and transportation stress of juvenile Chinook salmon relative to their reintroduction upriver of Shasta Dam, California, 2017-18: U.S. Geological Survey Open-File Report 2018-1144, 60 p., https://doi.org/10.3133/ofr20181144.

ISSN 2331-1258 (online) 


\section{Content}

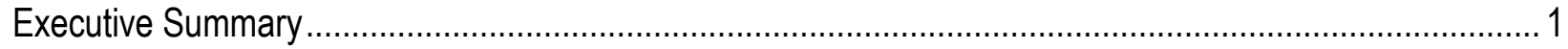

Chapter A. Distribution and Migration of Acoustic-Tagged Late-Fall Chinook Salmon Released

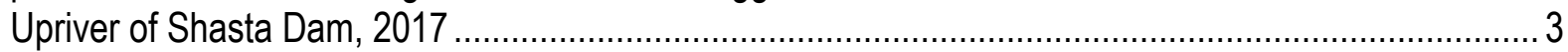

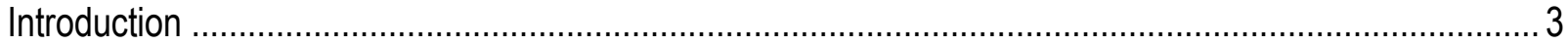

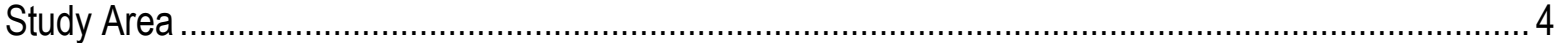

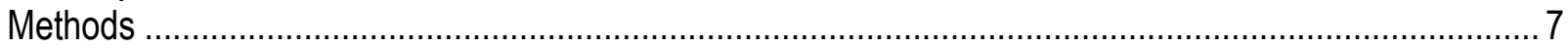

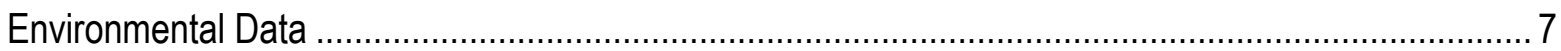

Transmitters and Fish Tagging .............................................................................................

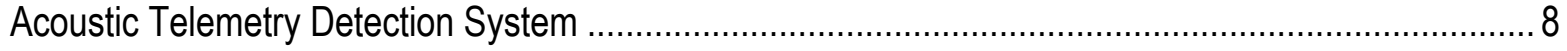

Travel Times and Movements Upriver of Shasta Dam.............................................................. 10

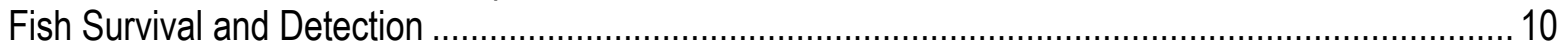

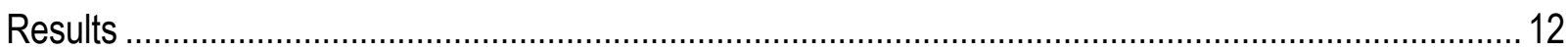

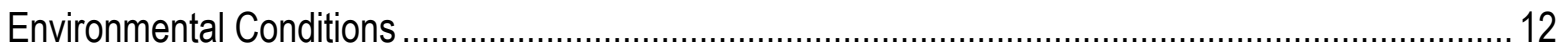

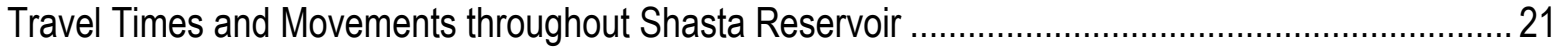

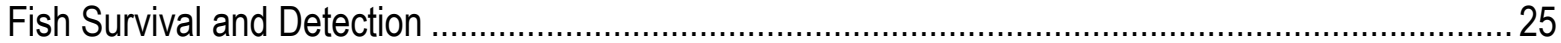

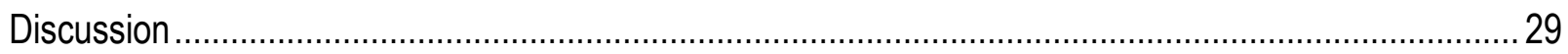

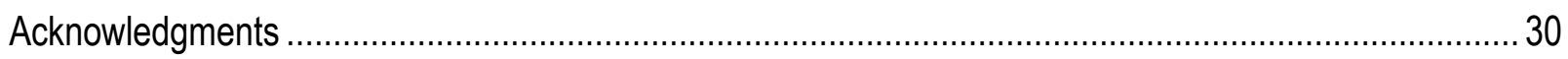

References Cited................................................................................................................ 31

Chapter B. Stress Physiology of Juvenile Chinook Salmon Following Transport........................................ 33

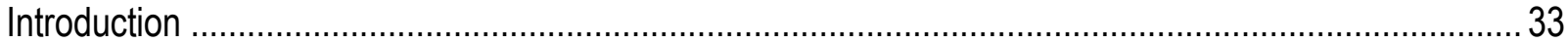

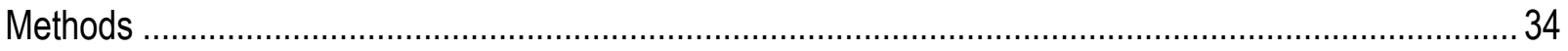

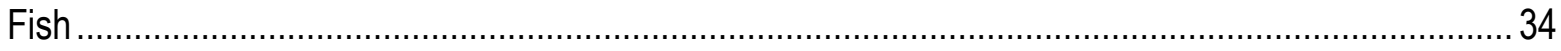

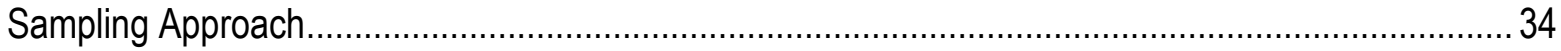

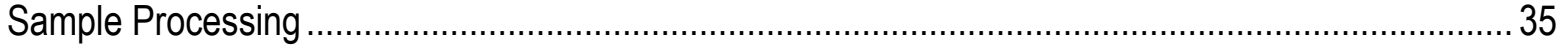

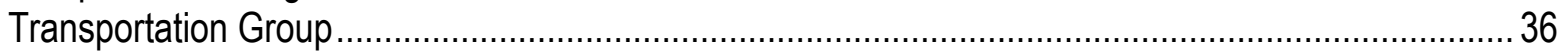

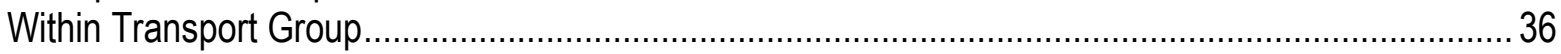

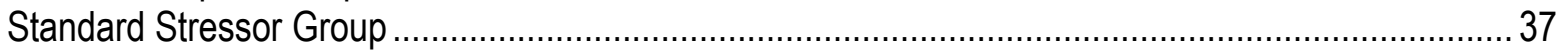

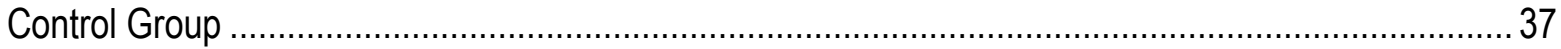

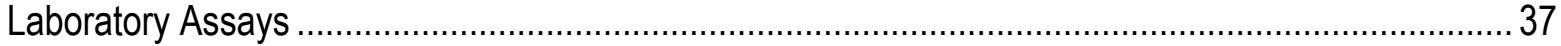

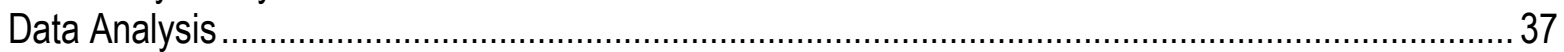

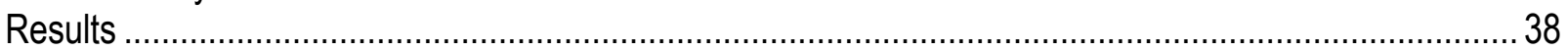

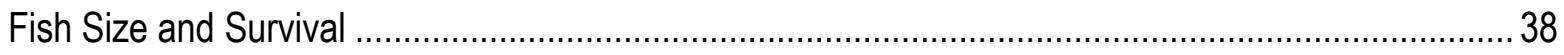

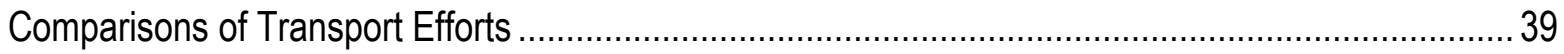

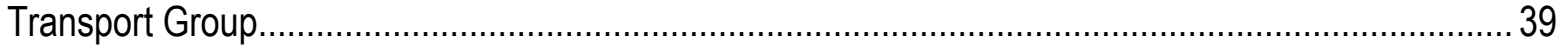

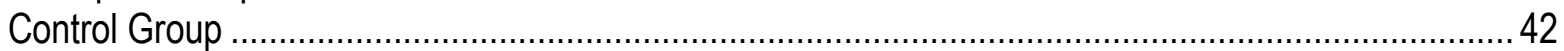

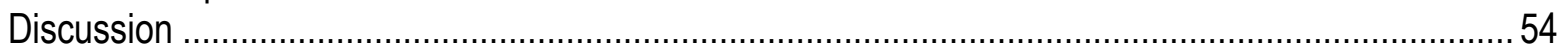

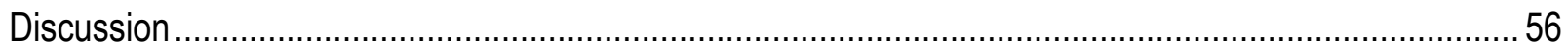

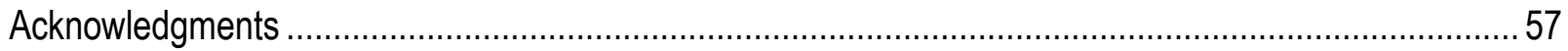

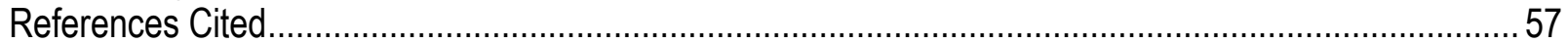

Appendix 1. Summary of Detection Counts for the First (February) Release Group of Acoustic-Tagged Late-Fall Run Chinook Salmon by Detection Location and River Kilometer, Shasta Dam, California, 2017 


\section{Figures}

\section{Chapter A}

Figure A-1. Shasta Dam, Shasta Reservoir and its tributaries the upper Sacramento River, McCloud River, and Pit River, California 5

Figure A-2. The Sacramento River from Shasta Reservoir to San Francisco, California.

Figure A-3. Diagram showing schematic of the structure and spatial layout of the Cormack-Jolly-Seber model that was fitted to the detection data of acoustic-tagged late-fall run Chinook salmon released into the McCloud River upriver of Shasta Dam, 2017.

Figure A-4. Graphs showing flow, turbidity, and water temperature at the streamgage (MSS) located

$3.3 \mathrm{rkm}$ upstream of the McCloud River Bridge, California, during the first release (top graph, February 1May 10, 2017) and the second release (bottom graph November 12, 2017-March 11, 2018)

Figure A-5. Mean daily 2017 flow, turbidity, and water temperature at the streamgage (MSS) located

$3.3 \mathrm{rkm}$ upstream of the McCloud River Bridge, California and the daily minimum and maximum of 2007-2016 ... 14

Figure A-6. Daily plots of discharge at Shasta Dam, discharge at Shasta Dam river outlet, flows into

Shasta Reservoir, and daily change in water storage in Shasta Reservoir, California, during the first study (a;

February 1-May 10, 2017) and the second study (b; November 12, 2017-March 11, 2018)

Figure A-7. Daily plots of discharge at Shasta Dam, discharge at Shasta Dam river outlet, daily flows, and change in water storage in Shasta Reservoir, California during 2017, and the daily minimum and maximum, 2007-16

Figure A-8. Percentage of acoustic-tagged juvenile late-fall run Chinook salmon released February 1-3, 2017, and detected by date and location through May 10, 2017

Figure A-9. Percentage of acoustic-tagged juvenile late-fall run Chinook salmon released November 12-15, 2017, and detected by date and location through March 11, 2018, Shasta Dam, California

Figure A-10. Kaplan-Meier plots of travel times (in days) of acoustic-tagged juvenile late-fall run Chinook salmon between release at the McCloud River Bridge and detection arrays in Shasta Reservoir and tributaries, California, through May 10, 2017.

Figure A-11. Kaplan-Meier plots of travel times (in days) of acoustic-tagged juvenile late-fall run Chinook salmon between release at the McCloud River Bridge and detection arrays in the McCloud River, Shasta Reservoir, and Keswick Dam forebay, California, through March 11, 2018

Figure A-12. Graph showing apparent survival estimates (per $100 \mathrm{rkm}$ ) for acoustic-tagged late-fall run Chinook salmon that were released at the McCloud River Bridge, California, February 2017

\section{Chapter B}

Figure B-1. Graph showing levels of cortisol, glucose, and lactate in juvenile Chinook salmon prior to a 60 -minute transport $(t=0)$, at the mid-point of transport $(t=30)$, and immediately following transport $(t=60)$, compared to baseline controls $(\mathrm{BL})$ and the control group (CON)

Figure B-2. Graph showing levels of cortisol, glucose, and lactate in juvenile Chinook salmon subjected to a 60-minute transport (TRAN, shown in solid blue), and a baseline control group (shown in dashed black) serially sampled from immediately following transport (time $=0 \mathrm{~h}$ ) through $48 \mathrm{~h}$

Figure B-3. Graph showing levels of cortisol, glucose, and lactate in Chinook salmon subjected to a standard stressor (STD, shown in green), and a baseline control group (shown in black) serially sampled from immediately following transport (time $=0 \mathrm{~h}$ ) through $48 \mathrm{~h}$

Figure B-4. Graph showing levels of cortisol, glucose, and lactate in Chinook salmon in the control group (CON, shown in orange), and a baseline control group (shown in black) serially sampled from immediately following transport (time $=0 \mathrm{~h}$ ) through $48 \mathrm{~h}$ 
Figure B-5. Graph showing levels of cortisol in three groups of Chinook salmon monitored for $48 \mathrm{~h}$ following a stressor.

Figure B-6. Graph showing levels of glucose in three groups of Chinook salmon monitored for $48 \mathrm{~h}$ following a stressor.

Figure B-7. Graph showing levels of lactate in three groups of Chinook salmon monitored for $48 \mathrm{~h}$ following a stressor.

Figure B-8. Graph showing levels of glucose measured by laboratory assay (lab) and field meter (meter) in three groups of Chinook salmon monitored for $48 \mathrm{~h}$ following a stressor

Figure B-9. Graph showing levels of glucose and lactate measured within a transport (WT) experience by laboratory assay (lab) and field meter (meter) in Chinook salmon prior to a 60-minute transport $(\mathrm{t}=0)$, at the mid-point of transport $(t=30)$, and immediately following transport $(t=60)$, compared to baseline controls $(\mathrm{BL})$ and the control group (CON)...

Figure B-10. Graphs showing levels of lactate measured by laboratory assay (lab) and field meter (meter) in three groups of Chinook salmon monitored for $48 \mathrm{~h}$ following a stressor

\section{Tables}

\section{Chapter A}

Table A-1. Summary statistics for the numbers and sizes of juvenile late-fall run Chinook salmon released into the McCloud River during 2017.

Table A-2. Distances in river kilometers between detection arrays in Shasta Reservoir and tributaries, 2017 ....... 9

Table A-3. Summary of reach-specific survival and detection parameters that were estimated from the acoustic detections of late-fall run Chinook salmon released into the McCloud River ( $r k m=590)$ above Shasta Dam and Reservoir during 2017

Table A-4. The percentage of acoustic-tagged juvenile late-fall run Chinook salmon detected by each detection array

Table A-5. Summary statistics for travel times (days) of acoustic tagged juvenile late-fall run Chinook salmon that traveled from the release at the McCloud River Bridge to locations downriver.

Table A-6. Summary statistics for the number of trips to each detection site by acoustic-tagged juvenile late-fall run Chinook salmon released at the McCloud River Bridge.

Table A-7. Observed detection counts by location and those expected under the Cormack-Jolly-Seber model fit to the detection data on late-fall run Chinook salmon released at the McCloud River Bridge in February 2017

Table A-8. Summary statistics of the posterior distributions for each of the Cormack-Jolly-Seber survival model parameters (1) detection probability, p, (2) apparent survival probability, $\phi,(3)$ the joint probability of detection and survival, $\lambda$, and (4) the corresponding derived estimates of apparent survival provided as per kilometer basis. ... 27

\section{Chapter B}

Table B-1. Number and fork lengths (in millimeters) of juvenile Chinook salmon monitored for stress physiology

Table B-2. Number and weights (in grams) of juvenile Chinook salmon monitored for stress physiology 38

Table B-3. Cortisol, glucose, and lactate from standard laboratory assays and field meters for Chinook salmon by sample period and group 


\section{Conversion Factors}

U.S. customary units to International System of Units

\begin{tabular}{ccc}
\hline Multiply & By & To obtain \\
\hline Flow rate & \\
\hline cubic foot per second $\left(\mathrm{ft}^{3} / \mathrm{s}\right)$ & 0.02832 & cubic meter per second $\left(\mathrm{m}^{3} / \mathrm{s}\right)$ \\
\hline
\end{tabular}

International System of Units to U.S. customary units

\begin{tabular}{lcl}
\hline \multicolumn{1}{c}{ Multiply } & \multicolumn{1}{c}{ By } & \multicolumn{1}{c}{ To obtain } \\
\hline millimeter $(\mathrm{mm})$ & Length & \\
kilometer $(\mathrm{km})$ & 0.03937 & inch (in.) \\
& 0.6214 & mile $(\mathrm{mi})$ \\
\hline square meter $\left(\mathrm{m}^{2}\right)$ & Area & \\
\hline & 10.76 & square foot $\left(\mathrm{ft}^{2}\right)$ \\
\hline kilometer per day $(\mathrm{km} / \mathrm{d})$ & Migration rate & \\
\hline & 0.6214 & mile per day $(\mathrm{mi} / \mathrm{d})$ \\
\hline square kilometer per day $\left(\mathrm{km}^{2} / \mathrm{d}\right)$ & Diffusion rate & \\
\hline & 0.3861 & square mile per day $\left(\mathrm{m}^{2} / \mathrm{d}\right)$ \\
\hline gram $(\mathrm{g})$ & Mass & ounce, avoirdupois $(\mathrm{oz})$ \\
kilogram $(\mathrm{kg})$ & 0.03527 & pound avoirdupois $(\mathrm{lb})$ \\
\hline
\end{tabular}

Temperature in degrees Celsius $\left({ }^{\circ} \mathrm{C}\right)$ may be converted to degrees Fahrenheit $\left({ }^{\circ} \mathrm{F}\right)$ as follows:

$$
{ }^{\circ} \mathrm{F}=\left(1.8 \mathrm{x}^{\circ} \mathrm{C}\right)+32
$$

\section{Abbreviations}

SDFPE Shasta Dam Fish Passage Evaluation

USGS United States Geological Survey 


\title{
Emigration and Transportation Stress of Juvenile Chinook Salmon Relative to their Reintroduction Upriver of Shasta Dam, California, 2017-18
}

\author{
By Noah S. Adams, Theresa L. Liedtke, John M. Plumb, Lisa K. Weiland, Amy C. Hansen, and Scott D. Evans
}

\section{Executive Summary}

The Bureau of Reclamation supports the Shasta Dam Fish Passage Evaluation (SDFPE; Yip, 2015) program, and in 2016 set out to determine the feasibility of reintroducing winter-run and springrun Chinook salmon (Oncorhynchus tshawytscha) and steelhead (O. mykiss) to tributaries upstream of Shasta Dam. Ideally, reintroduction strategy includes trapping naturally produced downstreammigrating juvenile fish at the head of Lake Shasta (upstream of Shasta Dam), or near the mouth of the tributaries where they flow into the lake. However, evaluations of a juvenile collection system in one of the target tributaries (McCloud River) was delayed because of concerns about the fish source to be used as surrogate for winter-run Chinook salmon and the location and impact of the trap-and-haul operations.

In 2017, the U.S. Geological Survey (USGS) was contracted to evaluate the reintroduction of winter-run salmon into tributaries upstream of Shasta Dam, and the McCloud River, having the most suitable spawning and rearing habitat for salmon adjacent to Shasta Reservoir (Lake) was the chosen study area. The first stage of the project was to assess the feasibility using a head-of-reservoir fish trap to collect juvenile salmon, but these efforts were delayed, so efforts were used to assess how juvenile Chinook salmon would distribute within the McCloud River and Shasta Reservoir and help determine the feasibility of collecting fish at Shasta Dam. Importantly, NOAA fisheries was also conducting an acoustic telemetry project through the Sacramento River, and they provided the additional acoustic detection data on our tagged fish to San Francisco Bay. These data were collected beyond original study goals, but added a large contribution to the findings and inferences from this study.

To determine how fish distribute upriver of Shasta Dam and the fates of fish below Shasta Dam, we (USGS) used acoustic telemetry to track tagged fish from their release point in the McCloud River to the San Francisco Bay. We released fish over two periods: (1) February 1-3, 2017, and (2) November 12-15, 2017. Test fish and environmental conditions varied greatly during the two release periods, allowing us to gather a wide range of information in a relatively short time. Flows were an order of magnitude different between the two release groups (about 75,000 cubic feet per second versus 5,000 $\mathrm{ft}^{3} / \mathrm{s}$ ), the time of year was different (February-May and November-March), and the study fish differed in age, size, and chromosome structure (diploid and triploid). In our first (February) release of 262 tagged fish, 182 (70 percent) were detected at least once at the dam, 41 (16 percent) were detected at least once downstream of Shasta Dam, and 3 (1 percent) traveled as far downriver as San Francisco Bay. During the second (November) release of 355 tagged fish, just 4 fish (1 percent) were detected at Shasta Dam and 1 downstream of Shasta Dam. When estimable, detection rates of tagged fish were high at Shasta Dam (0.975) and ranged from 0.33 to 0.61 at the sites downriver of Shasta Dam. Reachspecific apparent survival probabilities (per 100 kilometer $[\mathrm{km}]$ ) for the February release were 0.710 from release to Shasta Dam, 0.222 from Shasta Dam to Salt Creek (river kilometer 456.9), 0.912 from 
Salt Creek to Butte Bridge, and 0.841 from Butte Bridge to Antioch. The survival for fish traveling from Shasta Dam to Salt Creek may be lower because this reach includes the mechanistic mortality associated with dam passage. Our estimates of survival rates of fish should be interpreted cautiously because they are likely biased due to fish travel times and the expected battery life of the transmitter. Slow-traveling fish are more likely to exceed the expected battery life of the transmitter or monitoring period ( $>100$ days) when arriving at downstream locations later in time. The number of fish detected during the November release were sparse, and likewise survival probabilities were inestimable for this second group of tagged fish. The detection of tagged fish anywhere downstream of Shasta Dam was an unexpected result. The first release of fish was fortuitously exposed to exceptionally high river flows and dam discharges, which likely contributed to the downstream-migration success of these fish. The reported fish travel times, detection, and survival rates are the first estimates produced for juvenile salmon emigrating from locations upstream of Shasta Dam in more than 70 years, and should help inform how to best collect juvenile winter-run Chinook salmon and assist in their reintroduction to watersheds upriver of Shasta Dam.

Without a collector to test in the first year, it was impossible to evaluate the condition of juvenile fish that would have been trapped and hauled downstream of Shasta Dam. However, we were able to evaluate the stress that might be experienced during the trap-and-haul event by designing a study that mimicked what fish would experience. The 60-minute transportation simulations we designed indicated that it was significantly more stressful than a 30-second net stress. However, this is not an unexpected result, and fish were able to quickly mitigate the stress responses as shown by all stress indicators being significantly reduced 4 hours after the peak levels were observed. Recovery timelines following a stressor such as transportation provide practical guidance for fishery management programs that move fish. Such information may help determine if a holding period after transportation is necessary. In addition to evaluating the stress of the proposed transportation, we also evaluated the use of field meters as an alternative to laboratory assays to quantify the stress response. The field meters are easy to use in field settings and provide a fast and cost-effective assessment of stress indicators. Our results indicate that the meters we tested would be useful to evaluate the relative, rather than absolute, stress response of fish during a trap-and-haul scenario.

In addition to the telemetry study and experimental stress-response tests, we also accomplished several other tasks that were integral to evaluating fish collection and reintroduction efforts in subsequent years. We conducted on-site surveys throughout the McCloud River to identify locations for habitat sampling, passive integrated transponder (PIT)-tag detection arrays, and screw-traps that will be used to estimate fish habitat use, movement, and abundance. We also continued to work with federal and state agencies to establish the necessary ESA permitting and coordination requirements to sample and release fish during future evaluations. Most of the monitoring equipment has been procured (PITtag antennas, data readers and recording equipment, screw traps and electrofishing gear) and tested to ensure it is ready for implementation in future studies. We anticipate that, in 2018-19, research will commence to evaluate the efficacy and performance of Juvenile Collection Structure(s), evaluate the dispersal, growth, and survival of juvenile salmon released into the tributaries of interest, and to determine the spatiotemporal distribution of resident fishes in the river of interest. Subsequent evaluations will build on these activities in addition to estimating egg-to-fry survival during reintroduction efforts, and evaluating the movements, habitat use, and pre-spawn survival of adult salmon that have been transported and released in tributaries upstream of Shasta Dam. 


\title{
Chapter A. Distribution and Migration of Acoustic-Tagged Late-Fall Chinook Salmon Released Upriver of Shasta Dam, 2017
}

\author{
By John M. Plumb, Noah S. Adams, Amy C. Hansen, and Scott D. Evans
}

\section{Introduction}

The Shasta Dam Fish Passage Evaluation (Yip, 2015) program was created among federal, state, tribal, and private stakeholders to determine the feasibility of reintroducing anadromous fish to tributaries upstream of Shasta Dam. Shasta Dam was completed in 1945, causing the extirpation of all spawning salmon (Oncorhynchus species) and steelhead (O. mykiss) populations upriver of the dam. In 2009, the National Marine Fisheries Service (2009) determined that some dams, including Shasta Dam, were jeopardizing the continued existence of federally-listed fish species and stocks such as Sacramento River winter-run Chinook salmon (Oncorhynchus tshawytscha), Central Valley spring-run Chinook salmon (O. tshawytscha), California Central Valley steelhead, and the southern distinct population segment of the North American green sturgeon (Acipenser medirostris). The 2009 determination prompted issuance of Biological Opinion that set forth a series of Reasonable and Prudent Alternatives (RPAs) that allow continued operation of Shasta Dam and Lake in compliance with the Federal Endangered Species Act.

Consequently, the SDFPE program is the first attempt to reintroduce salmon upriver of Shasta Dam in over 70 years. The reintroduction of anadromous fish upstream of Shasta Dam would entail a multi-year endeavor that would initially focus on how to best collect juvenile salmon that are emigrating from tributaries upriver of the dam because without successful juvenile fish collection and transportation it is difficult to restore salmon populations upriver of the dam (Lusardi and Moyle, 2017). It is unclear at this time if it is better to collect fish as they enter the lake, arrive at the dam, or both. Fish collection and survival through the lake to the dam was anticipated to be poor because of the relatively slow water velocities, complex shape, and abundance of piscivorous sport fishes (for example, smallmouth bass [Micropterus dolomieu]; spotted bass, [Micropterus punctulatus], rainbow trout [O. mykiss], and brown trout [Salmo trutta]), which would decrease fish survival and the feasibility of collecting fish at the dam. Head-of-lake fish collection is attractive because fish loss in the lake would be eliminated, but operational difficulties resulting from variable water levels and velocities, debris loads, and a need for high trap efficiencies makes head-of-lake fish collection a difficult task. Consequently, information on how juvenile salmon distribute and survive as they emigrate from tributaries and through the lake to the dam should help inform resource managers on how and where to best locate fish collection effort. 
Biotelemetry technology has been successfully used to evaluate the movements and survival of juvenile salmonids in the Snake (Venditti and others, 2000; Plumb and others, 2006; Adams and others 2014), Columbia (Beeman and Maule, 2001; Skalski and others, 2002), Sacramento (Perry and others, 2010; Plumb and others, 2015), and South Fork McKenzie (Beeman and others, 2016) Rivers, and provide information on individual fish behavior at finer space and time scales that are otherwise unattainable. For example, Plumb and others (2006) used multiple years of telemetry data to evaluate fish migration rates and the frequency of upriver travel within the reservoir upstream of Lower Granite Dam in relation to Snake River flows. Similarly, Adams and others (2014) used multiple years of telemetry data to evaluate fish passage and the performance of a fish collection structure at Lower Granite Dam in relation to dam operations. In the South Fork McKenzie River in the Willamette River Basin, Beeman and others (2016) used acoustic telemetry and an acoustic camera to evaluate a floating fish collector at Cougar Dam. In the Columbia River, Beeman and Maule (2001) used telemetry technology to evaluate the movements and passage of juvenile salmon at dams between day and night periods, and Skalski and others (2002) demonstrated how to use telemetry data to statistically estimate fish detection and survival rates through and between hydroelectric dams. In the Sacramento River, Perry and others (2010) built upon the methods of Skalski and others (2002) and used telemetry technology to evaluate how fish distribute and survive through a complex series of routes in the Sacramento River Delta, California. Collectively, these studies demonstrated how biotelemetry provides a flexible and powerful tool to obtain detailed information about juvenile Chinook salmon distribution and survival upstream and downstream of Shasta Dam and Lake.

Given the flexibility and detail of information that can be obtained from biotelemetry, we chose to use acoustic telemetry to monitor the movements of juvenile late-fall run Chinook salmon released into the McCloud River upriver of Shasta Dam. Particularly, resource managers wanted to know (1) emigration rates of fish from the McCloud River into Shasta Reservoir, (2) fish distribution within the reservoir and likelihood of obtaining sufficient fish-distribution data and (3) fish detection and survival rates to and downstream of Shasta Dam. Fortuitously, fish were released during very different river flows and dam operations, providing information on fish movements during both extreme and average river flows.

\section{Study Area}

Shasta Reservoir, created by Shasta Dam, is the largest reservoir in California, with a surface area of approximately 29,500 acres, a volume of 4.55 million acre feet, and approximately 400 miles of shoreline (Bureau of Reclamation, 2015). The three major tributaries to Shasta Reservoir are the Upper Sacramento, McCloud, and Pit Rivers. Many smaller tributary creeks and streams (both seasonal and perennial) flow into these major tributaries and Shasta Reservoir (fig. A-1). Our study area includes Shasta Reservoir and the lower portions of the McCloud River where acoustic-tagged fish were released (fig. A-1), but also downriver from Shasta Dam on the Sacramento River to the Golden Gate Bridge near San Francisco, California (fig. A-2). Additionally, there was interest in determining if fish moved into the Sacramento and Pit Rivers after emigrating from the McCloud River and into the lake. To address this objective, we deployed detection arrays near the mouth of the Sacramento and Pit arms of the lake and included this in our study area during the first release of acoustically tagged fish 



Figure A-1. Shasta Dam, Shasta Reservoir and its tributaries (upper Sacramento, McCloud, and Pit Rivers), California. Pink markers show the locations for acoustic telemetry detection arrays that were used to estimate fish survival, movements, and detection while traveling to Shasta Dam during the (a) February 2017 release and the (b) November 2017 release. Image source: Google Earth ${ }^{\mathrm{TM}}$, Landsat, Copernicus. 


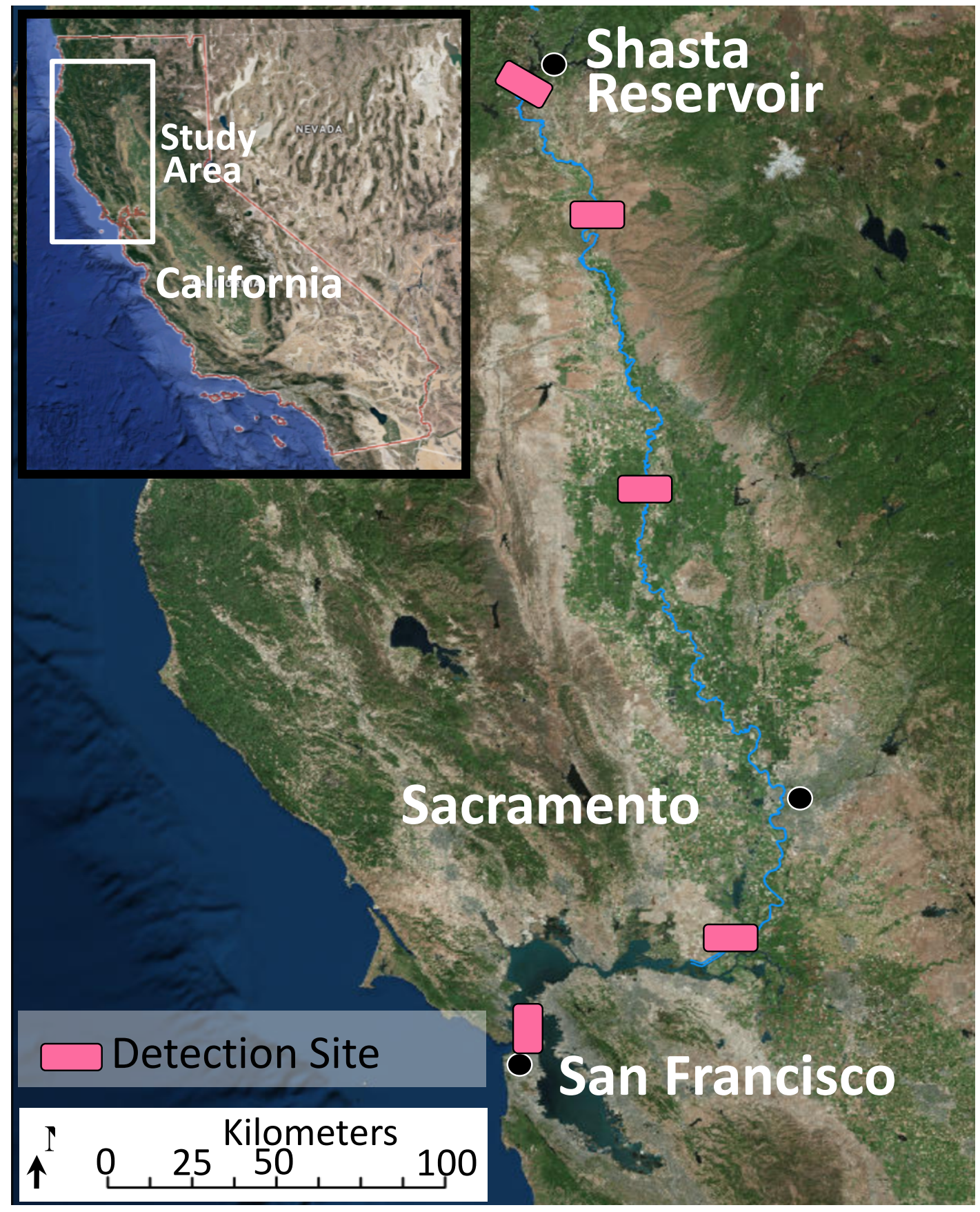

Figure A-2. The Sacramento River from Shasta Reservoir to San Francisco, California. Pink boxes show locations for acoustic telemetry detection arrays that were used to estimate fish survival and detection downstream of Shasta Dam. Image source: Google Earth ${ }^{\mathrm{TM}}$, Landsat, Copernicus. 


\section{Methods}

\section{Environmental Data}

To provide information on environmental conditions in both the McCloud River and Shasta Reservoir during our study, we used daily summaries of river flow, water temperature, turbidity, and Shasta Dam operations that were provided by the California Department of Environmental Quality (CDEC) at http://cdec.water.ca.gov/cdecstation2/ (stations MSS and SHA). Hourly McCloud River data were presented in the 2017 studies but were summarized as mean daily values in the 2007-16 summaries. Turbidity values were omitted when flagged as errors on the CDEC website.

\section{Transmitters and Fish Tagging}

We released fish in two separate groups that differed in time period, tag type, fish size, and genetic type. For our first release in February, 2017, we used acoustic tags manufactured by Advanced Telemetry Systems (Isanti, Minnesota, https://atstrack.com/) that had a mean mass in air of 0.34 grams (g; range 0.34-0.36 g), and mean dimensions of 10.76-millimeters $(\mathrm{mm})$ long $\times 5.23$-mm-wide $\times 3.61$ $\mathrm{mm}$-deep. Expected transmitter battery life at the nominal pulse rate interval of 10 seconds was about 90 days, we monitored all hydrophones for 100 days subsequent to activation of the transmitter and the release of the fish. For the November release group, the acoustic tag had a mean mass in air of $0.43 \mathrm{~g}$ (range $0.40-0.45 \mathrm{~g}$ ) and was 11.75 -mm-long $\times 6.25$-mm-wide $\times 3.47$-mm-deep. Hydrophones were monitored for 130 days following tag activation.

All tagged fish were hatchery-origin juvenile late-fall run Chinook salmon reared at the Coleman National Fish Hatchery in Anderson, California (table A-1). Fish were held in outdoor concrete raceways (total 2.44-m-long $\times 12.38$-m-wide; 34,433 liters [L] in volume) or indoor troughs (about 4-m-long $\times 1$-m-wide $\times 0.6$-m-deep, and about $900 \mathrm{~L}$ in volume) supplied with continuously flowing water. Fish were netted into $75.71 \mathrm{~L}$ containers and held without access to food for an average of 24 hours ( $h$; range 21.7-25.1 h) prior to tagging. Over a 3-day period, we acoustic-tagged 262 fish and released them February 1-3, 2017; over a 4-day period we acoustic-tagged 355 fish and released them November 12-15, 2017. On average, during the first release period in February, we tagged larger fish and a larger range in fish sizes than during the second release period in November. For example, the mean tag burden for fish in the February release was 1.2 percent, but was 2.8 percent for the November release.

Table A-1. Summary statistics for the numbers and sizes of juvenile late-fall run Chinook salmon released into McCloud River, California, 2017-18.

[mm, millimeter]

\begin{tabular}{clllll}
\hline \multicolumn{1}{c}{ Release } & Fish measurement & \multicolumn{1}{c}{ Mean } & Median & \multicolumn{1}{c}{ Range } & $\begin{array}{c}\text { Mean tag burden } \\
\text { (percent) }\end{array}$ \\
\hline February 2017 & Fork length (mm) & 134.5 & 136 & $97-171$ & - \\
& Weight (grams) & 28.9 & 28.4 & $10.3-62.8$ & 1.2 \\
\multirow{2}{*}{ November 2017 } & Fork length (mm) & 111.9 & 112 & $97-125$ & - \\
& Weight (grams) & 15.7 & 15.6 & $10.2-21.9$ & 2.8 \\
\hline
\end{tabular}


Acoustic transmitters were surgically implanted using the protocols reported by Liedtke and others (2012). Fish were considered suitable for tagging if they were free of major injuries; had no external signs of gas-bubble trauma, major fin damage, or fungus; were less than 20 percent descaled; had no visible signs of deformities or disease; and were not previously tagged. Fish were anesthetized using AQUI-S ${ }^{\circledR} 20 \mathrm{E}$ (AQUI-S, Lower Hutt, New Zealand). The AQUI-S ${ }^{\circledR} 20 \mathrm{E}$ concentration range was 30-45 milligrams per liter. Weight and length of each anesthetized fish were recorded immediately prior to surgery. All weighing, measuring, and containment equipment were treated with a $0.25 \mathrm{~mL} / \mathrm{L}$ concentration of Stress Coat Plus ${ }^{\circledR}$ (Aquarium Pharmaceuticals, Inc., Chalfont, Pennsylvania) to reduce handling related stress to the fish through electrolyte loss. Fish were placed in a 19-L perforated bucket filled with $7 \mathrm{~L}$ of river water immediately after surgery. Dissolved oxygen concentrations were maintained between 80 and 130 percent saturation during recovery. The density in a recovery bucket ranged from 5.1 to 17.6 grams per liter $(\mathrm{g} / \mathrm{L})$ for hatchery Chinook salmon. Water quality (water temperature, dissolved oxygen, and total dissolved gas) was monitored in holding buckets, transport tanks, the recovery raceway, and at release sites. Fish were transported and released at the McCloud Bridge after an 18-36 hour recovery period (mean 21 hours).

\section{Acoustic Telemetry Detection System}

We used the juvenile salmonid acoustic telemetry system (JSATS) for the collection of acoustic telemetry data (McMichael and others, 2010). Acoustic detection arrays upstream of Shasta Dam were installed at different locations during the February and November fish-releases (table A-2). Regardless of the study period or location, however, the acoustic arrays were deployed such that the full width of the river was monitored to increase detection ability of the acoustic signals.

Signals from acoustic transmitters were collected using a JSATS hydrophone. Acoustic signals from tagged fish were detected using autonomous hydrophones spaced across the width of the river or reservoir. In previous studies, we empirically determined in the eastern arm of Cougar Reservoir, Oregon, that 82 percent of the expected number of transmissions were detected at a range of $105 \mathrm{~m}$, and 10 percent were detected at a range of 180 meters (m; Beeman and others, 2013). Based on those data, the hydrophones were spaced about $100 \mathrm{~m}$ from shorelines and $200 \mathrm{~m}$ from each other at a depth of about $33 \mathrm{~m}$ from the water surface along transect lines across the reservoir (hereinafter referred to as "arrays"). When the water surface depth was less than $33 \mathrm{~m}$, hydrophones were positioned $1.8-4.5 \mathrm{~m}$ from the river bottom. Hydrophones were deployed using methods similar to those described by Titzler and others (2010), except that burlap bags filled with sand were used as anchors. The autonomous hydrophones were electronically tuned to optimize signal detection prior to releasing acoustically tagged fish. The hydrophones were retrieved to download data every 4 weeks and then redeployed in their original location.

To detect acoustic-tagged fish as they migrated through the McCloud River and Shasta Reservoir after release on February 1-3, 2017 (table A-1), we deployed autonomous hydrophones at six locations: (1) one hydrophone in the McCloud River Arm at 0.8 river kilometer (rkm) downstream of the release site at the McCloud River Bridge; (2) two hydrophones in the McCloud River Arm about $10.3 \mathrm{rkm}$ downstream of the release site; (3) four hydrophones in the McCloud River Arm about 22.1 rkm downstream of release; (4) three hydrophones in East Shasta Reservoir; (5) five hydrophones in the Sacramento River Arm located 12.6 rkm upstream of Shasta Dam; and (6) five hydrophones in the forebay about 200-400 m upstream of Shasta Dam (fig. A-1). 
Table A-2. Distances in river kilometers between detection arrays in Shasta Reservoir and tributaries, California, 2017.

\begin{tabular}{lcccccc}
\hline & $\begin{array}{c}\text { McCloud } \\
\text { River } \\
\text { Bridge }\end{array}$ & $\begin{array}{c}\text { Mid- } \\
\text { McCloud } \\
\text { River }\end{array}$ & $\begin{array}{c}\text { McCloud } \\
\text { River } \\
\text { Arm }\end{array}$ & $\begin{array}{c}\text { East Shasta } \\
\text { Reservoir }\end{array}$ & $\begin{array}{c}\text { Sacramento } \\
\text { River } \\
\text { Arm }\end{array}$ & $\begin{array}{c}\text { Shasta } \\
\text { Dam } \\
\text { forebay }\end{array}$ \\
\hline & \multicolumn{2}{c}{ First release (February 1-3, 2017) } \\
\hline Release & 0.8 & 10.3 & 22.1 & 25.4 & 34.1 & 37.4 \\
McCloud River Bridge & & 9.5 & 21.3 & 24.6 & 33.3 & 36.6 \\
Mid-McCloud River & & & 11.8 & 15.1 & 23.9 & 27.2 \\
McCloud River Arm & & & 3.3 & 12.1 & 15.4 \\
East Shasta Reservoir & & & & 13.0 & 15.4 \\
Sacramento River Arm & & & & & 12.6 \\
\hline
\end{tabular}

\begin{tabular}{lccccccc}
\hline \multicolumn{7}{c}{ Second release (November 12-15, 2017) } \\
& $\begin{array}{c}\text { McCloud } \\
\text { River } \\
\text { Bridge }\end{array}$ & $\begin{array}{c}\text { Mid- } \\
\text { McCloud } \\
\text { River }\end{array}$ & $\begin{array}{c}\text { McCloud } \\
\text { River Arm }\end{array}$ & $\begin{array}{c}\text { West of } \\
\text { I-5 Bridge }\end{array}$ & $\begin{array}{c}\text { Below } \\
\text { Sacramento } \\
\text { River Arm }\end{array}$ & $\begin{array}{c}\text { Shasta Dam } \\
\text { forebay }\end{array}$ & $\begin{array}{c}\text { Keswick } \\
\text { Dam } \\
\text { forebay }\end{array}$ \\
\hline Release & 3.3 & 10.3 & 22.1 & 25.6 & 30.3 & 36.6 & 52.4 \\
McCloud River Bridge & & 7.0 & 18.8 & 22.3 & 27.0 & 33.3 & 49.2 \\
Mid-McCloud River & & & 11.8 & 15.3 & 20.0 & 26.3 & 42.2 \\
McCloud River Arm & & & & 3.5 & 8.3 & 14.5 & 30.4 \\
West of I-5 Bridge & & & & & 4.7 & 11.0 & 26.8 \\
Downstream of & & & & & 6.3 & 22.1 \\
$\quad$ Sacramento River Arm & & & & & & & 15.9 \\
Shasta Dam forebay & & & & & & & \\
\hline
\end{tabular}

Given the Shasta Dam fish detections that we observed during the first release of fish in February, it was decided that hydrophones should be more concentrated at the dam and placed in a more linear fashion from the McCloud River to the dam. It was hoped that this hydrophone arrangement would provide a more complete picture of fish migration to the dam and their approach paths and passage routes at Shasta Dam. To detect acoustic-tagged fish from the November 12-15, 2017, release of fish (table A-2), we deployed autonomous hydrophones at eight locations:

1. One hydrophone in the McCloud River Arm at $3.3 \mathrm{rkm}$ downstream of the release site at the McCloud River Bridge;

2. Two hydrophones in the McCloud River Arm about $10.3 \mathrm{rkm}$ downstream of the release site;

3. Four hydrophones in the McCloud River Arm about $22.1 \mathrm{rkm}$ downstream of release site;

4. Five hydrophones $1.2 \mathrm{rkm}$ west of the I5 Bay Bridge;

5. Six hydrophones downstream of the Sacramento River Arm;

6. Five hydrophones in the forebay about $320-400 \mathrm{~m}$ upstream of Shasta Dam;

7. Five hydrophones mounted on the upstream face of Shasta Dam; and

8. Two hydrophones mounted on the upstream face of Keswick Dam ( $\mathrm{rkm} 536.6)$. 
Data from the hydrophones were processed to remove false-positive records prior to analysis. False-positive records are those that indicate detection of a transmitter when the transmitter was not present and are common in most active telemetry systems (Beeman and Perry, 2012). We used the procedures developed by Pacific Northwest National Laboratory (Mark Weiland, written communication, June 17, 2010) to remove false-positive records. The steps include removing records from tag codes not released, records suspected of being from reflections of valid tag signals (multipath), and records that are not close to a multiple of the tag pulse interval (McMichael and others, 2010).

\section{Travel Times and Movements Upriver of Shasta Dam}

Travel times were assessed using time-to-event methods (Hosmer and Lemeshow, 1999). Travel times for each fish were defined as the difference in time between two locations. The time elapsed from fish release to a subsequent detection event was described using Kaplan-Meier survivorship functions where the survivorship function gives the probability of not being detected at an array over time. As such, the median time occurs when the survivorship function (proportion remaining) equals 0.5 . An event represents a fish first detected at an array. We provide summary statistics for the fish travel times rates. We also tabulated the fraction of fish detected at each tributary arm of Shasta Reservoir as well as the number of trips by fish to a detection array after being detected at a previous location.

\section{Fish Survival and Detection}

We used additional acoustic tag detections at locations downriver of Shasta Dam and the framework of a Cormack-Jolly-Seber (CJS; Cormack, 1964; Jolly, 1965; Seber, 1965) model to estimate apparent fish survival and detection probabilities from the McCloud River to the Golden Gate Bridge - a distance of $590 \mathrm{~km}$ (figs. A-2 and A-3; table A-3). Acoustic detection data obtained at sites downriver of Shasta Dam were supplied by hydrophones deployed and maintained by the National Marine Fisheries Service (Arnold Ammann; Santa Cruz, California, arnold.ammann@noaa.gov). Because the number of detections downstream of Shasta Dam were low, we pooled detection sites that were relatively close to each other to represent a single detection array for that approximate location (table A-3; appendix 1). These five locations were chosen to provide estimates of survival over predefined reaches, such that survival estimates represent the result of all survival processes and routes between each of the demarked locations. The distances between locations varied from about 37 to 250 $\mathrm{km}$, so we also provide estimates of fish survival on a per-km basis. The relatively long distance (590 $\mathrm{km})$ and small sample size ( $<355$ fish) resulted in relatively sparse detection data downriver of Shasta Dam. As a result, the estimation of survival and detection using maximum likelihood methods was unreliable. To overcome this, we used Bayesian methods and Markov Chain Monte Carlo optimization (Gibbs sampler) to solve for the detection and survival parameters while following the statistical structure of the Cormack-Jolly-Seber model (fig. A-3; table A-3; Gelman and others, 2014). Analyses and model fitting were done using R software (R Core Team, 2015) and the 'rjags' package. 
It is important to note that these acoustic telemetry studies were not designed to provide robust estimates of survival. The main objective was to examine travel time and detection probabilities of tagged fish during their migration out of the McCloud River and to Shasta Dam. As a result, the survival estimates that we calculated are not as accurate as they would have been had we designed the study specifically to address survival. Since fish were detected in relatively high numbers at the dam and some were detected in the Sacramento River Delta, it was determined that there was sufficient data to get a first look at what survival was for these fish, something that had not been done before. Perhaps the most important thing to keep in mind is that low sample size prevented us from accounting for the potential for negative bias caused by tag failure. Accounting for tag failure is necessary to obtain more accurate estimates of fish survival. Because we could not account for this, the survival estimates should be interpreted as a pilot study to provide guidance for designing future survival studies.

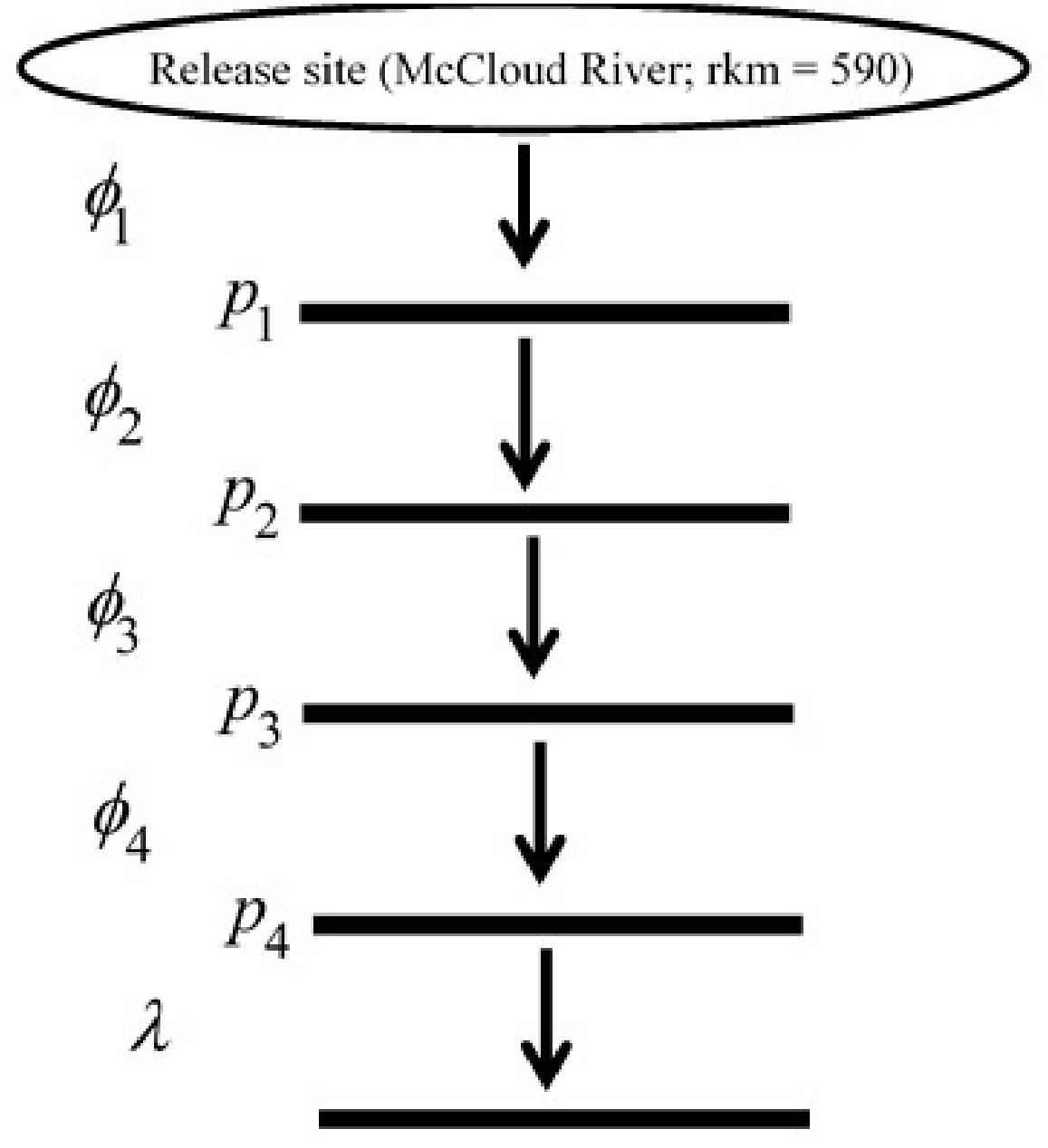

Figure A-3. Diagram showing schematic of the structure and spatial layout of the Cormack-Jolly-Seber model that was fitted to the detection data of acoustic-tagged late-fall run Chinook salmon released into the McCloud River upriver of Shasta Dam, 2017. 
Table A-3. Summary of reach-specific survival and detection parameters that were estimated from the acoustic detections of late-fall run Chinook salmon released into the McCloud River $(\mathrm{rkm}=590)$ upstream of Shasta Dam and Reservoir during, 2017.

\begin{tabular}{|c|c|c|c|}
\hline Parameter & Definition & $\begin{array}{l}\text { Distance (kilometer) or } \\
\text { location (river kilometer) }\end{array}$ & Reach or location \\
\hline$\phi_{1}$ & Apparent survival & 37.4 & McCloud River to Shasta Dam \\
\hline$\phi_{2}$ & Apparent survival & 95.7 & Shasta Dam to Salt Creek \\
\hline$\phi_{3}$ & Apparent survival & 119.3 & Salt Creek to Butte Bridge \\
\hline$\phi_{4}$ & Apparent survival & 251.1 & Butte Bridge to Antioch \\
\hline$p_{1}$ & Detection probability & 552.5 & Shasta Dam \\
\hline$p_{2}$ & Detection probability & 456.9 & Salt Creek \\
\hline$p_{3}$ & Detection probability & 337.6 & Butte Bridge and Colusa (combined) \\
\hline$p_{4}$ & Detection probability & 86.5 & $\begin{array}{l}\text { Antioch Bridge and Decker Island } \\
\text { (combined) }\end{array}$ \\
\hline$\lambda$ & $\begin{array}{l}\text { Joint probability of } \\
\text { survival and detection }\end{array}$ & $71.7-1.7$ & $\begin{array}{l}\text { Antioch, Chipps Island, and Golden } \\
\text { Gate (combined) }\end{array}$ \\
\hline
\end{tabular}

\section{Results}

\section{Environmental Conditions}

McCloud River flows were an order of magnitude greater during the first release (February) than during the second release (November) of acoustic-tagged fish. McCloud River flows after the February release of fish peaked at 35,059 cubic feet per second ( $\mathrm{ft}^{3} / \mathrm{s}$; fig. A-4, top graph), whereas flows following the November release of fish peaked at 1,061 $\mathrm{ft}^{3} / \mathrm{s}$ (fig. A-4, bottom graph). Mean hourly flows in the McCloud River during the first study were 4,144 $\mathrm{ft}^{3} / \mathrm{s}$ (range 1,226-35,059 $\mathrm{ft}^{3} / \mathrm{s}$ ) and peaked shortly after release and on February $21\left(14,443 \mathrm{ft}^{3} / \mathrm{s}\right)$, March $22\left(6,931 \mathrm{ft}^{3} / \mathrm{s}\right)$, April 7 $\left(5,939 \mathrm{ft}^{3} / \mathrm{s}\right)$, and April $13\left(7,208 \mathrm{ft}^{3} / \mathrm{s}\right)$. During the second study, mean hourly flow was $517 \mathrm{ft}^{3} / \mathrm{s}$ (range 304-2,785 ft $3 / \mathrm{s}$ ). Compared to the previous 10 years, mean daily 2017 flows in February were higher than the 10-year maximum but November flows were closer to the minimum during the second study (fig. A-5). Turbidity in the McCloud River peaked when river flows peaked in February and ranged 0.5-396.3 nephelometric units (NTU), and ranged 0.8-22.2 NTU in March, 1.5-3.9 NTU in April, 1.4-2.3 NTU in May (fig. A-4, top graph). Turbidity was inconsistent following the November release of fish and 54.9 percent of downloaded records were flagged as errors in the data and removed (http://cdec.water.ca.gov/cdecstation2/). The remaining turbidity data in November showed a mean turbidity of 66.3 NTU (range 0-396.7), and ranged 0.0-2.8 NTU in December, 0.7-8.3 NTU in January, 0.7-3.4 NTU in February, and 0.0-45.0 NTU March 1-20 (fig. A-4, bottom graph). Hourly water temperature steadily increased during the first study from the fish release $\left(6.9^{\circ} \mathrm{C}\right)$ to last monitoring date on May $10\left(13.1^{\circ} \mathrm{C}\right.$; fig. A-4, top graph). During the second study, hourly water temperature ranged $3.2-10.3{ }^{\circ} \mathrm{C}$ and was variable during the study (fig. A-4, bottom graph). Mean daily water temperature was near average compared to the previous 10 years (fig. A-5). 

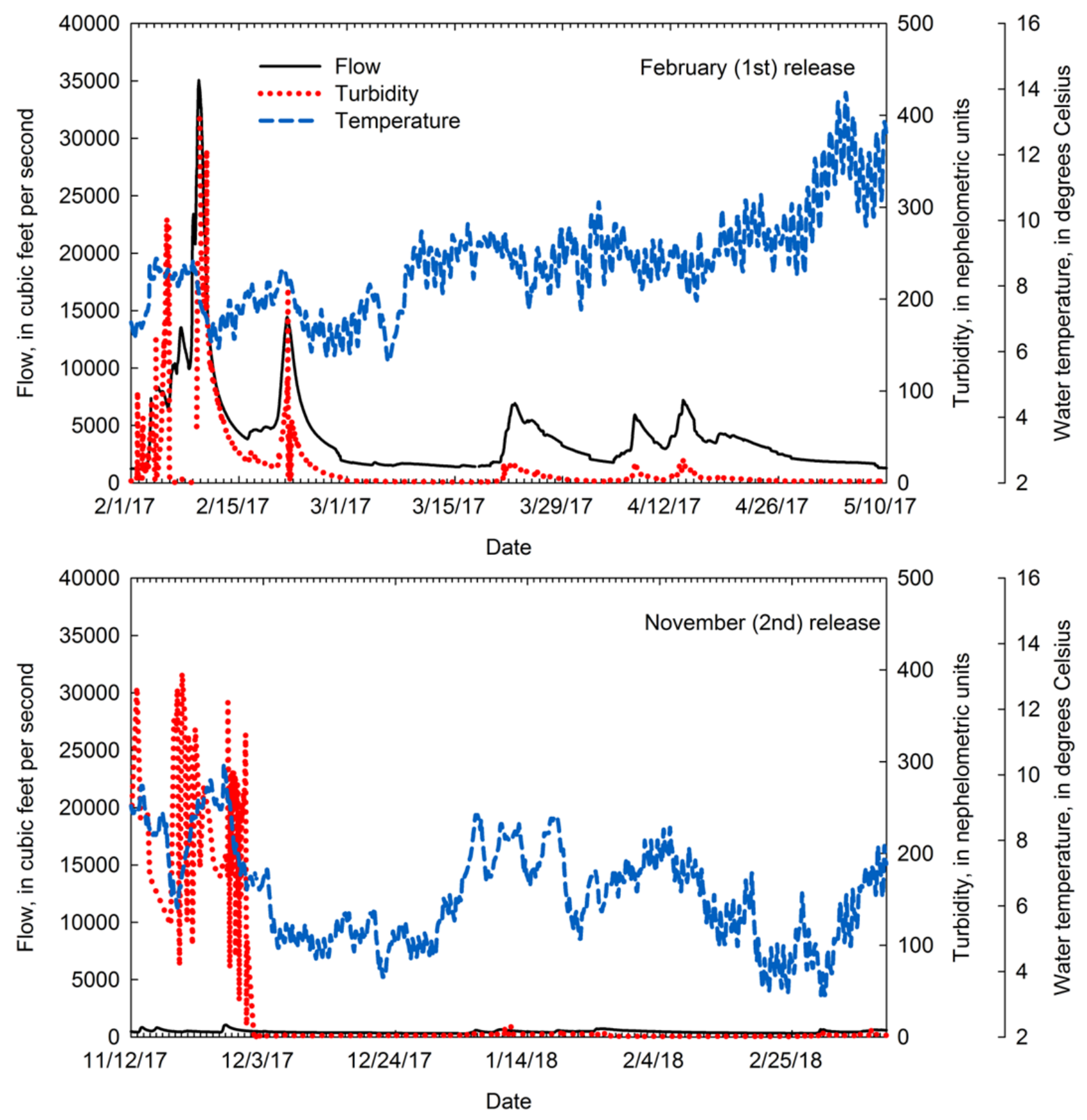

Figure A-4. Graphs showing flow, turbidity, and water temperature at the streamgage (MSS) located $3.3 \mathrm{rkm}$ upstream of the McCloud River Bridge, California, during the first release (top graph, February 1-May 10, 2017) and the second release (bottom graph November 12, 2017-March 11, 2018). 

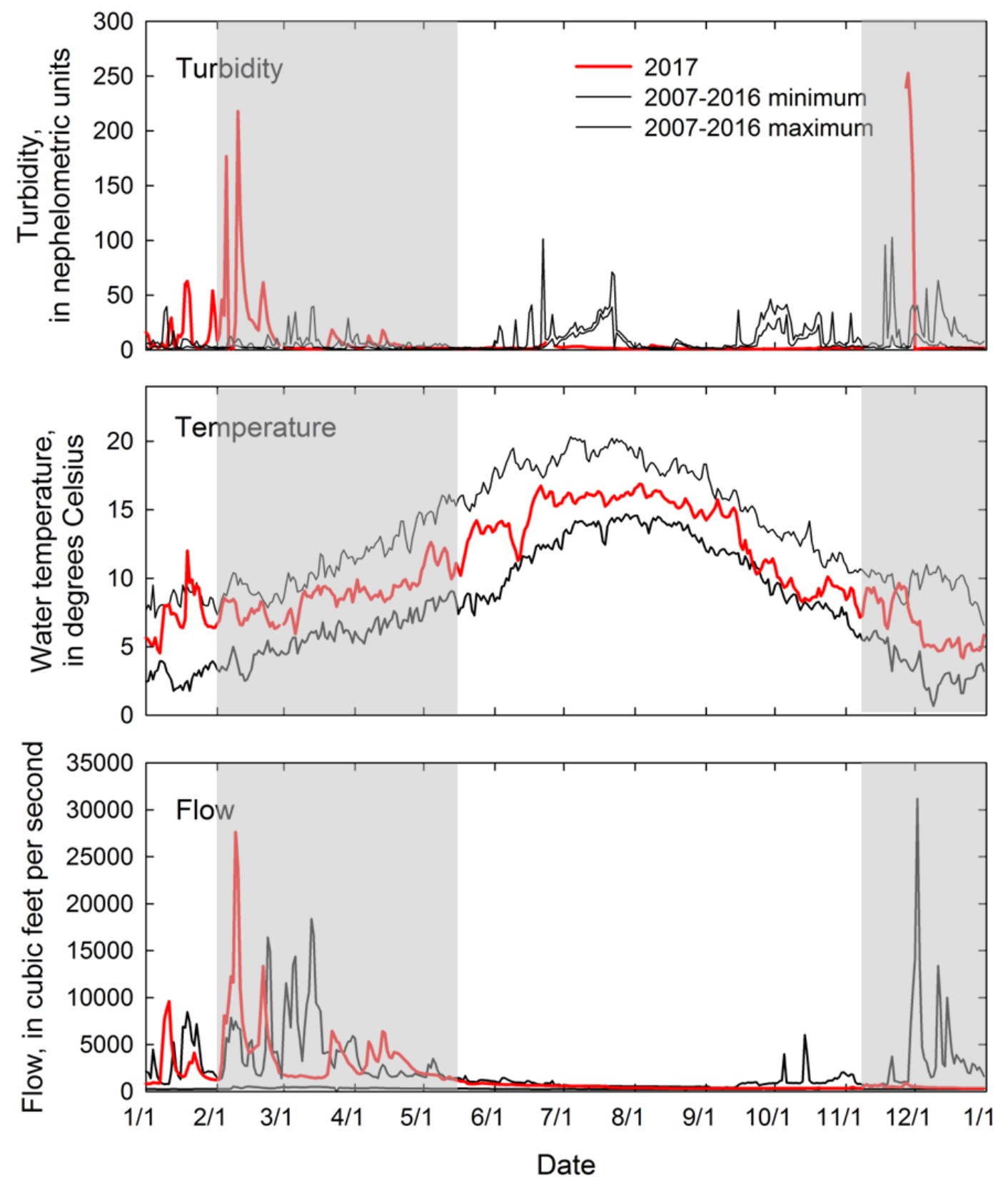

Figure A-5. Mean daily 2017 flow, turbidity, and water temperature at the streamgage (MSS) located $3.3 \mathrm{rkm}$ upstream of the McCloud River Bridge, California, and the daily minimum and maximum of 2007-2016. Gray shading indicates 2017 study periods. 
Environmental conditions in Shasta Reservoir were a combination of operations at Shasta Dam and tributary inputs from upstream. Discharges at the dam varied by an order of magnitude between the February and November release periods of acoustic-tagged fish (fig. A-6). Total daily outflow peaked in mid- to late-February and had a small increase in late April. Outflow ranged 16,374-74,605 $\mathrm{ft}^{3} / \mathrm{s}$ in February, 4,845-64,767 $\mathrm{ft}^{3} / \mathrm{s}$ in March, 7,181-30,218 $\mathrm{ft}^{3} / \mathrm{s}$ in April, and 3,909-10,082 $\mathrm{ft}^{3} / \mathrm{s}$ during May 1-10. In contrast, total daily outflow following the November release of acoustic-tagged fish was more consistent and ranged 2,214-5,173 ft 3 /s November 12, 2017-March 11, 2018 (mean $3,769 \mathrm{ft}^{3} / \mathrm{s}$ ). Similar to the McCloud River outflow, 2017 flow in February was higher than the previous 10 years and average during the second study (fig. A-7). The river outlets at Shasta Dam were used daily February 1-March 8, 2017. The mean discharge over this period was $24,918 \mathrm{ft}^{3} / \mathrm{s}^{\mathrm{s}}$ and the maximum discharge was $56,141 \mathrm{ft}^{3} / \mathrm{s}$. From April 12-29, 2017 the mean discharge was $8,442 \mathrm{ft}^{3} / \mathrm{s}$ and the maximum discharge was $15,690 \mathrm{ft}^{3} / \mathrm{s}$. In contrast, the river outlets were not used at all following the November release of acoustic-tagged fish (fig. A-6b) nor commonly during the past 10 years (fig. A-7). Daily change in reservoir storage was highly variable in February and early March 2017 but remained within 50,000 acre-feet of 0 for the remainder of the first study period (fig. A-6a). During the second study, daily change in reservoir storage was near 0 (fig. A-6b). Compared to the 10year minimum and maximum daily change in reservoir storage, 2017 had greater changes in February and March (fig. A-7). Inflow followed the same trends as daily change in reservoir storage during both study periods, but was greater in February than the maximum during the previous 10 years (fig. A-7). 

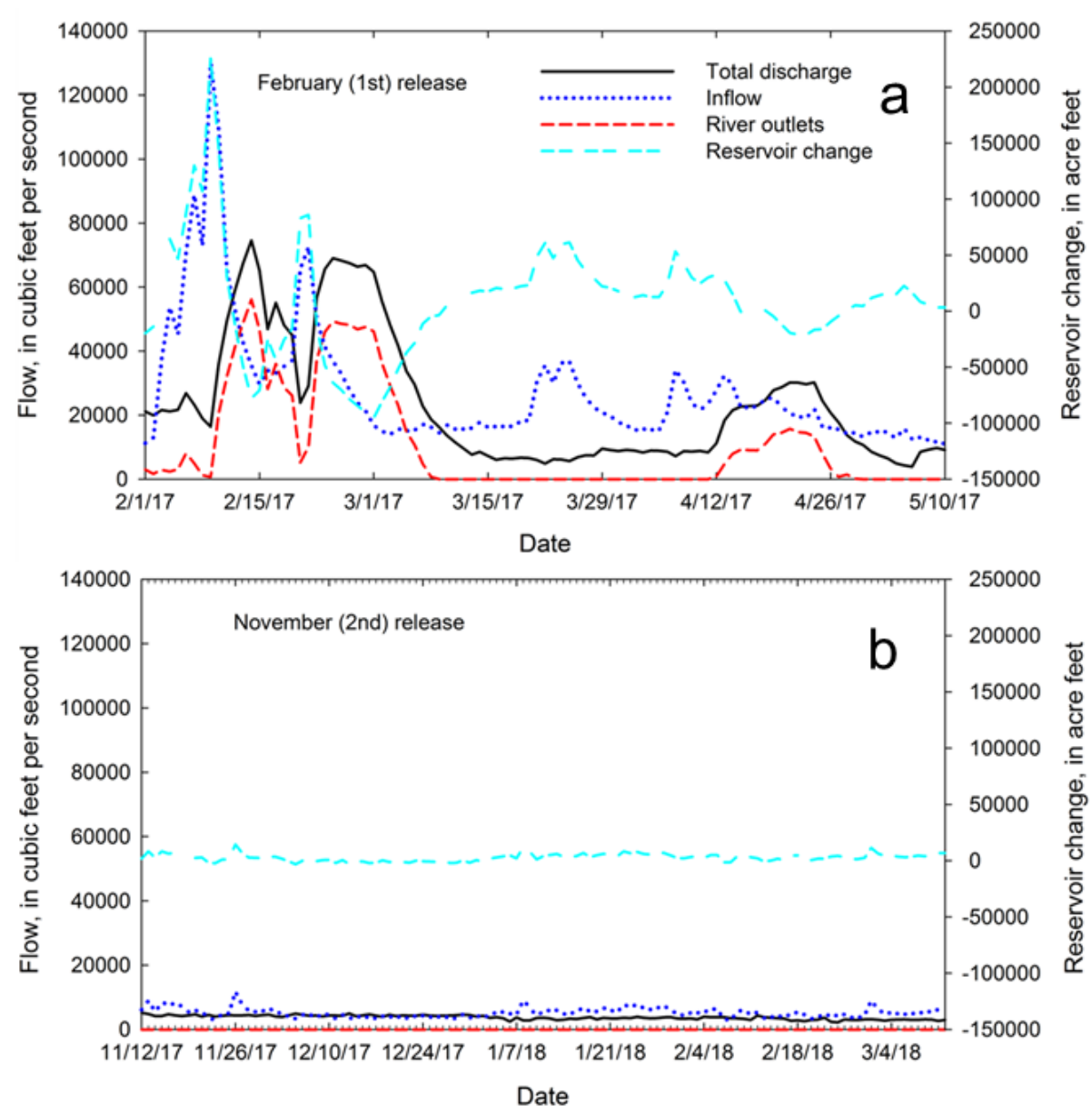

Figure A-6. Daily plots of discharge at Shasta Dam, discharge at Shasta Dam river outlet, flows into Shasta Reservoir, and daily change in water storage in Shasta Reservoir, California, during (a) the first study (February 1-May 10, 2017) and (b) the second study (November 12, 2017-March 11, 2018). 

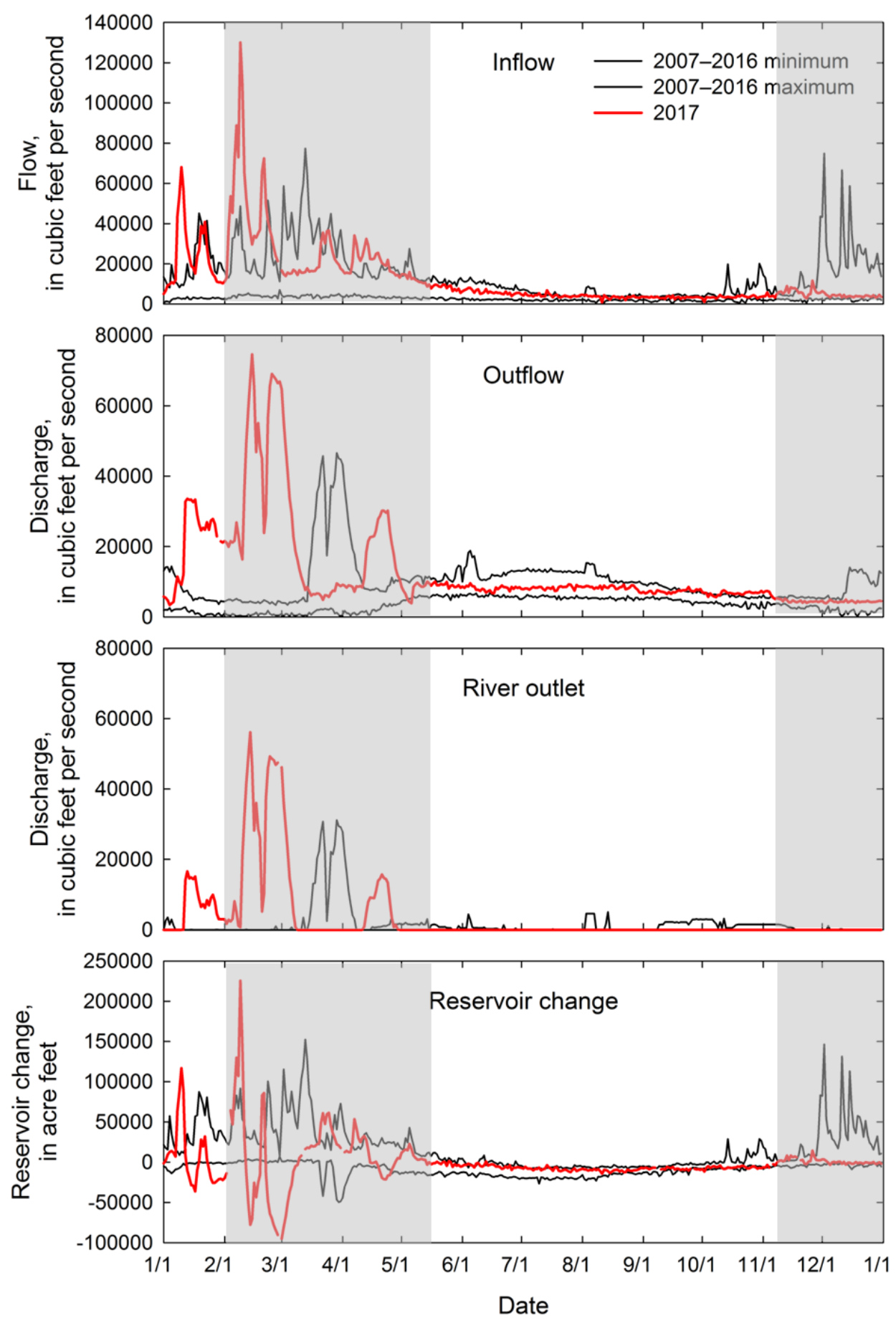

Figure A-7. Daily plots of discharge at Shasta Dam, discharge at Shasta Dam river outlet, daily flows, and change in water storage in Shasta Reservoir, California during 2017, and the daily minimum and maximum, 2007-16. Gray shading indicates 2017 study periods. 


\section{Fish Detections Upstream and Downstream of Shasta Dam}

Of the 262 tagged fish that were released into the McCloud River during February, 261 (99.6 percent) were detected in the study area through May 10, 2017. Most of the fish (82 percent) were detected at the mid-McCloud River array at $10.3 \mathrm{rkm}$ downstream of the release site, and 77 percent were detected at the array near the confluence of the McCloud River Arm and Shasta Reservoir (22.1 rkm from release; table A-4; fig. A-7). Fish were detected at the other acoustic detection arrays after leaving the McCloud River: 20 percent at the East Shasta Reservoir array, 26 percent at the Sacramento River Arm array, and 70 percent at the Shasta Dam forebay array. We continued to detect fish in the forebay of Shasta Dam up to the expected $100 \mathrm{~d}$ battery life of the transmitter, suggesting some fish from the first release group may have passed Shasta Dam beyond the expected battery life of the transmitter (fig. A-8). A total of 41 fish (16 percent) were detected at telemetry sites between Redding and San Francisco Bay (table A-4; appendix 1). Among detection arrays that we pooled for detection estimation downstream of Shasta Dam, we detected 24 ( 9 percent) fish from the first release group as far downriver as San Francisco Bay (table A-4; appendix 1).

Of the 355 fish that were released into the McCloud River during November, 311 (88 percent) were detected in the study area. About 87.6 percent of all fish released were detected $3.3 \mathrm{rkm}$ downstream of the release site and 28 percent were detected at the Mid-McCloud site $10.3 \mathrm{rkm}$ from release (table A-4; figs. A-8 and A-9). In contrast to the February period, just 5 percent of tagged fish were detected at the confluence of the McCloud River Arm and Shasta Reservoir (22.1 rkm from release). Three percent were detected at the array west of the I-5 Bridge, 2 percent of fish were detected at the Sacramento River Arm, and 1 percent of fish were detected at Shasta Dam. One fish (0.3 percent) was detected at Keswick Dam on January 2-5, 2018.

Table A-4. Percentage of acoustic-tagged juvenile late-fall run Chinook salmon detected by each detection array, 2017-18.

[Although detection areas shared a general location, they differed by location and configuration between the fish release groups]

\begin{tabular}{lcc}
\hline \multicolumn{1}{c}{ Detection location } & Number detected & Percent detected \\
\hline McCloud River Bridge & First release February 2017 (n=262) & 98 \\
Mid-McCloud River & 257 & 82 \\
McCloud River Arm & 215 & 77 \\
East Shasta Reservoir & 202 & 20 \\
Sacramento River Arm & 53 & 22 \\
Shasta Dam forebay & 57 & 70 \\
Downriver of Shasta Dam & 182 & 16 \\
\hline & 41 & 88 \\
\hline McCloud River Bridge & Second release November 2017 (n=355) \\
Mid-McCloud River & 311 & 28 \\
McCloud River Arm & 98 & 5 \\
West of I-5 Bridge & 18 & 3 \\
Downstream of Sacramento River Arm & 9 & 2 \\
Shasta Dam forebay & 7 & 1 \\
Keswick Dam forebay & 4 & $<1$ \\
\hline
\end{tabular}




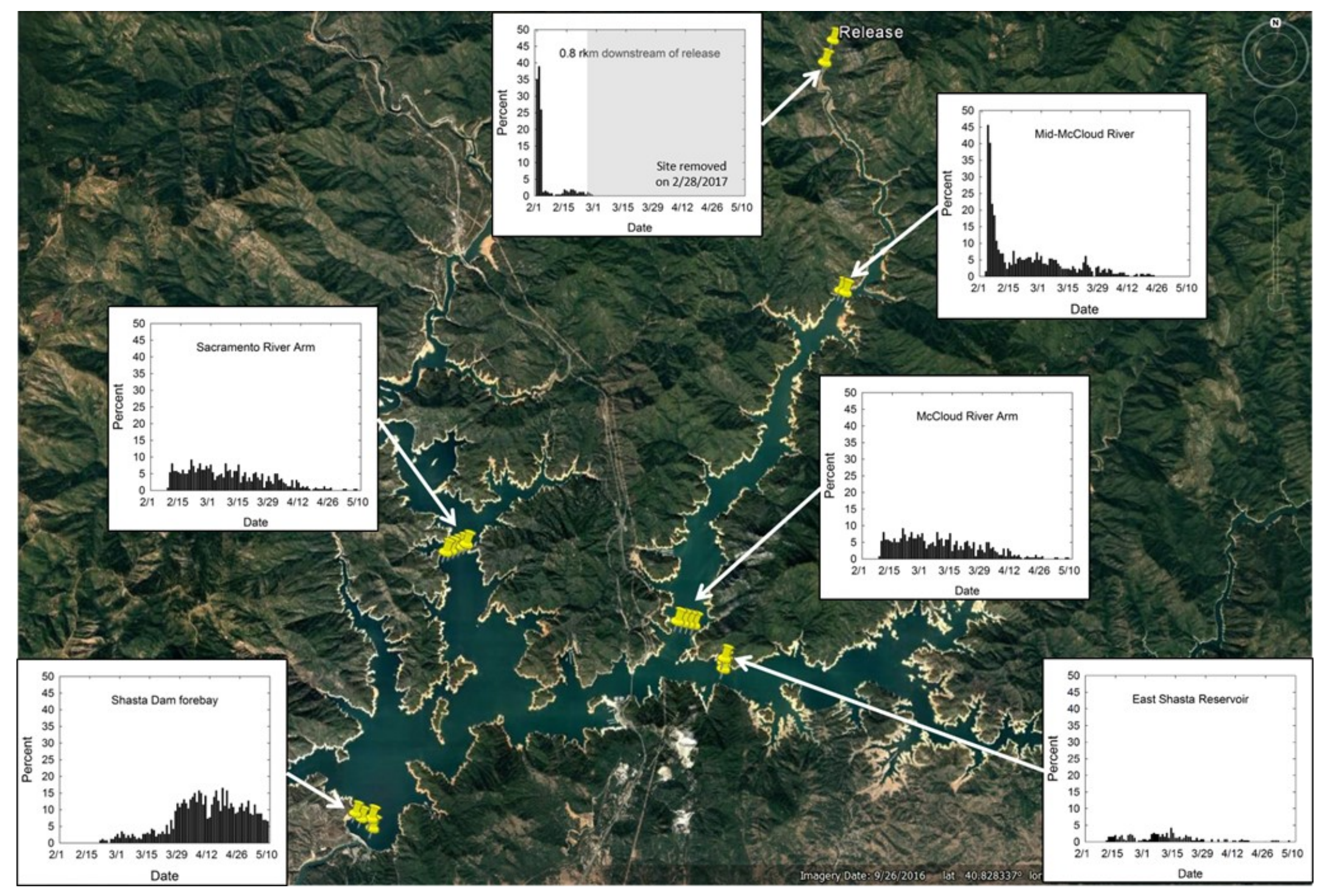

Figure A-8. Percentage of acoustic-tagged juvenile late-fall run Chinook salmon released February 1-3, 2017, and detected by date and location through May 10, 2017. Bars represent the percentage of total tagged fish released. Acoustic receiver array locations are designated by the yellow pins. The site located $0.8 \mathrm{rkm}$ downstream of the release location was removed on February 28, 2017. Image source: Google Earth ${ }^{\mathrm{TM}}$, Landsat, Copernicus. 


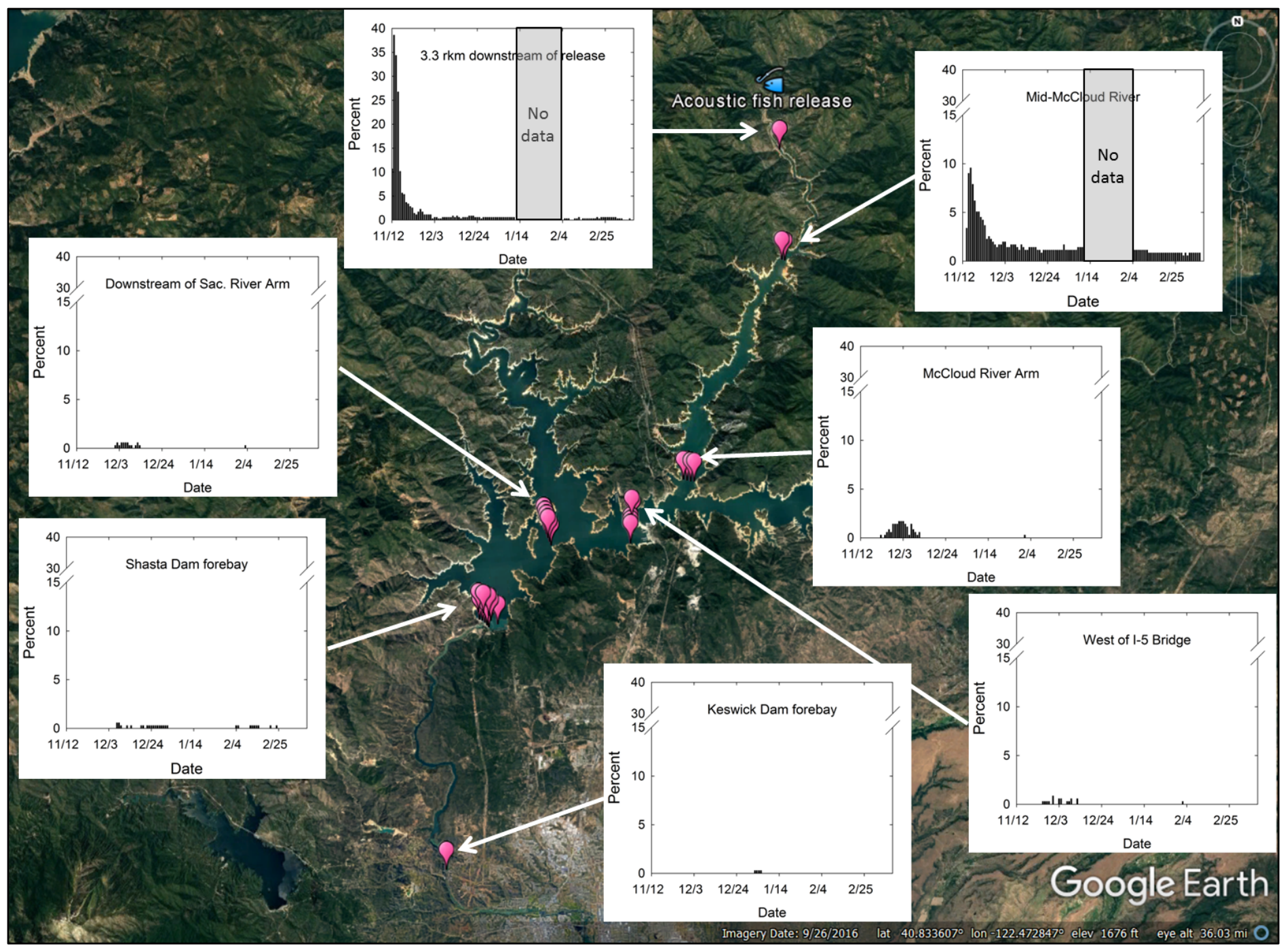

Figure A-9. Percentage of acoustic-tagged juvenile late-fall run Chinook salmon released November 12-15, 2017, and detected by date and location through March 11, 2018, Shasta Dam, California. Bars represent the percentage of total tagged fish released. Acoustic detection array locations are designated by the pink pins. No data were collected at the two uppermost detection arrays from approximately January 10 to February 5, 2018. Note the y-axis break on all plots except "3.3 rkm downstream of release." Image source: Google Earth ${ }^{\mathrm{TM}}$, Landsat, Copernicus. 


\section{Travel Times and Movements throughout Shasta Reservoir}

During the February release of acoustic-tagged fish, the fish moved downstream relatively quickly, with most fish detected $0.8 \mathrm{rkm}$ downstream on the day of the release (figs. A-8 and A-9). Based on the Kaplan-Meier curves, the 50th percentile of travel time for tagged fish arriving at the midMcCloud River detection site was 2.9 days (d), whereas the 50th percentile of travel time to the McCloud River Arm detection site was 39.7 d. Less than 50 percent of the fish were detected at East Shasta Reservoir and the Sacramento River Arm. The first fish arrived at the East Shasta Reservoir detection site $8 \mathrm{~d}$ after release, and the mean travel time for the 53 fish detected there was $31.0 \mathrm{~d}$ (table A-5). The mean travel time to the Sacramento River Arm array was 58.6 d. A total of 182 fish (69.5 percent) were detected at least once at the Shasta Dam forebay, and it took them an average of $54 \mathrm{~d}$ to get there. The first fish arrived $17 \mathrm{~d}$ after release and fish steadily arrived through the last data collection at $98 \mathrm{~d}$ from the first release. About 11 percent of the tagged fish were detected daily at Shasta Dam. Fish were observed making multiple trips to some of the detection sites (table A-6). For example, one fish had the following sequence of detections: mid-McCloud, McCloud Arm, East Shasta Reservoir, McCloud Arm, mid-McCloud, McCloud Arm, mid-McCloud, McCloud Arm and back to the East Shasta Reservoir, a total of approximately $79.2 \mathrm{rkm}$ between these locations. Interestingly, there were more multiple trips observed among the detection sites during the February release of fish compared to the November release of fish (table A-6). This observation was in spite of the higher river flows, more spread-out detection arrays, and a smaller sample size of fish during the February release.

The acoustic-tagged fish released in November had a very different pattern of detection and travel time from those released in February. Of the November-released fish that were detected in the study area, most were detected $3.3 \mathrm{rkm}$ downstream of the release location within the first 3 days after release (figs. A-9, A-11). Between day 3 and 10, fish steadily arrived at the mid-McCloud River array, but few fish were first detected after day 10. Few fish were detected outside of the McCloud River Arm. Four fish were detected at Shasta Dam forebay with travel times of 23.8, 24.8, 37.0, and 83.4 days from release (fig. A-11). All of these fish were detected at each of the detection arrays in sequential order (upriver to downriver) with no upriver movement (table A-6). One of these fish was subsequently detected at Keswick Dam at $50.4 \mathrm{~d}$ after release. Travel time from last detection at Shasta Dam to first detection at Keswick Dam was $19.2 \mathrm{~h}$. 
Table A-5. Summary statistics for travel times (days) of acoustic tagged juvenile late-fall run Chinook salmon that traveled from the release at the McCloud River Bridge to locations downriver, California, 2017.

\begin{tabular}{|c|c|c|c|c|c|c|c|c|c|}
\hline \multirow[b]{2}{*}{ Location } & \multirow[b]{2}{*}{$\begin{array}{c}\text { Distance } \\
\text { (rkm) }\end{array}$} & \multicolumn{7}{|c|}{ Travel time } & \multirow[b]{2}{*}{$\begin{array}{c}\text { Mean rate } \\
(\mathrm{km} / \mathrm{d})\end{array}$} \\
\hline & & $\mathbf{N}$ & Mean & Minimum & 25th & Median & 75th & Max & \\
\hline \multicolumn{10}{|c|}{ First release February 2017} \\
\hline McCloud River Bridge & 0.8 & 257 & 0.1 & $<0.1$ & 0.1 & 0.1 & 0.1 & 2.07 & 7.2 \\
\hline Mid-McCloud River & 10.3 & 215 & 2.9 & 1.2 & 2.1 & 2.6 & 3.4 & 19.0 & 3.5 \\
\hline McCloud River Arm & 22.1 & 202 & 27.6 & 6.3 & 12.0 & 22.3 & 39.0 & 92.6 & 0.8 \\
\hline East Shasta Reservoir & 25.4 & 53 & 31.0 & 8.5 & 15.9 & 29.9 & 39.8 & 94.3 & 0.8 \\
\hline Sacramento River Arm & 34.1 & 57 & 58.6 & 18.1 & 45.2 & 55.7 & 70.1 & 92.7 & 0.6 \\
\hline Shasta Dam forebay & 37.4 & 182 & 54.2 & 17.8 & 40.9 & 54.2 & 70.4 & 95.0 & 0.7 \\
\hline \multicolumn{10}{|c|}{ Second release November 2017} \\
\hline McCloud River Bridge & 3.3 & 311 & 0.5 & 0.1 & 0.3 & 0.4 & 0.5 & 12.0 & 6.6 \\
\hline Mid-McCloud River & 10.3 & 98 & 4.3 & 1.3 & 2.0 & 2.7 & 3.9 & 54.1 & 2.4 \\
\hline McCloud River Arm & 22.1 & 18 & 19.5 & 7.5 & 13.4 & 16.0 & 18.4 & 80.4 & 1.1 \\
\hline $\begin{array}{l}\text { West of I-5 Bridge } \\
\text { Downstream of Sacramento }\end{array}$ & 25.6 & 9 & 26.2 & 10.9 & 15.6 & 19.7 & 25.3 & 81.4 & 1.0 \\
\hline River & 30.3 & 7 & 30.5 & 16.9 & 19.6 & 21.0 & 30.2 & 81.8 & 1.0 \\
\hline Shasta Dam forebay & 36.6 & 4 & 42.2 & 23.8 & 24.3 & 30.9 & 60.2 & 83.5 & 0.9 \\
\hline Keswick Dam forebay & 52.4 & 1 & 50.4 & & & & & & 1.0 \\
\hline
\end{tabular}

Table A-6. Summary statistics for the number of trips to each detection site by acoustic-tagged juvenile late-fall run Chinook salmon released at the McCloud River Bridge, California, 2017.

\begin{tabular}{|c|c|c|c|c|c|c|}
\hline \multirow[b]{2}{*}{ Detection site } & \multicolumn{6}{|c|}{ Number of trips to each detection site } \\
\hline & 1 & 2 & 3 & 4 & 5 & 6 \\
\hline \multicolumn{7}{|c|}{ First release February 2017} \\
\hline Below McCloud River Bridge (0.8 rkm) & 256 & 1 & 0 & 0 & 0 & 0 \\
\hline Mid-McCloud River & 206 & 8 & 0 & 1 & 0 & 0 \\
\hline McCloud River Arm & 165 & 32 & 3 & 1 & 0 & 1 \\
\hline East Shasta Reservoir & 42 & 10 & 1 & 0 & 0 & 0 \\
\hline Sacramento River Arm & 63 & 3 & 1 & 0 & 0 & 0 \\
\hline Shasta Dam forebay & 170 & 12 & 0 & 0 & 0 & 0 \\
\hline \multicolumn{7}{|c|}{ Second release November 2017 release } \\
\hline Below McCloud River Bridge (3.3 rkm) & 311 & 0 & 0 & 0 & 0 & 0 \\
\hline Mid-McCloud River & 97 & 1 & 0 & 0 & 0 & 0 \\
\hline McCloud River Arm & 17 & 1 & 0 & 0 & 0 & 0 \\
\hline West of I-5 Bridge & 8 & 1 & 0 & 0 & 0 & 0 \\
\hline Downstream of Sac. River Arm & 5 & 1 & 0 & 0 & 0 & 0 \\
\hline Shasta Dam forebay & 4 & 0 & 0 & 0 & 0 & 0 \\
\hline
\end{tabular}



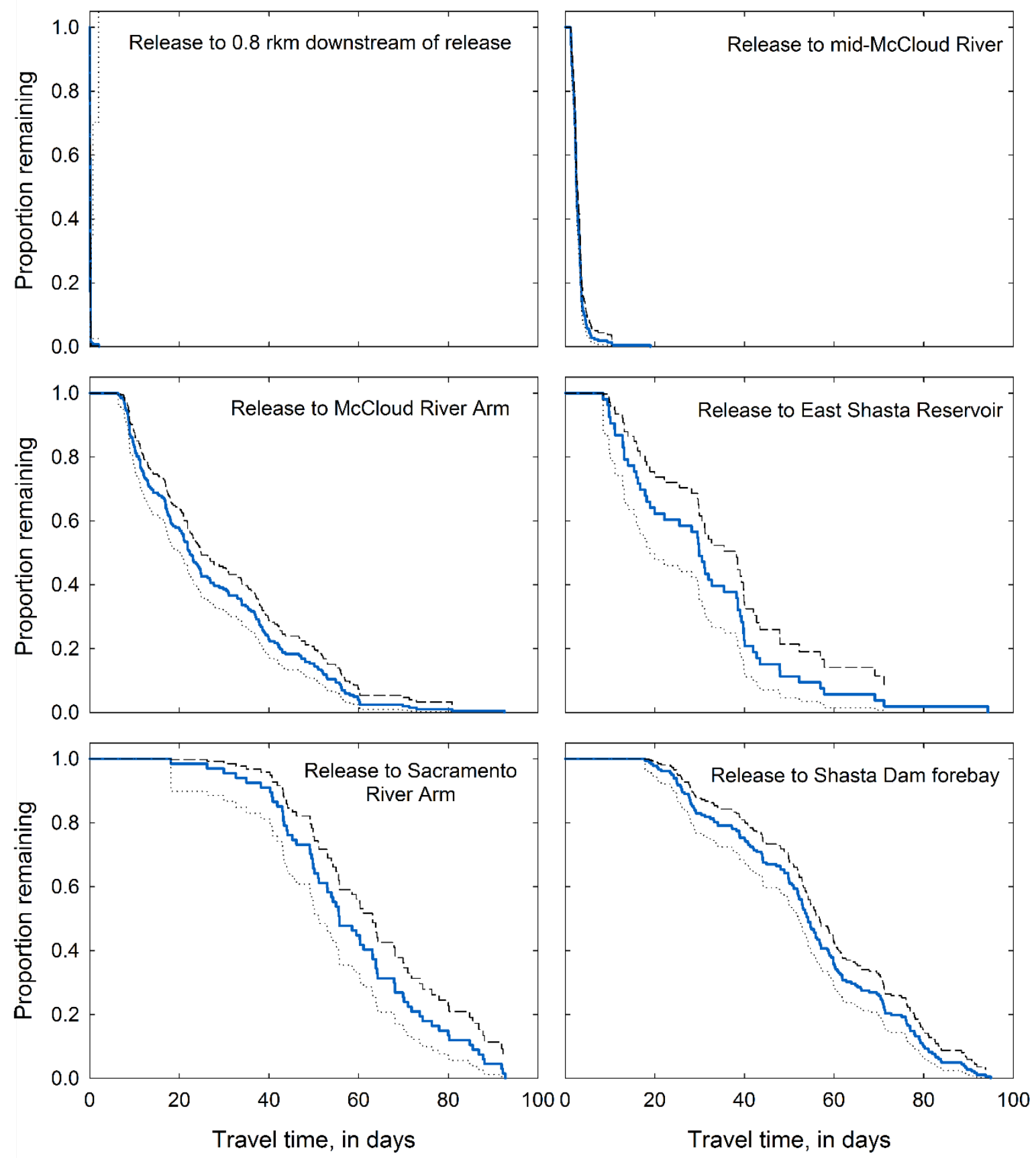

Figure A-10. Kaplan-Meier plots of travel times (in days) of acoustic-tagged juvenile late-fall run Chinook salmon between release at the McCloud River Bridge and detection arrays in Shasta Reservoir and tributaries, California, through May 10, 2017. Dotted and dash lines indicate the 95 percent upper and lower confidence interval. 

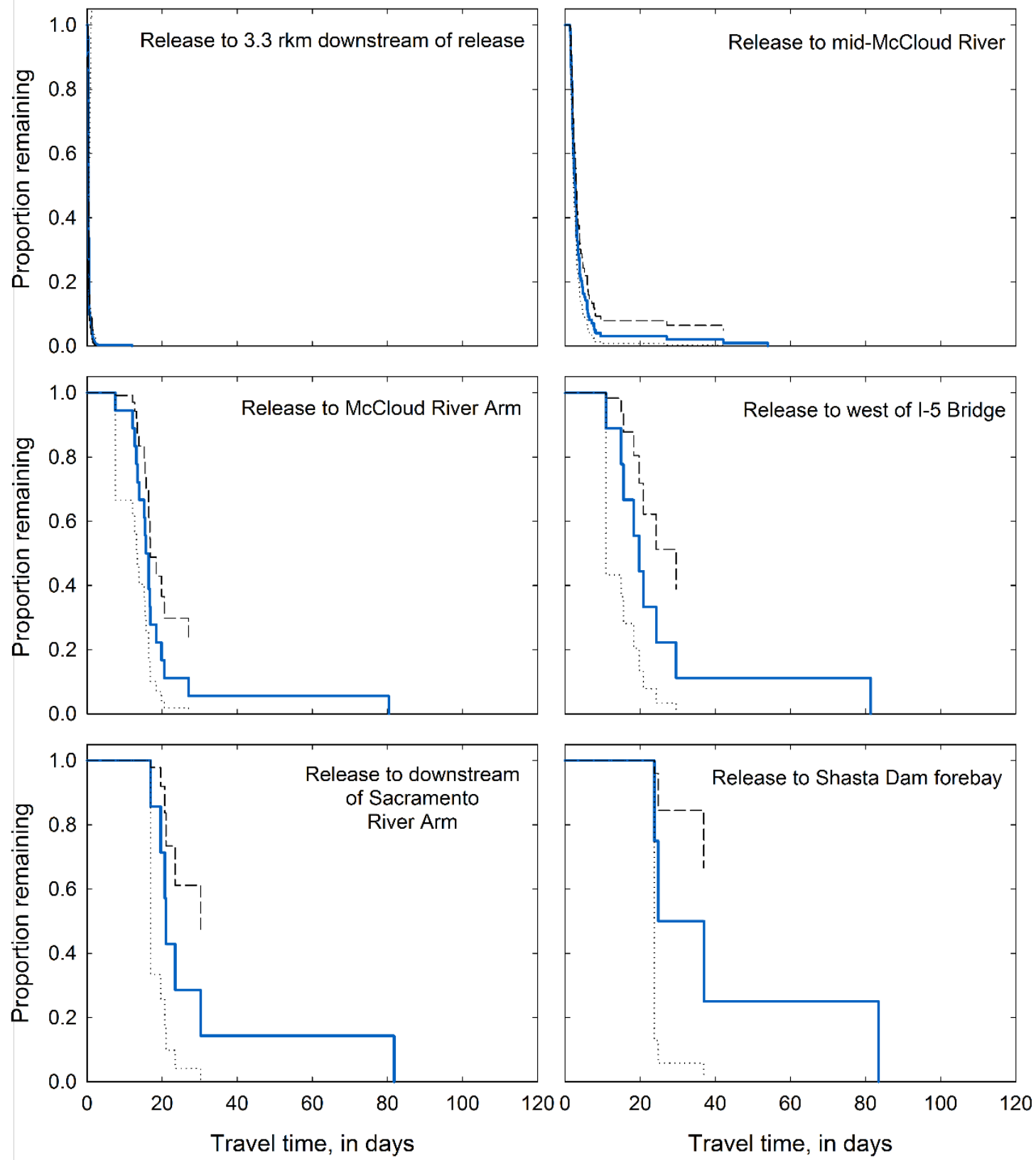

Figure A-11. Kaplan-Meier plots of travel times (in days) of acoustic-tagged juvenile late-fall run Chinook salmon between release at the McCloud River Bridge and detection arrays in the McCloud River, Shasta Reservoir, and Keswick Dam forebay, California, through March 11, 2018. Dotted and dash lines indicate the 95 percent upper and lower confidence interval. 


\section{Fish Survival and Detection}

Among the detection arrays, detection rates $\left(p_{1}=0.971\right.$, standard deviation $[\mathrm{SD}]=0.0279$; tables A-7, A-8) were highest at Shasta Dam, which might be expected given the relatively slow water velocities upriver of the dam, the high number of hydrophones that were located there, and the extra time fish needed to locate a passage route through the dam. Of the fish released, $0.71(\mathrm{SD}=0.034)$ survived the reservoir and arrived at Shasta Dam.

Detection rates for acoustic-tagged fish range from 0.331 to 0.608 downstream of Shasta Dam, indicating that detection rates were sufficient to provide a reasonably precise estimate of fish survival downriver of the dam (table A-8). Our ability to gather date on fish after they passed Shasta Dam was not anticipated prior to the study. However, these unexpected data enabled us to estimate fish survival as far downriver as the San Francisco Bay. Our estimates showed that fish survival was the lowest in the reach just downstream of Shasta $\operatorname{Dam}\left(\phi_{2}=0.222, \mathrm{SD}=0.0404\right)$, which makes sense given that the mortality associated with dam passage should contribute to a lower estimate. Likewise, fish survival was relatively high $(>0.84)$ in reaches without the dam, especially considering the greater distances $(>119$ $\mathrm{km}$ ) over which the fish had to travel. These findings indicate that fish survival through Shasta Dam was likely poor. For example, if we assume the survival in reach 2 (downstream of Shasta Dam) had the same per kilometer survival rate (table A-8; fig. A-8) as we measured in the next downriver reach (reach 3 ), then fish survival would have been about 0.91 in reach 2 , and dam survival would be about 0.24 to satisfy the measured survival rate of 0.22 for reach 2 . 
Table A-7. Observed detection counts by location and those expected under the Cormack-Jolly-Seber model fit to the detection data on late-fall run Chinook salmon released at the McCloud River Bridge, California, February, 2017.

[Detection location: 0, not detected; 1, detected]

\begin{tabular}{|c|c|c|c|c|c|c|}
\hline \multicolumn{5}{|c|}{ Detection location } & \multicolumn{2}{|c|}{ Frequency } \\
\hline Shasta Dam & Salt Creek & Butte Bridge & $\begin{array}{c}\text { Antioch } \\
\text { Bridge }\end{array}$ & $\begin{array}{c}\text { Golden Gate } \\
\text { Bridge }\end{array}$ & Observed & Expected \\
\hline 0 & 0 & 0 & 0 & 0 & 80 & 79 \\
\hline 0 & 0 & 0 & 0 & 1 & 0 & 0 \\
\hline 0 & 0 & 0 & 1 & 0 & 0 & 0 \\
\hline 0 & 0 & 0 & 1 & 1 & 0 & 0 \\
\hline 0 & 0 & 1 & 0 & 0 & 0 & 0 \\
\hline 0 & 0 & 1 & 0 & 1 & 0 & 0 \\
\hline 0 & 0 & 1 & 1 & 0 & 0 & 0 \\
\hline 0 & 0 & 1 & 1 & 1 & 0 & 0 \\
\hline 0 & 1 & 0 & 0 & 0 & 0 & 0 \\
\hline 0 & 1 & 0 & 0 & 1 & 0 & 0 \\
\hline 0 & 1 & 0 & 1 & 0 & 0 & 0 \\
\hline 0 & 1 & 0 & 1 & 1 & 0 & 0 \\
\hline 0 & 1 & 1 & 0 & 0 & 0 & 0 \\
\hline 0 & 1 & 1 & 0 & 1 & 0 & 0 \\
\hline 0 & 1 & 1 & 1 & 0 & 0 & 0 \\
\hline 0 & 1 & 1 & 1 & 1 & 0 & 0 \\
\hline 1 & 0 & 0 & 0 & 0 & 149 & 149 \\
\hline 1 & 0 & 0 & 0 & 1 & 0 & 0 \\
\hline 1 & 0 & 0 & 1 & 0 & 9 & 4 \\
\hline 1 & 0 & 0 & 1 & 1 & 0 & 1 \\
\hline 1 & 0 & 1 & 0 & 0 & 4 & 7 \\
\hline 1 & 0 & 1 & 0 & 1 & 1 & 1 \\
\hline 1 & 0 & 1 & 1 & 0 & 6 & 6 \\
\hline 1 & 0 & 1 & 1 & 1 & 0 & 1 \\
\hline 1 & 1 & 0 & 0 & 0 & 1 & 3 \\
\hline 1 & 1 & 0 & 0 & 1 & 0 & 0 \\
\hline 1 & 1 & 0 & 1 & 0 & 0 & 2 \\
\hline 1 & 1 & 0 & 1 & 1 & 0 & 0 \\
\hline 1 & 1 & 1 & 0 & 0 & 7 & 4 \\
\hline 1 & 1 & 1 & 0 & 1 & 2 & 0 \\
\hline 1 & 1 & 1 & 1 & 0 & 3 & 3 \\
\hline 1 & 1 & 1 & 1 & 1 & 0 & 0 \\
\hline
\end{tabular}


Table A-8. Summary statistics of the posterior distributions for each of the Cormack-Jolly-Seber survival model parameters, Shasta Dam, California, 2017-18.

[Parameters were estimated by fitting the survival model to the detection data on acoustic-tagged late-fall run Chinook salmon that were released at the McCloud River Bridge during February, 2017. Parameters were not estimable from the second release of fish during November, 2017. Parameter: $p$, detection probability; $\phi$, apparent survival probability; $\lambda$, the joint probability of detection and survival; the corresponding derived estimates of apparent survival provided as per kilometer basis]

\begin{tabular}{|c|c|c|c|c|c|c|}
\hline Parameter & Reach or location & Mean & $\begin{array}{l}\text { Standard } \\
\text { deviation }\end{array}$ & 2.5 percent & 50 percent & $\begin{array}{c}97.5 \\
\text { percent }\end{array}$ \\
\hline$\phi_{1}$ & $\begin{array}{l}\text { McCloud River to Shasta } \\
\text { Dam }\end{array}$ & 0.710 & 0.0340 & 0.6468 & 0.7093 & 0.7819 \\
\hline$\phi_{2}$ & Shasta Dam to Salt Creek & 0.222 & 0.0404 & 0.1519 & 0.2188 & 0.3096 \\
\hline$\phi_{3}$ & Salt Creek to Butte Br & 0.912 & 0.0776 & 0.7112 & 0.9331 & 0.9973 \\
\hline$\phi_{4}$ & Butte Bridge to Antioch & 0.841 & 0.1156 & 0.5784 & 0.8615 & 0.9937 \\
\hline$p_{1}$ & Shasta Dam & 0.971 & 0.0279 & 0.8965 & 0.9797 & 0.9993 \\
\hline$p_{2}$ & Salt Creek & 0.331 & 0.0794 & 0.1872 & 0.3279 & 0.4966 \\
\hline$p_{3}$ & Butte Bridge & 0.608 & 0.0907 & 0.4263 & 0.6097 & 0.7779 \\
\hline$p_{4}$ & Antioch & 0.563 & 0.1128 & 0.3574 & 0.5575 & 0.7957 \\
\hline$\lambda$ & Antioch to Golden Gate & 0.119 & 0.0576 & 0.0331 & 0.1105 & 0.2545 \\
\hline$\phi \mathrm{km}_{1}$ & Release to Shasta Dam & 0.991 & 0.0013 & 0.9884 & 0.9909 & 0.9935 \\
\hline$\phi \mathrm{km}_{2}$ & Shasta Dam to Salt Creek & 0.984 & 0.0019 & 0.9805 & 0.9842 & 0.9878 \\
\hline$\phi \mathrm{km}_{3}$ & Salt Creek to Butte Bridge & 0.999 & 0.0008 & 0.9972 & 0.9994 & 1.0000 \\
\hline$\phi \mathrm{km}_{4}$ & Butte Bridge to Antioch & 0.999 & 0.0006 & 0.9978 & 0.9994 & 1.0000 \\
\hline
\end{tabular}




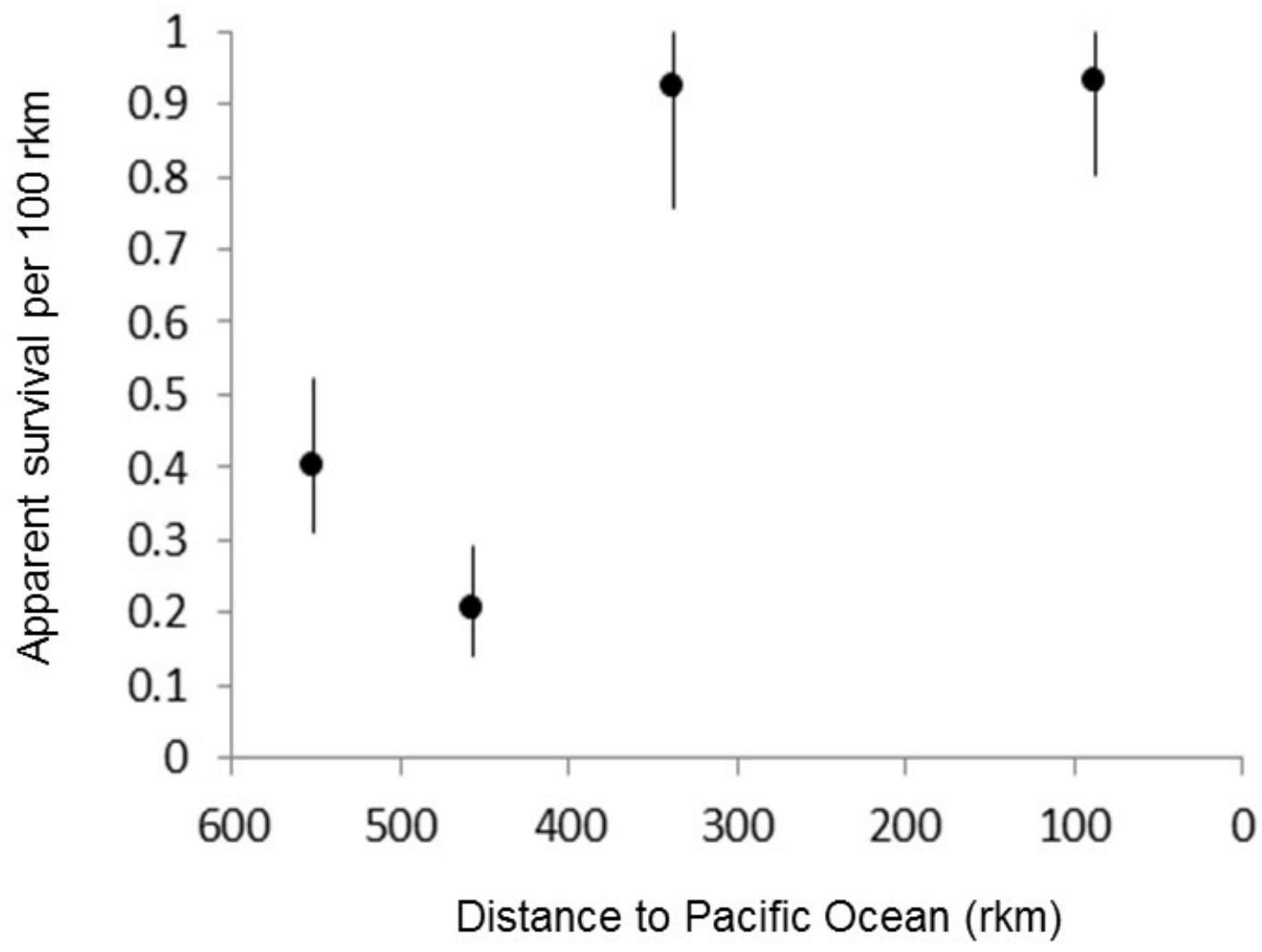

Figure A-12. Graph showing apparent survival estimates (per $100 \mathrm{rkm}$ ) for acoustic-tagged late-fall run Chinook salmon that were released at the McCloud River Bridge, California, February 2017. Error bars represent the 95 percent credible interval about the posterior distribution. rkm, river kilometer. 


\section{Discussion}

It has been more than 70 years since juvenile salmon have emigrated from tributaries upstream of Shasta Dam, and this report provides the first estimates about juvenile Chinook salmon movements and survival after release into tributaries upriver of Shasta Dam. Fortuitously, the acoustic-tagged fish were released between two periods having very different river flows, reservoir conditions, and dam operations. River flows in the McCloud River and through Shasta Dam differed by an order of magnitude between the two release periods. River flows were historically high during the February release, but similar to average river flows during the November release. Despite these very different river flows between the two release periods, water turbidities and temperatures were not as markedly different as the inflows and outflows at Shasta Reservoir. Consequently, this study measures juvenile Chinook salmon behavior over a wide range of river flows that may be used to help inform resource managers about how to best implement a trap-and-haul program when reintroducing anadromous fish into tributaries upriver of Shasta Dam.

Acoustic-tagged fish were detected throughout Shasta Reservoir from Pit River mouth to the mouth of the upper Sacramento River, indicating that juvenile salmon can disperse throughout Shasta Reservoir, especially when flows are high. Some fish were recorded making multiple trips between locations in the reservoir. However, despite the historically high river flows during the February release, the wider spatial arrangement of the detection arrays, fewer tagged fish released, and hydrophones at Shasta Dam, the tagged fish during the February release exhibited the greatest number of trips, greater average travel times to Shasta Dam, and were detected as far down river as San Francisco Bay. In contrast, the fish during the November release were exposed to average river flows, a linear arrangement in detection locations, and higher density of hydrophones at Shasta Dam. However, the fish from the November release were detected in much lower proportions, and if detected, had relatively faster travel times with fewer trips measured among the detection sites. The detection rates of these fish were so low that only one fish was detected downstream of Shasta Dam at Keswick Dam, and fish detections were too sparse to estimate detection and apparent survival probabilities.

Clearly the historic differences in river flows and the atypical dam operations contributed to the observed differences in fish detections among the first and second release groups. However, several other factors likely also contributed to the release-specific differences in fish detections. First, the groups were released in different seasons. Although all fish were Sacramento River late-fall run Chinook salmon, life stages of salmon are differentiated by their migration phenology. Spring and fall Chinook salmon enter freshwater in those respective seasons, and juvenile chinook salmon can outmigrate at age $0^{+}$or $1^{+}$(Connor and others, 2004). Thus, differences in detection (and inferred behavior and survival) between the two groups is not surprising because differences in physiological development were inherent among the release groups. Second, the release groups also differed by age, with younger, smaller fish comprising most of the November release. On average, the smaller fish in the November release group had higher tag burdens, though all tag burdens in this study were well within a range reported to have minimal effects on juvenile Chinook salmon swimming ability (Perry and others, 2013). Nonetheless, higher survival for larger juvenile salmon has been documented (Muir and others, 2011), and likely contributed to the differences among the release groups. Lastly, the release groups differed genetically as diploid fish were released in February and triploid fish were released in November. These genetic differences could have also contributed to the observed differences among the release groups (O'Flynn and others, 1997; Garner and others, 2008).

Detecting fish as far downriver as San Francisco Bay was an unanticipated result. Prior to this study, the professional judgement of resource managers was that juvenile salmon survival would be poor while traveling through the reservoir to Shasta Dam. Under the very high flows during the February release, survival was unexpectedly high and similar to that measured at large run-of-the-river 
dams and reservoirs on the Columbia River (Adams and others, 2008). In contrast, under average river flows, the a priori expectation of poor fish survival to Shasta Dam was supported. Because of the unexpectedly high detection rates of tagged fish at Shasta Dam of the February release of acoustictagged fish, the decision was made to increase the number of hydrophones just upriver of Shasta Dam (a detection range of about $200 \mathrm{~m}$ from the dam) to gain a better understanding about fish approach and passage through the dam. Given the high rates of detection for the February release group under high river flows and with comparatively few hydrophones at the dam, the lower detection rates for the second release group of tagged fish suggests this group survived poorly. Thus, the extent to which detection array arrangement, high flows, season, fish age, fish size, and genetic differences contributed to the differences in fish detection, movements, and survival during our study is uncertain. Nonetheless, our findings strongly support the conclusion that under average reservoir flows, trap-and-haul operations for juvenile salmon located at Shasta Dam are unlikely to be successful, and so trapping operations may be best accomplished by using in-river and head-of-reservoir traps for the collection and transport of juvenile salmon to locations downstream of Shasta Dam.

It is important to remember that the detection of acoustic-tagged fish as far downriver as San Francisco Bay was unexpected, and thus, the detection and survival estimates provided in this report were not part of a planned experimental design aimed at estimating fish survival. Likewise, the survival estimates provided should be interpreted cautiously and the following caveats should be considered. First and perhaps foremost, our estimates do not account for the expected (about $100 \mathrm{~d}$ ) battery life of the transmitter. The median travel time (for fish that were detected) was about $31-55 \mathrm{~d}$, indicating that about one-third to one-half of the expected battery life of the transmitter had been used by the time fish arrived at Shasta Dam, and so some fish were arriving at Shasta Dam beyond the expected 100-d battery life. Consequently, our detection and survival estimates are likely biased towards faster traveling fish. Slower traveling fish would be more likely to have their transmitter expire by the time they arrived at the downriver sites, which could explain the relatively high (per $\mathrm{km}$ ) survival rates in the two farthest downriver reaches of our study area. Acoustic-tagged fish that traveled relatively slowly would be unlikely to be detected in these reaches (because of likely battery failure), but faster traveling fish would be more likely to be detected. Consequently, battery failure of slow fish would lead to greater detection of fast traveling fish and a positive bias in survival estimates, which might be most prevalent in the furthest downriver reaches. Eicher and others (1987) provided mean survival estimates from test releases of Chinook salmon during the early 1960s that ranged from 53 to 71 percent through Shasta Dam, so our estimates of fish survival in the reach just downriver of Shasta Dam are not outside expectations given the survival estimates of Eicher and others (1987). Nonetheless, because the survival estimates we present may be truncated due to long fish travel times relative to the battery life of the transmitter, this study's survival estimates may be best used as a guideline (for example, precision and sample size) for future studies that aim to estimate fish survival through and downstream of Shasta Dam.

\section{Acknowledgments}

We would like to extend our gratitude to the efforts of John Hannon with the Bureau of Reclamation and Randy Beckwith with the California Department of Water Resources. We would also like to thank U.S. Fish and Wildlife Service personnel Jim Smith, Kurt Brown, Robert Null, and Ron Stone, and the staff at the Coleman National Fish Hatchery, for assistance in obtaining, growing, and holding the fish used in this study. This work could not have been accomplished without the assistance of our USGS colleagues: Philip Haner, Gabriel Hansen, Tyson Hatton, Will Hurst, Rachel Ohnemus, Jamie Sprando, and Ryan Tomka. 


\section{References Cited}

Adams, N.S., Plumb, J.M., Hatton, T.W., Jones, E.C., Swyers, N.M., Sholtis, M.D., Reagan, R.E., and Cash, K.M., 2008, Survival and migration behavior of juvenile salmonids at McNary Dam, 2006: Annual Report of Research by the U.S. Geological Survey to the U.S. Army Corps of Engineers, Walla Walla District, Report number 2006-W68SBV60478899.

Adams, N.S., Plumb, J.M., Perry, R.W., and Rondorf, D.W., 2014, Performance of a surface bypass structure to enhance juvenile steelhead passage and survival at Lower Granite Dam, Washington: North American Journal of Fisheries Management, v. 34, p. 576-594.

Beeman, J.W., Evans, S.D., Haner, P.V., Hansel, H.C., Hansen, A.C., Hansen, G.S., Hatton, T.W., Sprando, J.M., Smith, C.D., and Adams, N.S., 2016, Evaluation of the biological and hydraulic performance of the portable floating fish collector at Cougar Reservoir and Dam, Oregon, 2014: U.S. Geological Survey Open-File Report 2016-1003, 127 p., doi:10.3133/ofr20161003.

Beeman, J.W., Hansel, H.C., Hansen, A.C., Haner, P.V., Sprando, J.M., Smith, C.D., Evans, S.D., and Hatton, T.W., 2013, Behavior and dam passage of juvenile Chinook salmon at Cougar Reservoir and Dam, Oregon, March 2011-February 2012: U.S. Geological Survey Open-File Report 2013-1079, $48 \mathrm{p}$.

Beeman, J.W., and Maule, A.G., 2001, Residence times and diel passage distributions of radio-tagged juvenile spring Chinook salmon and steelhead in a gatewell and fish collection channel of a Columbia River dam: North American Journal of Fisheries Management, v. 21, p. 455-463.

Beeman, J.W., and Perry, R.W., 2012, Bias from false-positive detections and strategies for their removal in studies using telemetry, in Adams, N.S., Beeman, J.W., and Eiler, J.H., eds., Telemetry techniques - A user guide for fisheries research: Bethesda, Maryland, American Fisheries Society, p. 505-518.

Bureau of Reclamation, 2015, Shasta Dam fish passage evaluation-Draft implementation plan: Bureau of Reclamation, accessed July 20, 2016, at https://www.usbr.gov/mp/bdo/docs/shasta-pilot-impplan.pdf.

Connor, W.P., Sneva, J.G., Tiffan, K.F., Steinhorst, R.K., and Ross, D., 2004, Two alternative juvenile life history types for Fall Chinook Salmon in the Snake River Basin: Transactions of the American Fisheries Society, v. 134, p. 291-304.

Cormack, R.M., 1964, Estimates of survival from the sighting of marked animals: Biometrika, v. 51, no. 3-4, p. 429-438.

Eicher, G.J., Bell, M.C., Campbell, C.J., Craven, R.E., and Wert, M.A., 1987, Turbine-related fish mortality-Review and evaluation of studies: Portland, Oregon, Eicher Associates, Inc., Portland, Prepared for Electric Power Research Institute, AP-5480 Research Project 2694-4.

Garner, S., Madison, B.N., Bernier, M.J., and Neff, B.D., 2008, Juvenile growth and aggression in diploid and triploid Chinook salmon Oncorhynchus tshawytscha (Walbaum): Journal of Fish Biology, v. 73, p. 169-185.

Gelman, A., Carlin, J.B., Stern, H.S., Dunson, D.B., Vehtari, A., and Rubin, D.B., 2014, Bayesian Data Analysis (3rd ed.): Boca Raton, Florida, CRC Press, 661 p.

Hosmer, D.W., and Lemeshow, S., 1999, Applied survival analysis-Regression modeling of time to event data: New York, Wiley, 386 p.

Jolly, G.M., 1965, Explicit estimates from capture-recapture data with both death and immigrationStochastic model: Biometrika, v. 52, p. 225-247.

Liedtke, T.L., Beeman, J.W., and Gee, L.P., 2012, A standard operating procedure for the surgical implantation of transmitters in juvenile salmonids: U.S. Geological Survey Open-File Report 2012$1267,50 \mathrm{p}$. 
Lusardi, R.A., and Moyle, P.B., 2017, Two-way trap and haul as a conservation strategy for anadromous salmonids: Bethesda, Maryland, Fisheries, v. 42, no. 9, p. 478-487.

McMichael, G.A., Eppard, M.B., Carlson, T.J., Carter, J.A., Ebberts, B.D., Brown, R.S., Weiland, M., Ploskey, G.R., Harnish, R.A., and Deng, Z.D., 2010, The juvenile salmon acoustic telemetry system-A new tool: Bethesda, Maryland, Fisheries, v. 35, no. 1, p. 9-22.

Muir, W.D., Marsh, D.M., Sandford, B.P., Smith, S.G., and Williams, J.G., 2011, Post-hydropower system delayed mortality of transported Snake River stream-type Chinook salmon-Unraveling the Mystery: Transactions of the American Fisheries Society, v. 135, p. 1523-1534, DOI:10.1577/T06049.1.

National Marine Fisheries Service, 2009, Biological opinion and conference opinion on the long term Central Valley Project and State Water Project: National Marine Fisheries Service.

O’Flynn, F.M., McGeachy, S.A., Friars, G.W., Benfey, T.J., and Bailey, J.K., 1997, Comparison of cultured triploid and diploid Atlantic salmon (Salmo Salar L.): Journal of Marine Science, v. 54, p. 1160-1165.

Perry, R.W., Plumb, J.M., Fielding, S.D., Adams, N.S., and Rondorf, D.W., 2013, Comparing effects of transmitters within and among populations-Application to swimming performance of juvenile Chinook salmon: Transactions of the American Fisheries Society, v. 142, p. 901-911.

Perry, R.W., Skalski, J.R., Brandes, P., Sandstrom, P.T., Klimley, A.P., Amman, A., and MacFarlane, B., 2010, Estimating survival and migration route probabilities of juvenile Chinook salmon in the Sacramento-San Joaquin River Delta: North American Journal of Fisheries Management, v. 30, p. 142-156.

Plumb, J.M., Adams, N.S., Perry, R.W., Holbrook, C.M., Romine, J.G., Blake, A.R., and Burau, J.R., 2015, Diel Activity patterns of juvenile late fall-run Chinook salmon with implications for operation of a gated water diversion in the Sacramento-San Joaquin River Delta: River Research and Applications, doi:10.1002/rra.

Plumb, J.M., Perry, R.W., Adams, N.S., and Rondorf, D.W., 2006, The effects of river impoundment and hatchery rearing on the migration behavior of juvenile steelhead in the lower Snake River, Washington: North American Journal of Fisheries Management, v. 26, p. 438-452.

R Core Team, 2015, R-A language and environment for statistical computing: Vienna, Austria, $\mathrm{R}$ Foundation for Statistical Computing, accessed October 31, 2017 at https:/www.R-project.org/ Seber, G.A.F., 1965, A note on the multiple recapture census: Biometrika, v. 52, p. 249-259. Skalski, J.R., Townsend, R., Lady, J., Giorgi, A.E., Stevenson, J.R., and McDonald, R.S., 2002, Estimating route-specific passage and survival probabilities at a hydroelectric project from smolt radio telemetry studies: Canadian Journal of Fisheries and Aquatic Sciences, v. 59, p. 1385-1393.

Titzler, P.S., McMichael, G.A., and Carter, J.A., 2010, Autonomous acoustic receiver deployment and mooring techniques for use in large rivers and estuaries: North American Journal of Fisheries Management, v. 30, p. 853-859.

Venditti, D.A., Rondorf, D.W., and Kraut, J.M., 2000, Migratory behavior and forebay delay of radiotagged juvenile fall Chinook salmon in a lower Snake River impoundment: North American Journal of Fisheries Management, v. 20, p. 41-52.

Yip, Garwin, 2015, Letter to Ron Milligan regarding the juvenile production estimate for Sacramento River winter-run Chinook salmon, in Bureau of Reclamation, Shasta Dam fish passage evaluationDraft implementation plan: Bureau of Reclamation, accessed July 20, 2016, at https://www.usbr.gov/mp/bdo/docs/shasta-fp-pilot-plan.pdf. 


\title{
Chapter B. Stress Physiology of Juvenile Chinook Salmon Following Transport
}

\author{
By Theresa L. Liedtke and Lisa K. Weiland
}

\section{Introduction}

Managed fish stocks like Pacific salmonids (Oncorhynchus species) are commonly subjected to handling and transportation processes. Hatchery settings or trap-and-haul operations, for example typically crowd, net, handle, and transport fish. Although these processes have been refined with the goal of reducing negative effects on fish, any of these processes, alone or in combination, can produce significant stress responses. Acute stressors such as these cause detectable physiological changes, which can be quantified to describe the degree of stress experienced by fish and to develop approaches to mitigate stress.

The Bureau of Reclamation initiated the Shasta Dam Fish Passage Evaluation (SDFPE) program in 2016 to determine the feasibility of reintroducing winter-run and spring-run Chinook salmon $(O$. tshawytscha) and steelhead (O. mykiss) to tributaries upstream of Shasta Dam. The strategy for reintroduction includes trapping juvenile fish at the head of the reservoir formed by Shasta Dam, or near the mouth of the tributaries where they join the reservoir. Once trapped, juvenile fish would be hauled by trucks to release locations downstream of Shasta and Keswick dams and may be held for a period to recover prior to being released to continue their migration. Minimizing the stress of transportation is a critical part of developing a successful trap-and-haul strategy for this reintroduction program.

Stress responses are physiological changes in an animal resulting from its attempt to adapt to stressful stimuli. Responses to stress have been categorized, with primary responses being hormonal, secondary responses being hematological or hydromineral, and tertiary responses occurring at the level of the whole animal (Barton and Iwama, 1991). Plasma cortisol, glucose, and lactate respond to stressors and are useful for measuring the magnitude of primary (cortisol) or secondary (glucose, lactate) stress responses. An elevation of plasma cortisol is the most widely used indicator of stress in fish (Wendelaar Bonga, 1997) and has been widely studied in salmon.

Transportation of fish involves a complex combination of stressors. Fish being transported typically encounter chasing or crowding during loading, netting and air exposure during transfer, and confinement, noise, and vibrations due to the moving vehicle. These individual stressors are known to induce significant stress responses (Schreck and others, 1989; Barton, 2000; Galt and others, 2018), and taken together they may have interactive, additive, or synergistic effects. Due to its complex nature, it is difficult to compare transportation stress response to other stressors or across species and studies (Leggatt and others, 2006). Additionally, salmonid species and strains have been shown to have different stress responses to the same stressors (Barton, 2000), so studies should address the specific species and transport conditions for which inferences are desired.

Evaluating stress responses in field settings can be challenging and expensive, but recent developments in portable field meters may grant significant savings in both time and cost. The development of point-of-care devices allows the rapid assessment of physiological indicators in physician or veterinary offices, and more recently in aquaculture and fisheries research settings (Cooke and others, 2008; Ball and Weber, 2017). The use of field meters is attractive because they negate the need for sample processing and storage for later analyses in laboratory settings. Blood glucose meters are the most common point-of-care device due to their use by human diabetes patients for self- 
monitoring. These pocket-size meters produce a reading in seconds when a very small blood sample is placed on a disposable test strip. Blood lactate meters are also available and operate similarly to blood glucose meters. Application of field meters to the assessment of stress responses in fish requires validation studies that compare the responses of specific species using both field meters and standard laboratory assays. Although some of these validations have been done (Cooke and others, 2008; Ball and Weber, 2017), each species, stressor, and meter require separate validation efforts before they can be broadly applied.

The purpose of this study was to describe the stress responses of juvenile Chinook salmon to a 60-minute (min) transport. The SDFPE program anticipates a 60-min transport for the proposed trapand-haul strategy, from the point of capture to the point of recovery and release. A non-transport (control) group and a standard stressor group were included as reference groups, to better understand the magnitude and duration of the transportation stress response. We measured aspects of the generalized stress response (plasma cortisol, glucose, and lactate) before, during, and 48-h after transportation. We hypothesized that the transportation group would show the largest physiological stress response, the standard stressor group would have an intermediate response, and the control group have the lowest stress response. The study also tested the efficacy of using glucose and lactate field meters to replace or support laboratory assays in future transportation applications.

\section{Methods}

\section{Fish}

Juvenile late-fall Chinook salmon from the U.S. Fish and Wildlife Service (USFWS) Coleman National Fish Hatchery in Anderson, California were used in this study. Although winter-run Chinook salmon are the primary population of interest for the SDFPE program, their imperiled status prevented their use in this evaluation. The late-fall Chinook salmon are considered an appropriate surrogate population for initial investigations on the stress physiology of transportation. Two weeks prior to the start of the study, approximately 4,000 fish were removed from the standard production raceways, sorted for size, and moved to the wet laboratory facility of the USFWS California-Nevada Fish Health Center, co-located with the hatchery. Fish were held indoors, in four rectangular fiberglass tanks $(84 \times$ $213 \times 38 \mathrm{~cm}$ [length by width by depth]), at a maximum density of $2.5 \mathrm{~g} / \mathrm{L}$. Fish were fed daily to satiation with commercial feed (Bio Oregon 1.0 millimeter [mm] pellet) and held under natural photoperiod at an average water temperature of $18^{\circ} \mathrm{C}$ (range $\left.17.6-18.2^{\circ} \mathrm{C}\right)$.

\section{Sampling Approach}

The study design included three primary study groups. The treatment group was subjected to a 60-min transport (hereafter, TRAN). A standard stressor group (hereafter, STD) was subjected to a 30sec net stress in order to provide a relevant comparison to the TRAN stress response. The third study group was a control (hereafter, $\mathrm{CON}$ ), which was minimally handled. All three study groups were serially sampled through $48 \mathrm{~h}$ (hour) post-treatment to monitor recovery.

The evaluation's targeting of small (50-60 mm fork length [FL]) Chinook salmon presented some challenges for the sampling approach. The small size of the fish prevented collection of sufficient blood from an individual to meet the total volume requirements for all stress indicators, even when fish were exsanguinated. The sampling approach we selected to overcome this challenge was to collect, pool, and mix blood from 20 individual fish to represent each sample. We held groups of 20 fish (a sample) in separate 19-L containers to avoid the repeated disruptions caused by serial removal of fish from a container where other fish remain to be sampled in the future. The maximum stocking density in 
the 19-L containers was $2.5 \mathrm{~g} / \mathrm{L}$. The individual container approach allowed us to access and process samples readily, with minimal disturbance to non-sampled fish, but it had the potential consequence of creating a stress response due to a new environment and (or) confinement. To mitigate this potential effect, groups of fish were anesthetized, measured, counted, and stocked into 19-L containers $36-48 \mathrm{~h}$ prior to the start of the test period in order to allow physiological indicators to stabilize. The mean fish size (FL and weight) for each sample was based on measurements of 6 of the 20 fish in the container, collected at the time of stocking. Following stocking, the 19-L containers were covered with secure lids, labelled with study group and sample period, and held in a $2.5 \mathrm{~m} \times 24.4 \mathrm{~m}$ concrete raceway at an average water temperature of $15.5^{\circ} \mathrm{C}$ (range: $12.9-17.8^{\circ} \mathrm{C}$ ). The containers were perforated with 4.8$\mathrm{mm}$ circular holes to retain fish but allow water exchange. The lower section of each 9-L container was non-perforated so when they were removed from the raceway they would retain $7 \mathrm{~L}$ of water.

Containers were made buoyant using an inflated ring near the top of the container, and they were held, floating, in sub-divided sections of the raceway (by group and sample period) to facilitate sample processing. Containers were removed from the raceway to conduct treatments (transport or net stress) and then returned to the raceway until they were processed at their designated post-treatment recovery time. Each study group had six sampling events during the post-treatment recovery period: $0,4,8,12$, 24, and $48 \mathrm{~h}$. At each sampling event, nine samples (nine containers of 20 fish each) were processed for each study group. The full study design therefore included 18 sampling events (3 groups with 6 events each) with 9 samples per event, for a total of 162 fish containers and 3,240 fish.

Sampling events were divided into two separate efforts to facilitate rapid sample processing and minimize sample variability through time. Study groups were initiated so that the 9 containers (180 total fish) for a given sampling event were composed of two sampling efforts separated by 30-60 min. For example, the CON sampling effort for 4-h post-treatment included sampling four containers (80 fish) and then 5 more containers (100 fish) 30-60 min later. This approach was selected to allow us to complete sample processing for all fish in a group within a short time. Following euthanasia, blood can only be effectively collected for a short time, especially in small fish due to coagulation. With the small fish used for this study, we were concerned that fish in the final container sampled might not provide sufficient blood for analysis. Sampling four or five containers of fish instead of nine containers in each session addressed this concern.

A baseline control group was included in the study design to describe the resting physiological status of study fish. We used 9 baseline control samples composed of 20 fish each (180 fish total) that were removed directly from the rectangular fiberglass holding tanks. This group was different from the CON group in that fish were not held in 19-L containers, and therefore is the most realistic depiction of the resting physiological status of the study fish. No size measurements were taken from the baseline control group in an effort to minimize disturbances.

\section{Sample Processing}

To expedite sample processing, we used a team of six personnel to euthanize fish and collect and process blood samples. A portable laboratory station was established immediately adjacent to the raceway where the 19-L containers were held so that containers could be removed from the water and fish euthanized within $1 \mathrm{~min}$. Each 19-L container was processed individually to ensure maximum blood collection from the 20 fish that composed a sample. A container was removed from the raceway, and tricaine methanesulfonate and sodium bicarbonate were immediately added in equal amounts to make the final concentration 200 milligrams per liter. Fish were completely immobilized in approximately 30 seconds. This approach has been shown to effectively arrest the physiological stress response in salmonids (Wedemeyer and others, 1990). Once fish were immobilized, the container was 
carried the short distance to the portable laboratory where blood was collected by four team members simultaneously. Blood collection for each container of 20 fish was completed within 5 min of euthanasia. Blood was collected by severing the caudal peduncle, capturing blood in ammoniumheparinized capillary tubes, and discharging the contents of the capillary tube into a micro-centrifuge tube. Blood from all 20 fish in a container was pooled into 1 tube, gently vortexed to mix, and a subsample was pipetted onto test strips specific for the glucose and lactate field meters. The remaining blood was centrifuged at 2,500 $\times \mathrm{g}$ for $10 \mathrm{~min}$, and plasma was aliquoted into separate tubes for each stress indicator. Samples were stored at $-80{ }^{\circ} \mathrm{C}$ until laboratory analysis.

Field meters were used to measure plasma glucose and lactate levels from the pooled blood for each sample. Currently, there are no field meters capable of assessing plasma cortisol levels. The AccuChek Aviva Plus glucose meter (Roche Diabetes Care, Indianapolis, Indiana) and Lactate Scout+ lactate analyzer (EKF Diagnostics, Cardiff, United Kingdom) were used according to manufacturer's instructions. Both field meters were tested daily against standards (per manufacturer's instructions) and were confirmed to be operating within specifications.

\section{Transportation Group}

The TRAN group was subjected to a 60-min transport, departing from and returning to the Coleman National Fish Hatchery. The transport route was 16.4 miles $(26.4 \mathrm{~km})$ along a paved, two-lane county highway in average condition and included two intersections that required the vehicle to stop. The transport vehicle maintained a steady speed between 30 and $35 \mathrm{miles} / \mathrm{hr}(48-56 \mathrm{~km} / \mathrm{hr})$ throughout the transport. The six sampling events for the TRAN group $(0,4,8,12,24$, and $48 \mathrm{~h}$ post-treatment) each included 9 samples, so 54 individual fish containers were transported and returned to the raceway until their designated sampling time. As per the sampling approach defined for the study (see section, "Sampling Approach"), two separate transports were completed, the first with 24 containers (4 from each of the 6 post-treatment sampling events) and the second with the remaining 30 containers (5 from each of 6 post-treatment sampling events). Each sampling event was represented during each transportation effort and both transport efforts followed the same route with similar timing. The transport used a metal tank $(2.5 \mathrm{~m} \times 4.5 \mathrm{~m} \times 0.5 \mathrm{~m})$ on a flatbed trailer. The tank had interior bracing designed to secure individual 19-L containers in rows, immersed to within approximately 10-15 centimeters $(\mathrm{cm})$ of the top of the container and accommodated the containers with the floatation ring in place. The tank was filled immediately prior to transport from the same water source used in the raceway, and water temperature and dissolved oxygen levels were recorded before and after transport. Each transport effort was initiated by removing containers from the raceway and securing them in the tank. Following the 60-min transport, all containers were removed from the tank and positioned in the raceway until their designated post-treatment sampling time. The $0 \mathrm{~h}$ samples were removed from the tank, and immediately euthanized and sampled.

\section{Within Transport Group}

A test group called "within transport" (WT) was added to the study design to describe the stress response of study fish within the 60-min transport. The primary treatment group (TRAN) allowed assessment of the stress response following transportation (starting at $4 \mathrm{~h}$ post-treatment), but not within the transport process. The WT group included 27 total samples (each sample represented by 20 fish in a 19-L container) and three sampling events. Nine samples were collected immediately prior to transport, at the mid-point of transport (30-min), and immediately following transport (60-min). Similar to the TRAN group, the WT group was divided across 2 separate transport efforts; 1 effort included 5 samples from each sampling event ( 15 containers) and the other included 4 samples from each sampling event 
(12 containers). During pre-transport sampling, the WT group was removed from the raceway, positioned in the transport tank, then immediately removed, euthanized, and sampled.

\section{Standard Stressor Group}

The STD group was subjected to a 30 -s net stress and sampled serially through a 48-h posttreatment recovery. The net stress was accomplished by removing individual 19-L containers from the raceway, pouring the fish from the container into a net, holding them in the net, exposing them to air for 30 seconds, and returning them to another container filled with water. Containers were then placed in the raceway and held until their designated post-treatment sampling. All containers for a sampling event were processed through the net-stress procedure and returned to the raceway within 5 min. The netstress processing occurred immediately adjacent to the holding raceway to limit handling, and all posttreatment containers were filled with water from the raceway to avoid any thermal stress. The $0 \mathrm{~h}$ netstress group was exposed to the net stress, returned to a water filled container, and then immediately euthanized and processed.

\section{Control Group}

Fish in the CON group were held in 19-L containers in the raceway with the TRAN and STD groups. They were not subjected to any treatment and were serially sampled to $48 \mathrm{~h}$ post-treatment, following the same approach used for the test groups. The timing of CON group sampling closely followed the TRAN group sampling, with a separation of approximately 30-min between these groups. For example, the TRAN 4-h post-treatment sampling was completed and then immediately followed by the CON 4-h post-treatment sampling. The baseline control group (see section, "Sampling Approach") was composed of a single sampling event, where fish were removed directly from holding tanks, without having experienced holding in 19-L containers.

\section{Laboratory Assays}

Laboratory assays were conducted at the USGS Columbia River Research Laboratory in Cook, Washington. Samples were transported from Coleman National Fish Hatchery to the USGS Laboratory on dry ice and then stored at $-80^{\circ} \mathrm{C}$ until assay. Plasma glucose and lactate levels were measured in the laboratory with the Sigma (St. Louis, Missouri) glucose hexokinase kit and lactate assay kit II following manufacturer's instructions. Plasma cortisol levels were measured with a commercially available ELISA kit (Neogen, Lexington, Kentucky) from unextracted samples following manufacturer's instructions. All samples were assayed in duplicate and the mean stress indicator level was reported.

\section{Data Analysis}

Plasma stress indicators were reviewed by calculating the coefficient of variation (CV) for the two duplicates of each sample. Samples where the CV was greater than 10 percent were assayed in duplicate again. Groups and sampling events were compared using ANOVA and significance was reported when $P<0.05$. Tukey's multiple comparison test was used when ANOVA findings were significant. Multiple comparison test results are shown as letter groups in figures and tables such that groups that share a common letter are not significantly different. 


\section{Results}

\section{Fish Size and Survival}

We collected and processed 198 samples (3,960 total fish) for our assessment of physiological stress response. The 1,134 fish sampled for size had a mean FL of $54.6 \mathrm{~mm}$ and a mean weight of $1.7 \mathrm{~g}$. The mean FL of the TRAN, STD, CON, and WT groups were not significantly different $(P=0.14$; table 9). The mean weight of the TRAN group was significantly higher than the STD group, but not significantly different from the other two groups $(P<0.001$; table 10). The actual differences in mean weight among the groups were small, ranging from $1.68 \mathrm{~g}$ for the STD group to 1.80 for the TRAN group (table 10). No size data were collected from the control baseline group, but those fish were likely of similar size as the main study groups because all study fish were from the same hatchery rearing group and were assigned to study groups randomly. No mortality was observed in any of the study groups. Mortalities would have been detected when 19-L containers were removed from the raceway for sampling, immediately prior to euthanasia.

Table B-1. Number and fork lengths (in millimeters) of juvenile Chinook salmon monitored for stress physiology, Shasta Dam, California, 2017-18.

[Group: TRAN, transportation group (experienced a 60-minute transport); STD, standard stressor (experienced a 30-sec net stress); CON, control (minimally handled); WT, within transport (sampled before, during, and after a 60-minute transport)]

\begin{tabular}{lllllll}
\hline Group & & N & Mean & $\begin{array}{l}\text { Standard } \\
\text { deviation }\end{array}$ & Minimum & Maximum \\
\hline TRAN & 324 & 54.5 & 2.9 & 47 & 62 \\
STD & 324 & 54.4 & 2.9 & 48 & 62 \\
CON & 324 & 54.9 & 2.8 & 47 & 62 \\
WT & 162 & 54.6 & 3.0 & 49 & 62 \\
\hline
\end{tabular}

Table B-2. Number and weights (in grams) of juvenile Chinook salmon monitored for stress physiology, Shasta Dam, California, 2017-18.

[Group: TRAN, transportation group (experienced a 60-minute transport); STD, standard stressor (experienced a 30-sec net stress); CON, control (minimally handled); WT, within transport (sampled before, during, and after a 60-minute transport)]

\begin{tabular}{|c|c|c|c|c|c|}
\hline Group & N & Mean & $\begin{array}{l}\text { Standard } \\
\text { deviation }\end{array}$ & Minimum & Maximum \\
\hline TRAN & 324 & $1.80 \mathrm{a}$ & 0.38 & 0.93 & 2.85 \\
\hline STD & 324 & $1.68 \mathrm{~b}$ & 0.36 & 0.90 & 2.66 \\
\hline $\mathrm{CON}$ & 324 & $1.73 \mathrm{ab}$ & 0.35 & 0.97 & 2.72 \\
\hline WT & 162 & $1.72 \mathrm{ab}$ & 0.40 & 0.98 & 2.94 \\
\hline
\end{tabular}




\section{Comparisons of Transport Efforts}

The two separate transport efforts for the TRAN group showed similar physiological responses and were pooled for analysis. The mean water temperatures for the two transport efforts were $16.7^{\circ} \mathrm{C}$ (range $16.4-17.2^{\circ} \mathrm{C}$ ) and $17.4^{\circ} \mathrm{C}$ (range $16.6-18.6^{\circ} \mathrm{C}$ ). Dissolved oxygen ranged from 100.3 to 111.5 percent on the first trip and from 102.0 to 110.1 percent on the second trip. There were no significant differences in plasma cortisol $(P=0.90)$ or glucose $(P=0.64)$ for the first or second transport effort at any of the post-treatment sampling events (4-48 h post-treatment). Plasma lactate was significantly higher $(P<0.001)$ for the second transport effort at 12 and $48 \mathrm{~h}$ post-treatment, but no difference was detected between the two transport efforts at $4 \mathrm{~h}, 8 \mathrm{~h}$, or $24 \mathrm{~h}$ post-treatment. All physiological indicators were pooled across the two transport efforts.

The WT group's two separate transport efforts were not significantly different for any of the physiological indicators and were pooled for analysis. The first transport effort had a mean water temperature of $15.9^{\circ} \mathrm{C}$ (range 14.6-17.4 ${ }^{\circ} \mathrm{C}$ ) and dissolved oxygen between 100.3 and 112.0 percent. The second trip had a mean water temperature of $16.8^{\circ} \mathrm{C}$ (range $15.4-18.1{ }^{\circ} \mathrm{C}$ ) and dissolved oxygen between 99.4 and 115.2 percent. There were no significant differences in plasma cortisol $(P=0.19)$, glucose $(P=0.97)$, or lactate $(P=0.09)$ at the 30 -min (mid-point of transport) or 60 -min (end-point of transport) sampling periods. All results for the WT group were therefore presented using the pooled values for each stress indicator.

\section{Transport Group}

The 60-min transport was stressful to fish, as evidenced by significant changes in stress indicators in the WT group. Plasma cortisol peaked at the midpoint of transport, with a level that was significantly higher $(P<0.001)$ than levels for pre-transport, immediately following transport, the $0 \mathrm{~h}$ control, or the baseline control (fig. B-1). By the end of the transport, cortisol levels had begun to decline, but were still significantly higher than pre-transport for either of the controls (fig. B-1). Plasma glucose levels peaked at the 60 -min sample and were significantly higher $(\mathrm{P}<0.001)$ than any other transport group or controls (fig. B-1). Plasma lactate levels did not change significantly during transport, but all transport levels (time 0,30 -min and 60-min) were significantly higher $(\mathrm{P}<0.001)$ than the control time 0 level and significantly lower $(P<0.001)$ than the control baseline (fig. B-1).

All stress indicators for the TRAN group showed significant changes during the 48-h recovery period following transport. For all indicators, the sample immediately after transport $(0 \mathrm{~h})$ was significantly higher $(P<0.001)$ than any other sample time (fig. B-2). Plasma cortisol levels were significantly lower $(P<0.001)$ than $0 \mathrm{~h}$ by $4 \mathrm{~h}$ after transport. During the period between $4 \mathrm{~h}$ and $12 \mathrm{~h}$, cortisol levels were not significantly different from each other and were similar to baseline controls (fig. B-2). There was a trend toward higher cortisol levels following the 8-h sample, with levels rising to be similar to the 4-h sample (fig. B-2). Plasma glucose levels declined steadily through the recovery period. By $4 \mathrm{~h}$ post-transport glucose levels had declined significantly $(P<0.001)$ compared to $0 \mathrm{~h}$ and continued to decline until $12 \mathrm{~h}$ post-transport, at which point glucose levels remained steady through 48 $\mathrm{h}$ and were comparable to the baseline control (fig. B-2). Plasma lactate showed a similar pattern to glucose, with a steady decline through the 48-h recovery period. Beginning at $4 \mathrm{~h}$ post-transport, lactate levels were significantly lower $(P<0.001)$ than $0 \mathrm{~h}$, not significantly different from other time periods, and were below the baseline control levels (fig. B-2). 

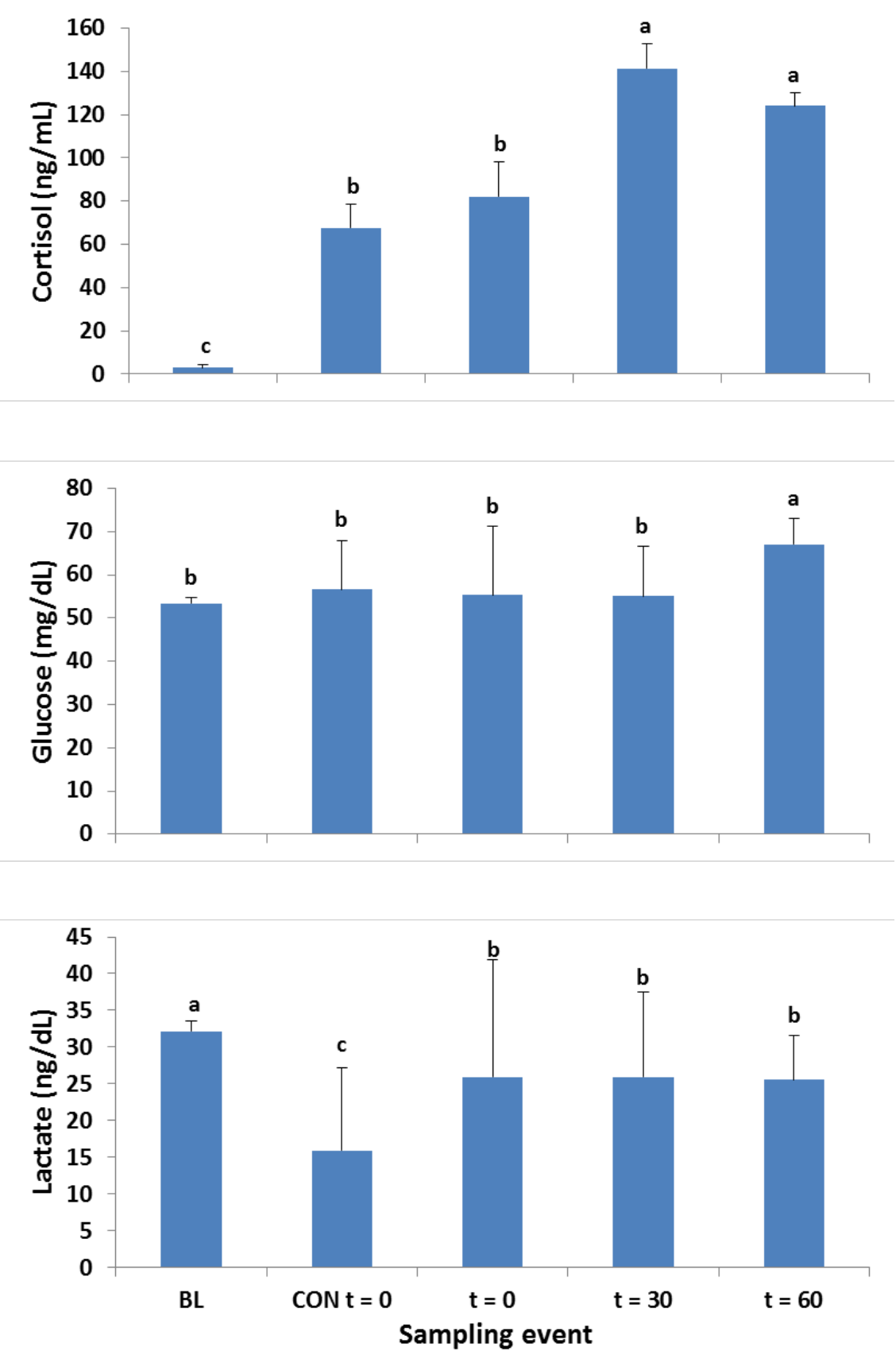

Figure B-1. Graph showing levels of cortisol, glucose, and lactate in juvenile Chinook salmon prior to a 60-minute transport $(t=0)$, at the mid-point of transport $(t=30)$, and immediately following transport $(t=60)$, compared to baseline controls (BL) and the control group (CON). Bars represent mean values, and error bars are the standard error. Within each indicator, sampling events were compared using ANOVA and Tukey's multiple comparison test. Groups without letters in common are significantly different. 

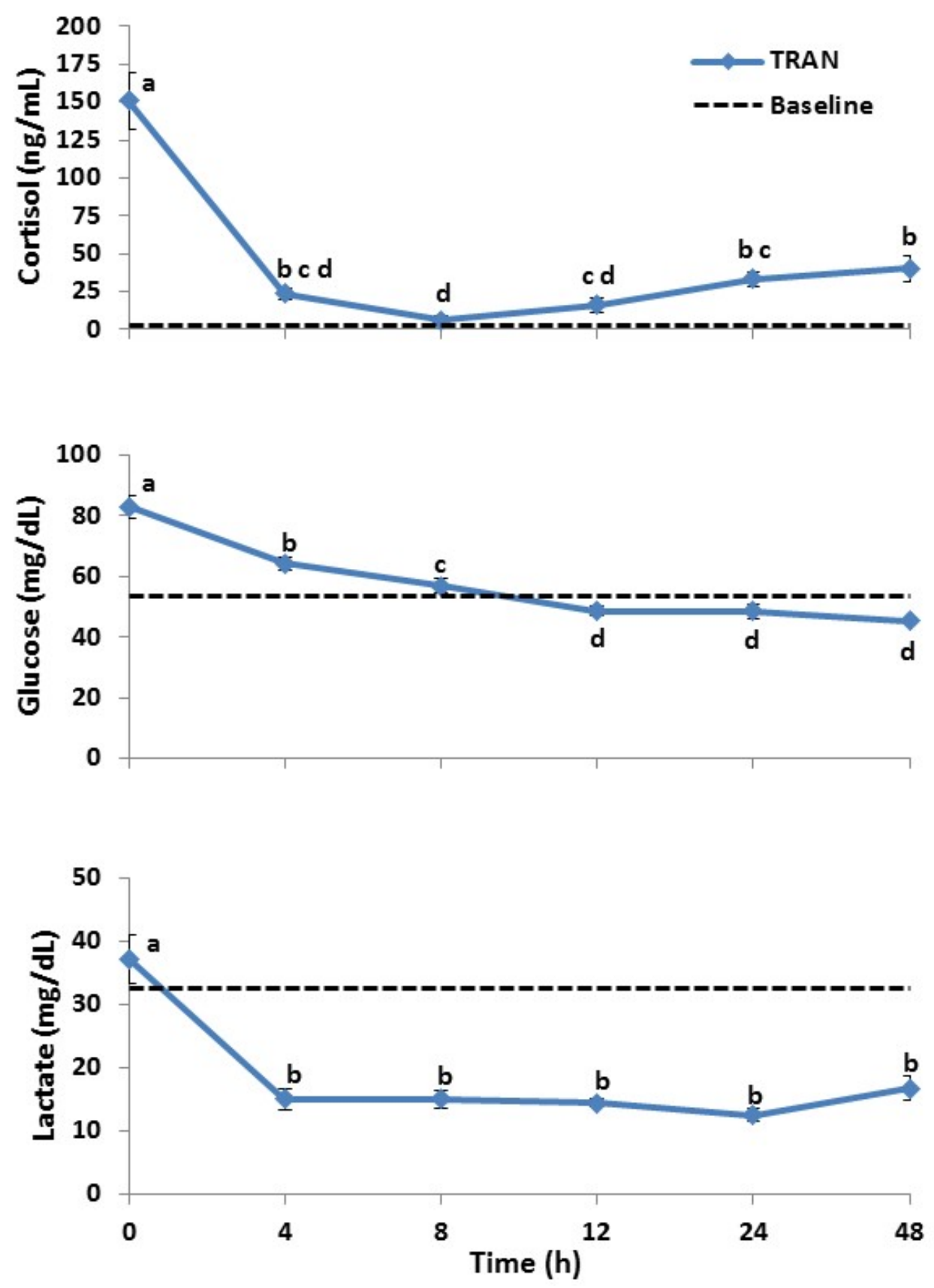

Figure B-2. Graph showing levels of cortisol, glucose, and lactate in juvenile Chinook salmon subjected to a 60minute transport (TRAN, shown in solid blue), and a baseline control group (shown in dashed black) serially sampled from immediately following transport (time $=0 \mathrm{~h}$ ) through $48 \mathrm{~h}$. Error bars are the standard error. Within each indicator, time periods were compared using ANOVA and Tukey's multiple comparison test. Groups without letters in common are significantly different. 


\section{Standard Stressor Group}

There were significant differences in stress indicators for the STD group through the poststressor recovery period. Plasma cortisol was highest at $0 \mathrm{~h}$, was significantly reduced $(P<0.01)$ by $4 \mathrm{~h}$ post-stressor, but was elevated again at 12 to $48 \mathrm{~h}$ (fig. B-3). Cortisol levels for all of the STD sampling events were higher than the baseline control (fig. B-3). Plasma glucose levels varied significantly over the 48 -h recovery period $(P=0.01)$. Glucose was highest at $4 \mathrm{~h}$ post-stressor, but was not significantly higher than $0 \mathrm{~h}$, and similar to the baseline control. Beginning at $8 \mathrm{~h}$ post-stressor, glucose levels remained low and steady (fig. B-3). Plasma lactate was highest at $0 \mathrm{~h}$, significantly higher $(P<0.001)$ than any other sampling period, but was significantly reduced by the 4 -h sampling. Lactate remained low from $4 \mathrm{~h}$ to $24 \mathrm{~h}$ post-stressor, but increased significantly at the 48 -h sample (fig. B-3). All lactate levels were lower than the baseline control except for $0 \mathrm{~h}$.

\section{Control Group}

The stress indicators for the CON group varied significantly over time. Plasma cortisol was significantly higher $(P<0.001)$ at $0 \mathrm{~h}$ than any other sample (fig. B-4). Cortisol was significantly reduced by the 4-h sample and remained low through the 12-h sample. The 24-h and 48-h samples were elevated and were not significantly different from the 4-h sample (fig. B-4). All cortisol samples for the CON group were higher than the baseline control. Plasma glucose levels were highest at $0 \mathrm{~h}$ and $4 \mathrm{~h}$, and levels trended down through time (fig. B-4). All glucose levels during the 48-h recovery -were similar to baseline control levels. Plasma lactate peaked at $4 \mathrm{~h}$, was significantly higher $(P<0.001)$ than 0 $\mathrm{h}$, and declined through time (fig. B-4). The CON lactate levels were less than the baseline control lactate levels throughout the 48-h recovery (fig. B-4). 

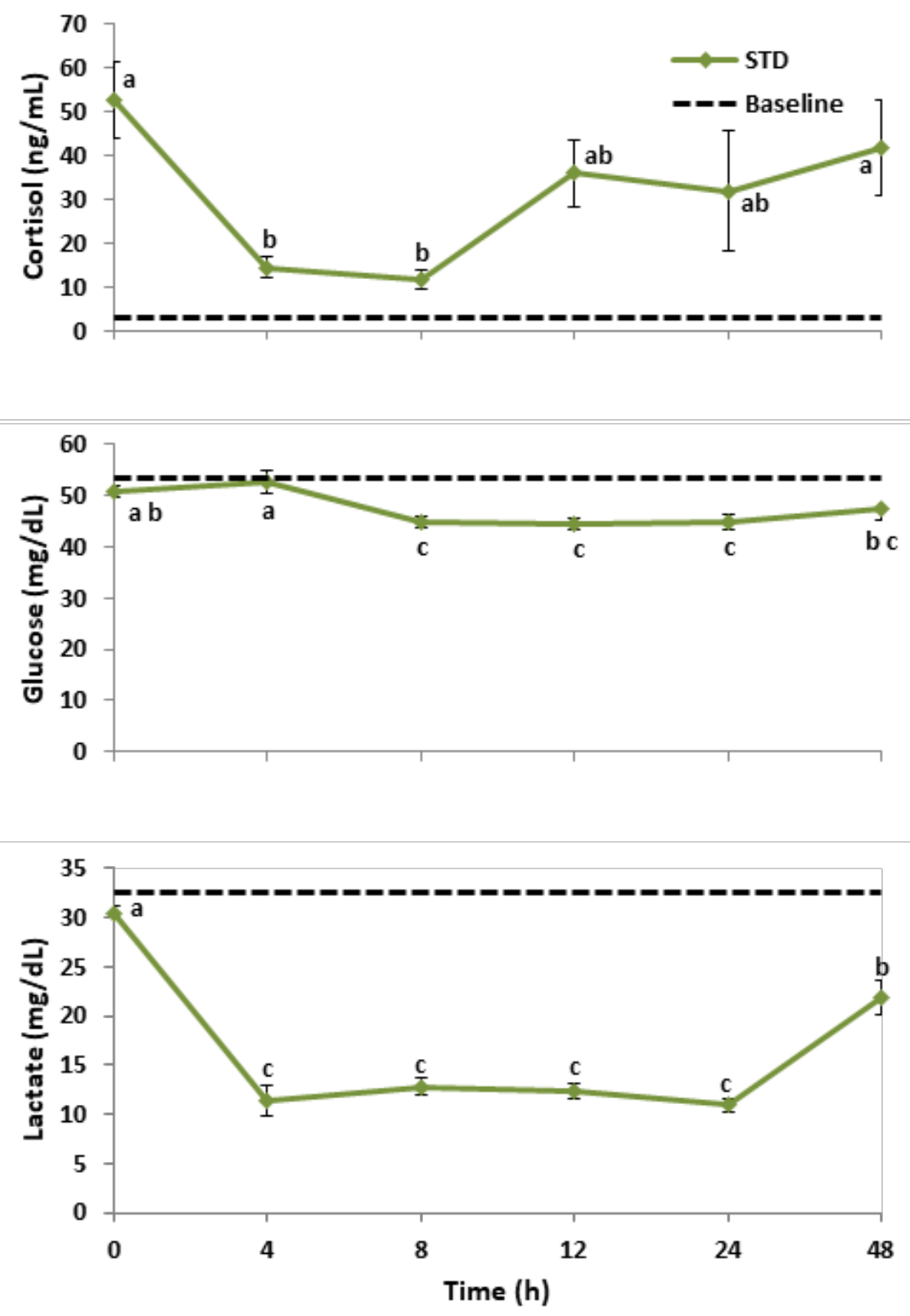

Figure B-3. Graph showing levels of cortisol, glucose, and lactate in Chinook salmon subjected to a standard stressor (STD, shown in green), and a baseline control group (shown in black) serially sampled from immediately following transport (time $=0 \mathrm{~h}$ ) through $48 \mathrm{~h}$. Error bars are the standard error. Within each indicator, time periods were compared using ANOVA and Tukey's multiple comparison test. Groups without letters in common are significantly different. 

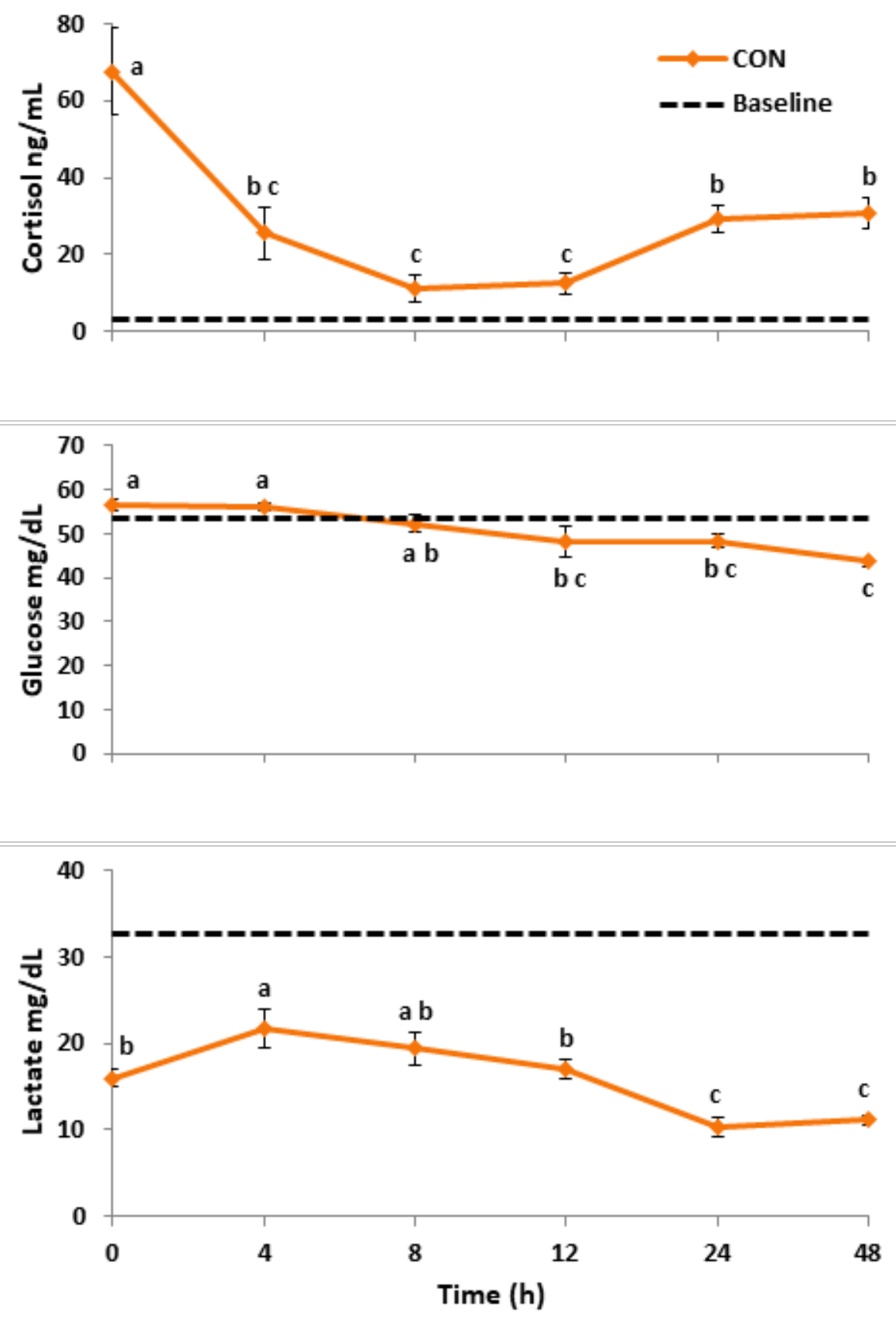

Figure B-4. Graph showing levels of cortisol, glucose, and lactate in Chinook salmon in the control group (CON, shown in orange), and a baseline control group (shown in black) serially sampled from immediately following transport (time $=0 \mathrm{~h}$ ) through $48 \mathrm{~h}$. Error bars are the standard error. Within each indicator, time periods were compared using ANOVA and Tukey's multiple comparison test. Groups without letters in common are significantly different. 


\section{Test Group Comparisons}

For each physiological stress indicator, we compared the test groups at each sampling during the 48-h recovery. The plasma cortisol comparisons at each sampling included the laboratory assay data for the TRAN, STD, and CON groups (table 11). For plasma glucose and lactate, the comparisons included both the laboratory assay and the field meter data for each group, resulting in six test groups at each sampling (table 11). Comparison of laboratory and field meter results will be presented in the "Field Meter Performance" section in this chapter.

Plasma cortisol findings suggest that the TRAN treatment was more stressful than the STD treatment or the CON group handling, but the stress response was quickly mitigated by study fish. Immediately after exposure to a stressor $(0 \mathrm{~h})$, cortisol levels in TRAN fish were significantly higher than the STD or CON groups (fig. B-5; table 11). The mean TRAN cortisol level was more than twice as high as either of the other groups (table 11). Despite the large magnitude of the cortisol response in the TRAN group, levels declined rapidly and by $4 \mathrm{~h}$ and $8 \mathrm{~h}$ there were no significant differences between the test groups (fig. B-5; table 10). Between $12 \mathrm{~h}$ and $48 \mathrm{~h}$ all three groups showed increasing cortisol levels. At $12 \mathrm{~h}$, cortisol was significantly higher for the STD group, but TRAN and CON were similar (fig. B-5). At both $24 \mathrm{~h}$ and $48 \mathrm{~h}$, the groups were not significantly different from each other (fig. B-5, table 11).

Plasma glucose levels determined by laboratory assay were different among the study groups early in the 48-h recovery, but differences became smaller over time. The overall trend for glucose was that the TRAN group had the highest levels, CON had mid-range levels, and STD had the lowest levels at each time period (fig. B-6). At $0 \mathrm{~h}$, glucose for the TRAN group was significantly higher than the CON group, which was significantly higher than the STD group (fig. B-6; table 11). There was no delay in response for plasma glucose for any group, as $0 \mathrm{~h}$ values were typically the highest during the recovery period. At $4 \mathrm{~h}$ and $8 \mathrm{~h}$ the trends were similar to $0 \mathrm{~h}$ with the exception that at $4 \mathrm{~h}$ the difference between the STD and CON groups was not significant (fig. B-6; table 11). None of the groups were significantly different from each other at either $12 \mathrm{~h}$ or $24 \mathrm{~h}$. At $48 \mathrm{~h}$, the STD group had significantly elevated glucose levels compared with the other groups, which were statistically similar (fig. B-6; table 11).

Laboratory assays for plasma lactate showed significant differences between the test groups at 5 of the 6 sampling events during the 48-h recovery, and lacked consistent group trends over time (fig. B7). Elevated lactate levels were observed at $0 \mathrm{~h}$ in both the TRAN and STD groups, which were both significantly higher than CON (fig. B-7; table 11). Both TRAN and STD had their highest levels at $0 \mathrm{~h}$ with lower levels at subsequent samplings. For the $4 \mathrm{~h}$ through $12 \mathrm{~h}$ sampling events, the TRAN and STD groups had reduced lactate compared to $0 \mathrm{~h}$ and were comparable to each other (table 11). For this same time period, the CON group was more elevated than at $0 \mathrm{~h}$ and significantly higher than both test groups (fig. B-7; table 11). By $24 \mathrm{~h}$, the CON lactate levels were reduced and not significantly different from TRANS or STD. The $48 \mathrm{~h}$ lactate levels were different from any other time period, with STD significantly higher than TRAN, which was significantly higher than CON (fig. B-7; table 11). 
Table B-3. Cortisol, glucose, and lactate from standard laboratory assays and field meters for Chinook salmon by sample period and group.

[For each indicator, groups were compared using ANOVA and Tukey's multiple comparison test. Groups without letters in common are significantly different]

\begin{tabular}{|c|c|c|c|c|c|c|c|}
\hline \multirow[b]{2}{*}{ Hour } & \multirow[b]{2}{*}{ Group } & & \multicolumn{3}{|c|}{ Laboratory assay } & \multicolumn{2}{|c|}{ Field meter } \\
\hline & & & Cortisol & Glucose & Lactate & Glucose & Lactate \\
\hline 0 & TRAN & & $150.9 \mathrm{a}$ & $83.1 \mathrm{a}$ & $37.1 \mathrm{a}$ & $67.2 \mathrm{~b}$ & $30.9 \mathrm{~b}$ \\
\hline 0 & STD & & $52.7 \mathrm{~b}$ & $50.8 \mathrm{~d}$ & $30.4 \mathrm{~b}$ & $40.8 \mathrm{e}$ & $22.5 \mathrm{c}$ \\
\hline \multirow[t]{2}{*}{0} & $\mathrm{CON}$ & & $67.5 \mathrm{~b}$ & $56.7 \mathrm{c}$ & $16.0 \mathrm{~d}$ & $47.0 \mathrm{~d}$ & $13.2 \mathrm{~d}$ \\
\hline & & ANOVA & $\mathrm{P}<0.001$ & $\mathrm{P}<0.001$ & $\mathrm{P}<0.001$ & & \\
\hline 4 & TRAN & & 23.5 & $64.4 \mathrm{a}$ & $15.0 \mathrm{bc}$ & $51.4 \mathrm{c}$ & $12.1 \mathrm{~cd}$ \\
\hline 4 & STD & & 14.4 & $52.8 \mathrm{bc}$ & $11.4 \mathrm{~cd}$ & $44.8 \mathrm{~d}$ & $9.0 \mathrm{~d}$ \\
\hline \multirow[t]{2}{*}{4} & $\mathrm{CON}$ & & 25.5 & $55.9 \mathrm{~b}$ & $21.7 \mathrm{a}$ & $47.3 \mathrm{~d}$ & $16.7 \mathrm{~b}$ \\
\hline & & ANOVA & $\mathrm{P}=0.22$ & $\mathrm{P}<0.001$ & $\mathrm{P}<0.001$ & & \\
\hline 8 & TRAN & & 6.0 & $56.8 \mathrm{a}$ & $15.0 \mathrm{~b}$ & $47.9 \mathrm{c}$ & $11.2 \mathrm{~cd}$ \\
\hline 8 & STD & & 11.6 & $44.9 \mathrm{c}$ & $12.8 \mathrm{bc}$ & $37.8 \mathrm{~d}$ & $8.0 \mathrm{~d}$ \\
\hline \multirow[t]{2}{*}{8} & $\mathrm{CON}$ & & 11.1 & $52.3 \mathrm{~b}$ & $19.4 \mathrm{a}$ & $45.6 \mathrm{c}$ & $14.6 \mathrm{bc}$ \\
\hline & & ANOVA & $\mathrm{P}=0.33$ & $\mathrm{P}<0.001$ & $\mathrm{P}<0.001$ & & \\
\hline 12 & TRAN & & $16.1 \mathrm{~b}$ & $48.5 \mathrm{a}$ & $14.4 \mathrm{~b}$ & $42.9 \mathrm{~b}$ & $10.3 \mathrm{~d}$ \\
\hline 12 & STD & & $35.9 \mathrm{a}$ & $44.5 \mathrm{ab}$ & $12.4 \mathrm{bc}$ & $37.3 \mathrm{c}$ & $8.2 \mathrm{e}$ \\
\hline \multirow[t]{2}{*}{12} & $\mathrm{CON}$ & & $12.4 \mathrm{~b}$ & $48.1 \mathrm{a}$ & $17.0 \mathrm{a}$ & $42.9 \mathrm{~b}$ & $12.3 \mathrm{~cd}$ \\
\hline & & ANOVA & $\mathrm{P}=0.01$ & $\mathrm{P}=0.004$ & $\mathrm{P}<0.001$ & & \\
\hline 24 & TRAN & & 33.2 & $48.6 \mathrm{a}$ & $12.4 \mathrm{a}$ & $43.9 \mathrm{~b}$ & $10.2 \mathrm{ab}$ \\
\hline 24 & STD & & 31.8 & $44.8 \mathrm{ab}$ & $10.9 \mathrm{a}$ & $38.6 \mathrm{c}$ & $7.3 \mathrm{~b}$ \\
\hline \multirow[t]{2}{*}{24} & $\mathrm{CON}$ & & 29.3 & $48.3 \mathrm{a}$ & $10.3 \mathrm{ab}$ & $40.8 \mathrm{bc}$ & $7.3 \mathrm{~b}$ \\
\hline & & ANOVA & $\mathrm{P}=0.95$ & $\mathrm{P}<0.001$ & $\mathrm{P}=0.014$ & & \\
\hline 48 & TRAN & & 40.1 & $45.3 \mathrm{ab}$ & $16.7 \mathrm{~b}$ & $39.2 \mathrm{de}$ & $11.7 \mathrm{c}$ \\
\hline 48 & STD & & 41.7 & $47.4 \mathrm{a}$ & $21.9 \mathrm{a}$ & $41.6 \mathrm{~cd}$ & $15.7 \mathrm{~b}$ \\
\hline \multirow[t]{2}{*}{48} & $\mathrm{CON}$ & & 30.6 & $43.7 \mathrm{bc}$ & $11.2 \mathrm{c}$ & $36.8 \mathrm{e}$ & $7.2 \mathrm{~d}$ \\
\hline & & ANOVA & $\mathrm{P}=0.60$ & $\mathrm{P}<0.001$ & $\mathrm{P}<0.001$ & & \\
\hline
\end{tabular}




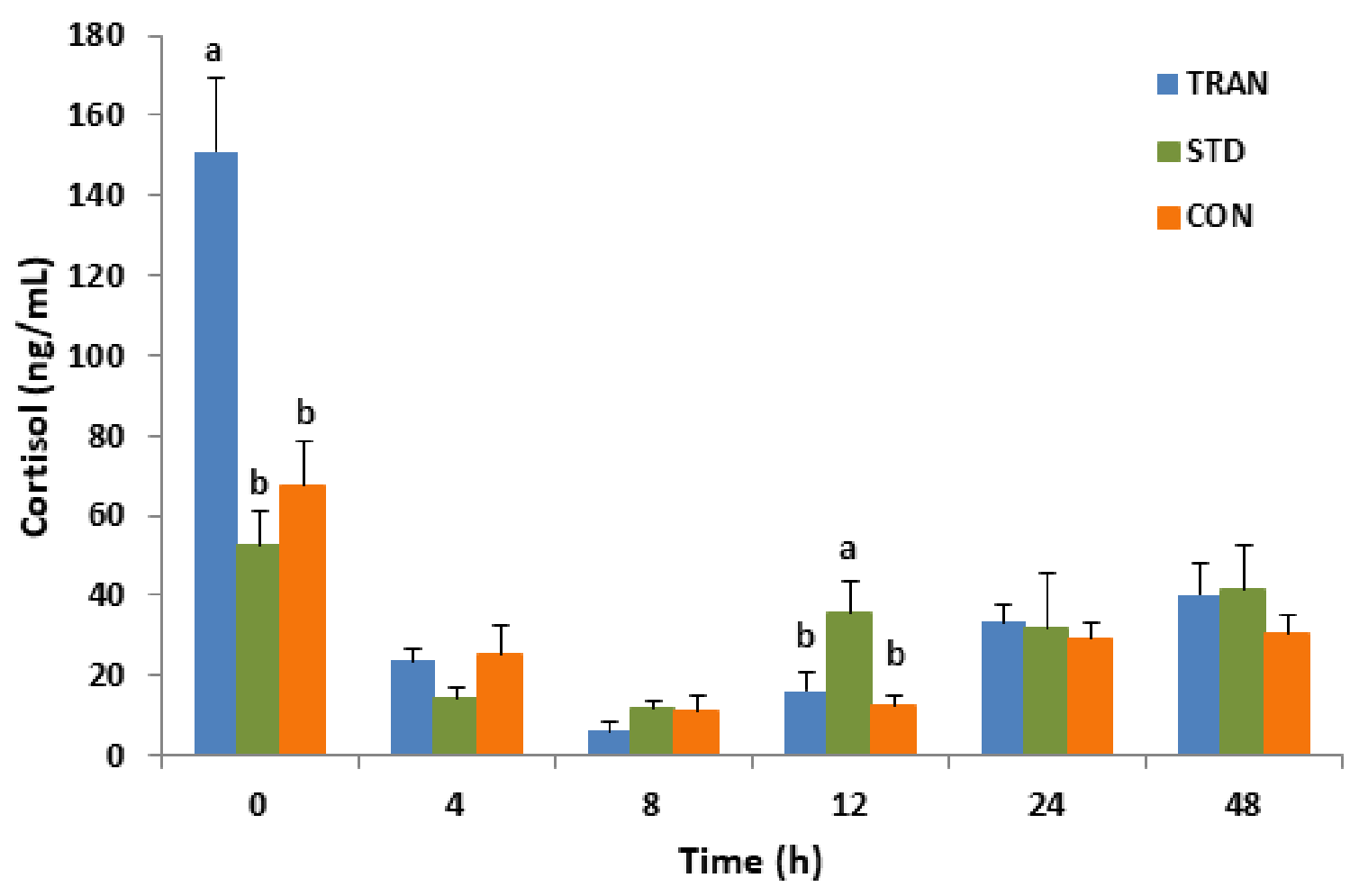

Figure B-5. Graph showing levels of cortisol in three groups of Chinook salmon monitored for $48 \mathrm{~h}$ following a stressor. The transportation group (TRAN, shown in blue) was subjected to a 60-minute transport, the standard stressor group (STD, shown in green), was subjected to 30-sec in a net, and the control group (CON, shown in orange) was minimally handled. Error bars are the standard error. Within each time period groups were compared using ANOVA and Tukey's multiple comparison test. Groups without letters in common are significantly different. 


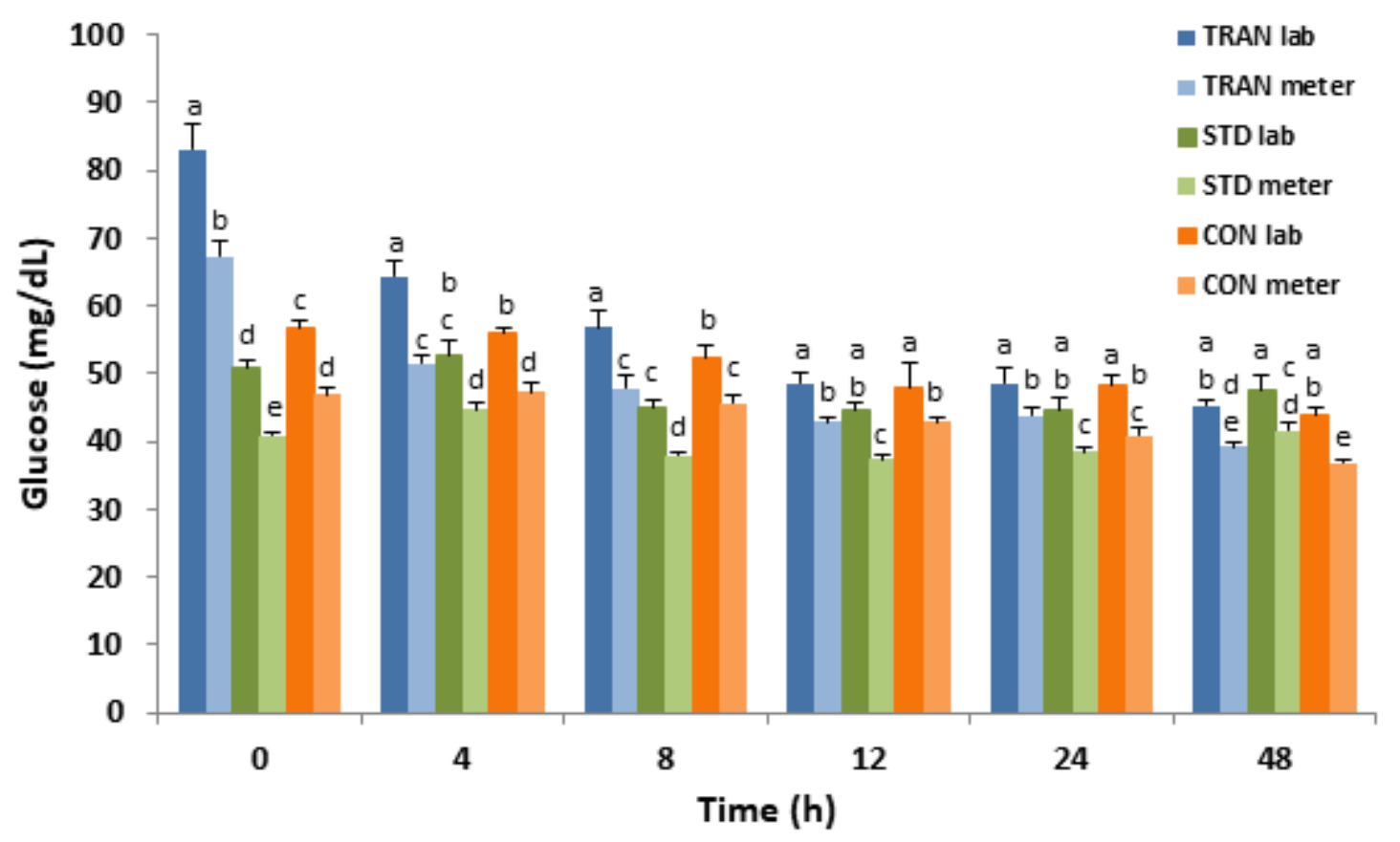

Figure B-6. Graph showing levels of glucose in three groups of Chinook salmon monitored for $48 \mathrm{~h}$ following a stressor. The transportation group (TRAN, shown in blue shades) was subjected to a 60 minute transport, the standard stressor group (STD, shown in green shades), was subjected to $30 \mathrm{sec}$ in a net, and the control group (CON, shown in orange shades) was minimally handled. Each group includes a measure of glucose based on laboratory assay (lab) and a measure based on a field meter (meter). Error bars are the standard error. Within each time period groups were compared using ANOVA and Tukey's multiple comparison test. Groups without letters in common are significantly different. 


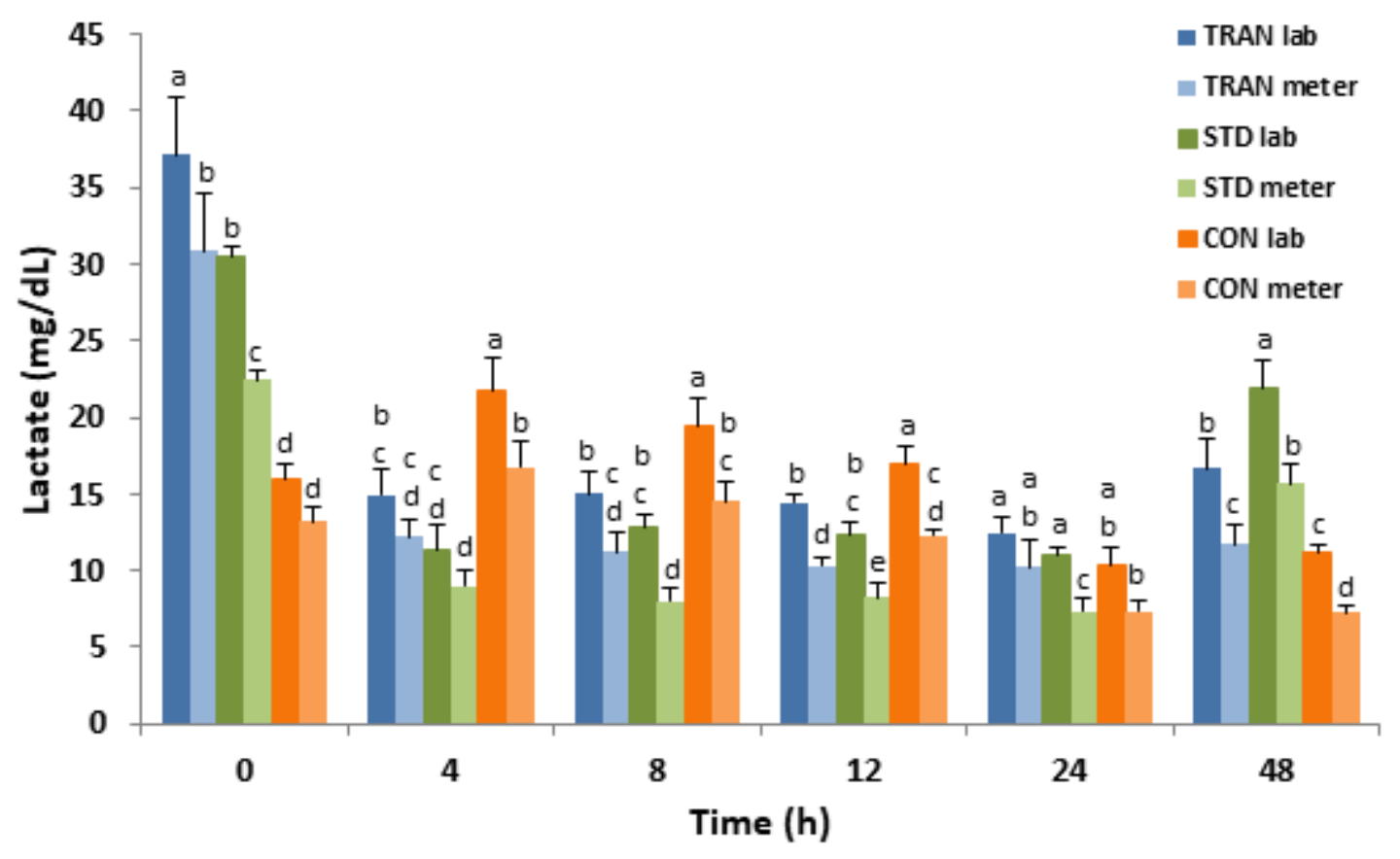

Figure B-7. Graph showing levels of lactate in three groups of Chinook salmon monitored for $48 \mathrm{~h}$ following a stressor. The transportation group (TRAN, shown in blue shades) was subjected to a 60-minute transport, the standard stressor group (STD, shown in green shades), was subjected to 30-sec in a net, and the control group (CON, shown in orange shades) was minimally handled. Each group includes a measure of glucose based on laboratory assay (lab) and a measure based on a field meter (meter). Error bars are the standard error. Within each time period groups were compared using ANOVA and Tukey's multiple comparison test. Groups without letters in common are significantly different. 


\section{Field Meter Performance}

The field meters used to monitor plasma glucose and lactate levels produced consistently lower readings than the corresponding laboratory assays, but were effective at detecting the timing of peak levels and tracking temporal trends. Meter and laboratory datasets for plasma glucose and lactate assay types were compared for the TRAN, STD, and CON groups during the $48 \mathrm{~h}$ recovery period and for the WT group.

Plasma glucose levels during the $48 \mathrm{~h}$ recovery period were always lower for the field meter when compared to the laboratory assay at each sampling event (fig. B-6; table 11). For the TRAN group, both assays determined the peak level at $0 \mathrm{~h}$, followed by the significant reduction at $4 \mathrm{~h}$ (fig. B7). The laboratory assay detected another significant reduction at $8 \mathrm{~h}$, but the meter assay showed the 8 $\mathrm{h}$ level to be similar to the $4 \mathrm{~h}$ level. Alternately, the field meter detected a significant reduction at $48 \mathrm{~h}$, but the laboratory assay showed the $48 \mathrm{~h}$ level as similar to the levels at $12 \mathrm{~h}$ and $24 \mathrm{~h}$ (fig. B-7). Despite these minor differences, the temporal trend in glucose levels for the TRAN group was very similar between the two glucose assays. The STD group trends were the same for both assays; peak glucose levels at $4 \mathrm{~h}$, a significant decline by $8 \mathrm{~h}$, and similar levels at $48 \mathrm{~h}$ and $0 \mathrm{~h}$ (fig. B-7). The CON group showed very similar temporal trends for both assays: steady until $24 \mathrm{~h}$ with a significant decline at $48 \mathrm{~h}$ based on the field meter, and a comparable level at $48 \mathrm{~h}$ based on the laboratory assay (fig. B-7).

The WT group's temporal trends in plasma glucose were similar between the field meter and laboratory assay. Like the $48 \mathrm{~h}$ recovery period comparisons, the meter levels at all points of comparison for the WT group were lower than the laboratory assay levels (fig. B-8). Both assays detected the highest levels of glucose at the 60-min sampling event, at the end of transport, which was significantly higher than the 30-min samples. The laboratory assay detected no significant differences between the baseline control, the CON group $0 \mathrm{~h}$, and the WT group at (fig. B-8). The field meter showed similar findings, but significantly lower levels for the CON group at $0 \mathrm{~h}$ and the WT group at time 0 (fig. B-8). These group differences did not alter the main trend detected by the field meter, which was very comparable to the trend detected by the laboratory assay (fig. B-8).

The field meter for plasma lactate generally reported lactate levels lower than the laboratory assay during the $48 \mathrm{~h}$ recovery period for the TRAN, STD, and CON groups, but levels were comparable in a few instances. For example, the TRAN group at $4 \mathrm{~h}$ and $24 \mathrm{~h}$, the STD group at $4 \mathrm{~h}$, and the $\mathrm{CON}$ group at $0 \mathrm{~h}$ (fig. B6; table 11). The temporal trends for the main test groups were identical based on the field meter and laboratory assay data (fig. B-9). For the TRAN group, both assays detected the peak at $0 \mathrm{~h}$ and significantly lower levels for all periods through $48 \mathrm{~h}$ (fig. B-9). Similarly for the STD and CON groups, both assays detected the same peaks, with significant differences (or not) from adjacent groups and the same sampling event for the lowest reported lactate value (fig. B-9).

Plasma lactate trends for the WT group were identical between the field meter and laboratory assays, although field meter levels were consistently lower. The peak value for the WT group comparisons was for the baseline control, and the lowest reported value was for the CON $0 \mathrm{~h}$ group (fig. B-8). Both assays showed no significant differences in plasma lactate levels before transport, mid-way through transport (30-min), or immediately following transport (fig. B-8). 

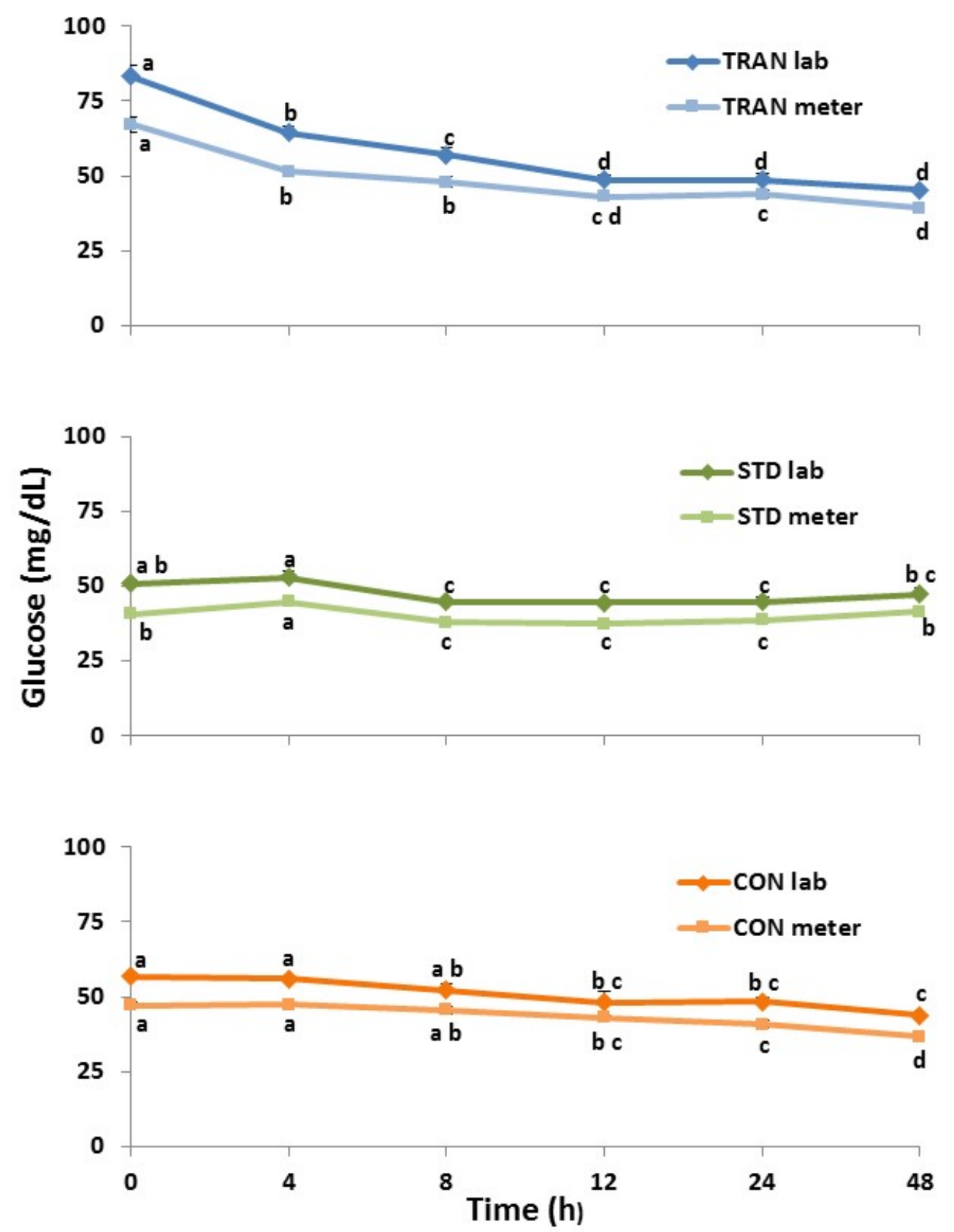

Figure B-8. Graph showing levels of glucose measured by laboratory assay (lab) and field meter (meter) in three groups of Chinook salmon monitored for $48 \mathrm{~h}$ following a stressor. The transportation group (TRAN, shown in blue shades) was subjected to a 60-minute transport, the standard stressor group (STD, shown in green shades), was subjected to 30-sec in a net, and the control group (CON, shown in orange shades) was minimally handled. Error bars are the standard error. Within each time period groups were compared using ANOVA and Tukey's multiple comparison test. Groups without letters in common are significantly different. 

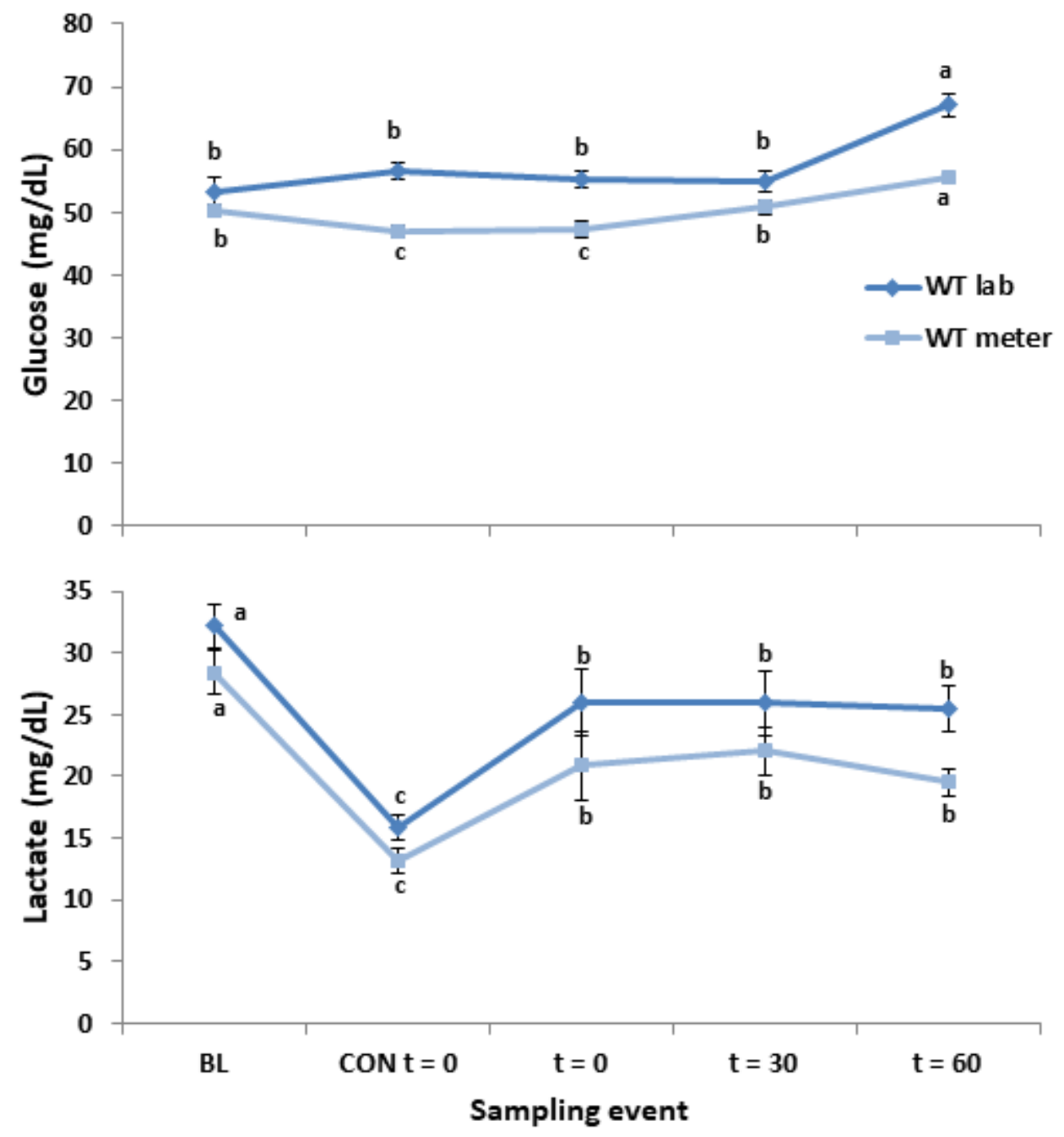

Figure B-9. Graph showing levels of glucose and lactate measured within a transport (WT) experience by laboratory assay (lab) and field meter (meter) in Chinook salmon prior to a 60-minute transport ( $\mathrm{t}=0$ ), at the midpoint of transport ( $\mathrm{t}=30)$, and immediately following transport $(\mathrm{t}=60)$, compared to baseline controls $(\mathrm{BL})$ and the control group (CON). Error bars are the standard error. Within each group, time periods were compared using ANOVA and Tukey's multiple comparison test. Groups without letters in common are significantly different. 

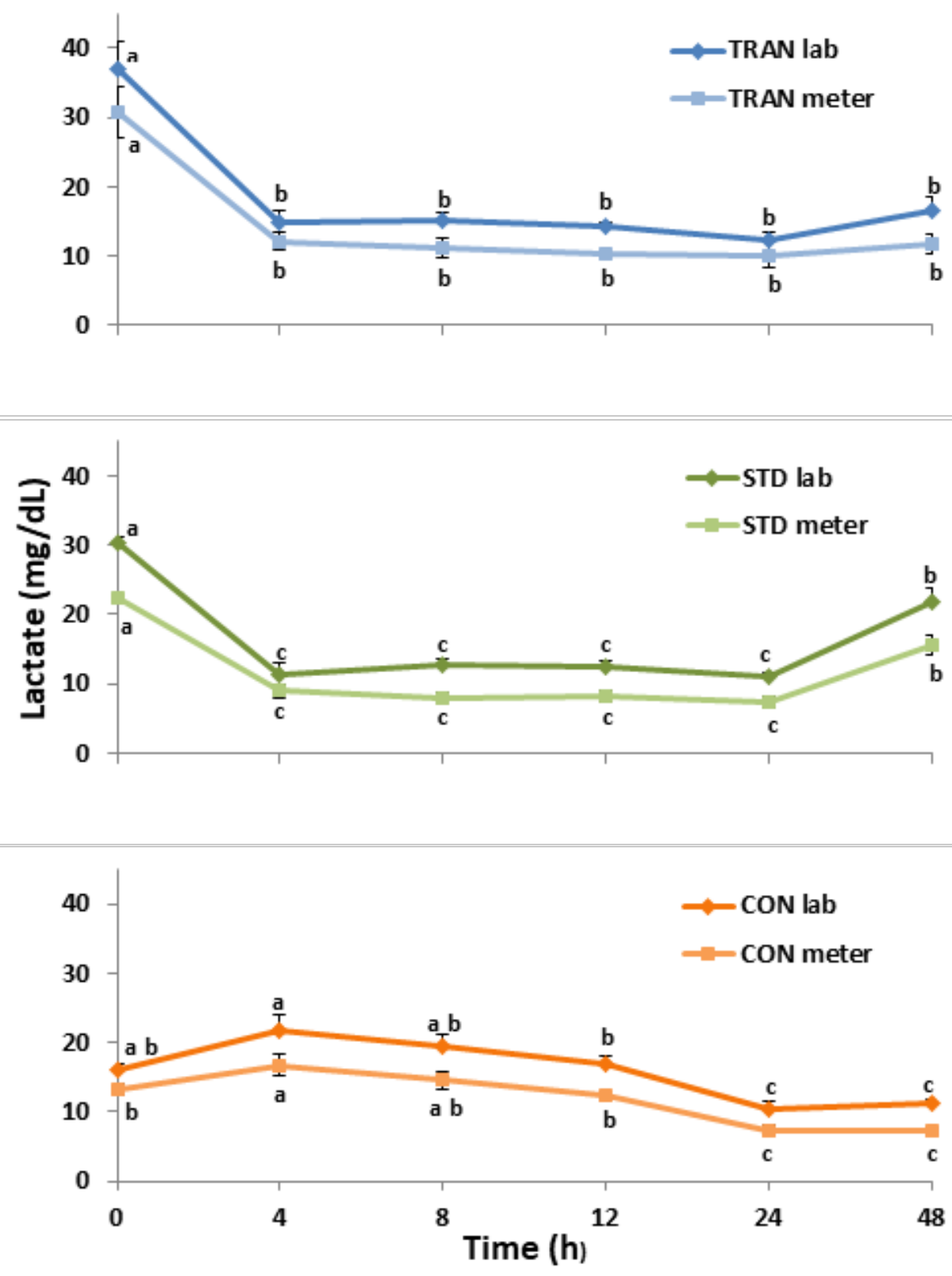

Figure B-10. Graphs showing levels of lactate measured by laboratory assay (lab) and field meter (meter) in three groups of Chinook salmon monitored for $48 \mathrm{~h}$ following a stressor. The transportation group (TRAN, shown in blue shades) was subjected to a 60-minute transport. The standard stressor group (STD, shown in green shades), was subjected to $30-\mathrm{sec}$ in a net. The control group (CON, shown in orange shades) was minimally handled. Error bars are the standard error. Within each time period, groups were compared using ANOVA and Tukey's multiple comparison test. Groups without letters in common are significantly different. 


\section{Discussion}

The 60-min transport was stressful to fish and was significantly more stressful than a 30-sec net stress. Plasma cortisol, which is the indicator that responds most rapidly to a stressor, peaked at the midpoint of the transport, and was more than twice as high as the STD or CON groups immediately following transport. Plasma glucose, which responds more slowly than cortisol, peaked at the end of the 60-min transport, and plasma lactate levels were relatively unchanged during the transport period. The stress response of the STD group was significantly reduced compared to the TRAN group, but was similar to the CON group. The similarity between the stress response of the STD and CON groups was contrary to our hypothesis. We anticipated that the 30-sec net stress would result in a stress response of greater magnitude than the unhandled CON, based on previous studies (Mesa, 1994; Feist and Schreck, 2002; Magnhagen and others, 2015). The likely explanation is that CON stress indicators were elevated above a resting level, thus minimizing the difference between the STD and CON groups.

Study fish were able to quickly mitigate the stress responses elicited by transportation and netting. All stress indicators were significantly reduced $4 \mathrm{~h}$ after the peak levels were observed, but varied in the time required to become similar to the CON group. Plasma cortisol levels for the TRAN and STD groups were similar to the CON group within $4 \mathrm{~h}$. Plasma glucose and lactate took longer to return to CON levels. For the TRAN group, glucose levels were similar to the CON group within $12 \mathrm{~h}$ and lactate levels were similar to CON within $24 \mathrm{~h}$. Similarly, for the STD group, glucose levels were comparable to controls within $8 \mathrm{~h}$ and lactate levels within $24 \mathrm{~h}$. The return to normal levels following a stressor is variable and dependent upon a range of physiological and environmental factors (Wendelaar Bonga, 1997; Pankhurst, 2011; Cooke and others, 2013). Plasma cortisol levels typically respond rapidly to a stressor, with dramatic changes in levels within minutes, followed by a slower return to background or resting levels on the scale of hours (Wendelaar Bonga, 1997; Cockrem, 2013). Plasma glucose and lactate are part of the secondary stress response and thus typically peak after plasma cortisol (Barton, 2000; Pankhurst, 2011) and return to resting levels on similar timelines as plasma cortisol. Transportation is a complex stressor, involving multiple stressors in combination, such as crowding, netting, air exposure, noise and vibration (Barton, 2000; Leggatt and others, 2006). Study fish were able, however, to respond to the stressors of transportation and to return to resting levels within 4 (cortisol) to $24 \mathrm{~h}$ (lactate). The STD stressor group followed a similar pattern, with a lower magnitude stress response and an 8-24 h return to resting levels.

Recovery timelines following a stressor such as transportation provide practical guidance for fishery management programs that move fish. Such information may guide decisions whether a holding period to allow for recovery may be useful after transportation to ensure that fish are not released in a compromised condition. Our findings demonstrated that the physiological stress response of juvenile Chinook salmon (all indicators combined) was detectable up to $24 \mathrm{~h}$ after transportation. The primary stress response (plasma cortisol), considered alone, suggested that within $4 \mathrm{~h}$ following transportation fish were no longer compromised. Barton (2000) reported that salmonids differ in their stress responses to handling and transport and warned that stress indicators should be used in combination (for example, consider cortisol and glucose or lactate) because single indicators are not reliable. To put our reported recovery timeline in perspective, it is important to consider the transportation approach used in this study as compared to traditional approaches. The TRAN group had small groups of fish (20 individuals) held in multiple 19-L containers within a tank. This approach was useful to allow efficient sampling and to minimize disturbances due to repeated sampling, but does not represent a typical fish transport process. Typically fish are transported in a large containers and at significantly higher densities. Transportation using traditional approaches is well documented to elicit stress responses (Schreck and others, 1989; Barton, 2000; Leggatt and others, 2006; Shabani and others, 2016), with recovery within 
24 to $48 \mathrm{~h}$ (Barton, 2000; Shabani and others, 2016). Our modified approach showed a predictable stress response and a similar recovery timeline. Our choice to use the small containers eliminated any significant fish handling immediately prior to transport because the containers were loaded into the tank. Fish were not crowded, chased, netted, or exposed to air during the loading process, whereas they would have been subjected to these stressors using typical transport procedures. The process of capturing and loading fish has been reported, in some cases, to be more stressful than the transport itself (Shabani and others, 2016), so the differences between our transport and traditional transport could be significant. It is likely that the TRAN group had a less stressful experience than fish in typical transport applications, so our reported recovery timelines should be considered minimal times required to ensure that fish are not compromised by transportation.

Variability in the observed stress responses was likely elevated due to our sampling approach. Holding fish in containers and holding containers in a common raceway contributed, separately or in combination, to sample variability and our ability to distinguish between stress indicator levels for test groups. The sampling approach was devised based on the small size of Chinook salmon targeted for evaluation. Study fish were, on average, 55-mm long and weighed less than $2 \mathrm{~g}$, so groups of 20 fish had to be sampled, and their blood combined, to meet the volume requirements for the three stress indicator assays. Individuals can vary widely in their response to the same stressor (Barton, 2000), and we expected lower variability in a pooled sample of 20 individuals. The need to keep a sample group together as they were exposed to a stressor and moved through a recovery period was the reason we elected to hold each sample group in a separate container. We anticipated that confinement in a container, even at the low density we used, might elicit a stress response. To mitigate this effect we added a baseline control group that was not subjected to holding in a container, and we allowed study groups a minimum of $36 \mathrm{~h}$ to adjust to the containers before any sampling occurred. It is difficult to determine if confinement in the container was in itself stressful, as all containers were held together in a raceway. The confinement appeared to be stressful based on cortisol because levels for CON at all sampling events were higher than the baseline control. Our study team was regularly working near the raceway to identify and remove containers for sampling during the $48 \mathrm{~h}$ recovery period. Although procedures were used to minimize disturbances to non-sampled containers, the stress indicators for all study groups suggest that our activity near the raceway could have caused a stress response. For example, the plasma cortisol levels of the TRAN and STD groups peaked at $0 \mathrm{~h}$, were reduced and stable for a period suggesting recovery from the stressor, and then trended toward higher levels beginning at $12 \mathrm{~h}$ (STD) or $24 \mathrm{~h}$ (TRAN). The cortisol levels observed at these times were lower than the peak levels, suggesting a less intense stressor, such as disturbances near the raceway. This background disturbance level is the most likely cause of the variability in the CON group through time. Plasma cortisol levels in the CON group were significantly higher at the start and end of the recovery period and significantly lower in the middle (8-12 h). Sampling activity around the raceway was most concentrated early and late in the recovery period, and aligns well with the higher cortisol levels in the CON group. The instability in CON stress indicator levels made it difficult to assess the intensity of the TRAN and STD responses relative to a control. Our use of individual containers held in a common raceway was useful in many ways, but appeared to contribute to variability in the results as well. Future, similar studies might best limit negative outcomes by separating study groups and sampling events into separate raceways at a distance from each other. 
The field meters reliably detected group differences and tracked temporal trends in plasma glucose and lactate. We included the use of field meters in our study design because they are easy to use in field settings and provide a fast and cost-effective assessment of stress indicators. A variety of field meters have been validated (Cooke and others, 2008; Ball and Webber, 2017; Lindholm and Altimiras, 2017), but each meter needs to be evaluated for each species or stock under study. In this evaluation, indicator levels reported by the field meters were typically lower than the corresponding laboratory assay, but significant changes in levels, such as the highest and lowest levels, were consistently detected. Other researchers have reported similar findings when comparing field meters to traditional laboratory assays (Iwama and others, 1995; Venn Beecham and others, 2006; Ball and Webber, 2017). The meters we tested would be useful in settings where relative, rather than absolute values, can be used to evaluate stress response. One such application may be for future transportation efforts, where managers may wish to document the stress response of transported fish relative to un-transported fish or between separate transport efforts where density and water quality conditions can vary. We would recommend an approach where field meters are used to measure both glucose and lactate to address the concerns raised by Barton (2000) that stress indicators should be used in combination, and single indicators may not accurately describe stress response.

This evaluation described the stress response of juvenile Chinook salmon to a 60-min transport in order to assist managers in the development of plans to protect and restore Chinook salmon in the Sacramento River. The experiments were performed during early summer using late-fall Chinook salmon. The results of the study may be extrapolated to other salmonid stocks, at different times of the year, in order to guide management decisions. Caution in this approach is advised due to the known differences in stress responses based on species/race/stock, age class, time of year, and water temperature (Barton, 2000; Thompson and others, 2008). In addition, as noted, the transport effort used in this study varied from traditional transport approaches. Future plans for transporting juvenile salmon should involve at least a cursory review of stress physiology with the target species, age class, water temperature and transport procedures.

\section{Discussion}

A 60-min transport was significantly more stressful to young Chinook salmon than a standard stressor of being held in a net out of water for $30-\mathrm{sec}$. All stress indicators returned to resting conditions by $24 \mathrm{~h}$ following application of a stressor. The study approach, tailored to working with small fish, increased the variability in indicator levels and contributed to the instability in control group levels over time. Field meters for plasma glucose and lactate consistently generated lower indicator levels than the corresponding laboratory assay, but detected group differences and tracked temporal trends effectively. The authors recommend the use of field meters for future assessments of stress response where relative comparisons, rather than absolute values, are appropriate. Based on these results, the use of a trap-andhaul strategy for the reintroduction of Chinook salmon upstream of Shasta dam should consider a 12-24 $\mathrm{h}$ recovery period after transportation to allow fish time to recover from the significant stress of the transportation process. Considering the non-traditional transport approach used for this evaluation, this recommended recovery period is conservative and may need to be increased to allow recovery from traditional transport approaches that will likely increase the stress response. Study findings are specific to the non-traditional transport approach used, in combination with the species, season, and water temperature during the study. Inference to other applications should be done with caution as stress responses are known to be influenced by a wide range of variables. 


\section{Acknowledgments}

We thank Scott Foot (USFWS), leader of the California-Nevada Fish Health Center, for his expertise and insights into study design and execution, and for use of his laboratory facilities. Ron Stone (USFWS), the production manager for Coleman National Fish Hatchery, and Scott Freund (USFWS), provided fish, facilities, and support throughout the study. This work could not have been accomplished without the assistance of our USGS colleagues: Matt Sholtis, Nick Swyers, Jamie Sprando, and Ryan Tomka.

\section{References Cited}

Ball, E., and Weber, M.J., 2017, Validating a diabetic glucose meter to assess Walleye glucose concentrations: North American Journal of Aquaculture, v. 79, p. 245-249.

Barton, B.A., 2000, Salmonid fishes differ in their cortisol and glucose responses to handling and transport stress: North American Journal of Aquaculture, v. 62, p. 12-18.

Barton, B.A., and Iwama, G.K., 1991, Physiological changes in fish from stress in aquaculture with emphasis on the response and effects of corticosteroids: Annual Review of Fish Diseases, v. 1, p. 326.

Cockrem, J.F., 2013, Individual variation in glucocorticoid stress responses in animals: General and Comparative Endocrinology, v. 181, p. 45-58.

Cooke, S.J., Raby, G.D., Donaldson, M.R., Hinch, S.G., O’Connor, C.M., Arlinghaus, R., Danylchuk, A.J., Hanson, K.C., and Patterson, D.A., 2013, The physiological consequences of catch-and-release angling, perspectives on experimental design, interpretation, extrapolation, and relevance to stakeholders: Fisheries Management and Ecology, v. 20, p, 268-287.

Cooke, S.J., Suski, C.D., Danylchuk, S.E., Danylchuk, A.J., Donaldson, M.R., Pullen, C., Bulte, G., O’toole, A., Murchie, K.J., Kopelman, J.B., Shultz, A.D., Brooks, E., and Goldberg, T.L., 2008, Effects of different capture techniques on the physiological condition of bonefish Albula vulpes evaluated using field diagnostic tools: Journal of Fish Biology, v. 73, p. 1351-1375.

Feist, G., and Schreck, C.B., 2002, Ontogeny of the stress response in Chinook salmon: Fish Physiology and Biochemistry, v. 25, p. 31-40.

Galt, N.J., Froehlich, J.M., McCormick, S.D., and Biga, P.R., 2018, A comparative evaluation of crowding stress on muscle HSP90 and myostatin expression in salmonids: Aquaculture, v. 483, p. $141-148$.

Iwama, G.K., Morgan, J.D., and Barton, B.A., 1995, Simple methods for monitoring stress and general condition of fish: Aquaculture Research, v. 26, p. 272-282.

Leggatt, R.A., Scheer, K.W., Afonso, L.O., and Iwama, G.K., 2006, Triploid and diploid rainbow trout do not differ in their stress response to transportation: North American Journal of Aquaculture, v. 68, p. $1-8$.

Lindholm, C., and Altimiras, J., 2017, Point-of-care devices for physiological measurements in field conditions - A smorgasbord of instruments and validation procedures: Comparative Biochemistry and Physiology, part A, v. 202, p. 99-111.

Magnhagen, C., Backstrom, T., Overli, O., Winberg, S., Nilsson, J., Vindas, M.A., and Brannas, E., 2015, Behavioral responses in a net restraint test predict interrenal reactivity in Arctic charr: Journal of Fish Biology, v. 87, p. 88-99.

Mesa, M.G., 1994, Effects of multiple acute stressors on the predator avoidance ability and physiology of juvenile Chinook salmon: Transactions of the American Fisheries Society, v. 123, p. 786-793.

Pankhurst, N.W., 2011, The endocrinology of stress in fish, an environmental perspective: General and Comparative Endocrinology, v. 170, p. 265-275. 
Schreck, C.B., Solazzi, M.F., Johnson, S.L., and Nickelson, T.E., 1989, Transportation stress affects performance of coho salmon, Oncorhynchus kisutch: Aquaculture, v. 82, p. 15-20.

Shabani, F., Erikson, U., Beli, E., and Rexhepi, A., 2016, Live transport of rainbow trout and subsequent live storage in market, water quality, stress and welfare considerations: Aquaculture, v. 453 , p. $110-115$.

Thompson, L.A., Cooke, S.J., Donaldson, M.R., Hanson, K.C., Gingerich, A., Kleforth, T., and Arlinghaus, R., 2008, Physiology, behavior, and survival of angled and air-exposed Largemouth Bass: North American Journal of Fisheries Management, v. 28, p. 1059-1068.

Venn Beecham, R., Small, B.C., and Minchew, C.D., 2006, Using portable lactate and glucose meters for catfish research, acceptable alternatives to established laboratory methods?: North American Journal of Aquaculture, v. 68, p. 291-295.

Wedemeyer, G.A., Barton, B.A., and Mcleay, D.J., 1990, Stress and acclimation, in Schreck, C.B., and Moyle, P.B., eds., Methods for fish biology: Bethesda, Maryland, American Fisheries Society, p. 451489.

Wendelaar Bonga, S.E., 1997, The stress response in fish: Physiological Reviews, v. 77, p. 591-625. 


\section{Appendix 1. Summary of Detection Counts for the First (February) Release Group of Acoustic-Tagged Late-Fall Run Chinook Salmon by Detection Location and River Kilometer, Shasta Dam, California, 2017}

\begin{tabular}{|c|c|c|c|c|}
\hline River kilometer & Location & $\begin{array}{c}\text { Number of fish } \\
\text { detected }\end{array}$ & Minimum date & Maximum date \\
\hline 476.278 & Blw_Paynes_Ck & 12 & $3 / 31 / 2017$ & $5 / 8 / 2017$ \\
\hline 456.888 & Blw_Salt & 13 & $3 / 31 / 2017$ & $5 / 8 / 2017$ \\
\hline 441.318 & Mill_Ck_Conf & 3 & $3 / 31 / 2017$ & $4 / 16 / 2017$ \\
\hline 425.158 & Abv_WoodsonBr & 15 & $3 / 31 / 2017$ & $5 / 8 / 2017$ \\
\hline 404.428 & GCID_blw & 7 & $4 / 1 / 2017$ & $5 / 9 / 2017$ \\
\hline 394.668 & Blw_IrvineFinch & 15 & $3 / 19 / 2017$ & $5 / 9 / 2017$ \\
\hline 361.728 & BlwOrd & 6 & $4 / 1 / 2017$ & $5 / 9 / 2017$ \\
\hline 344.108 & ButteBr & 16 & $4 / 1 / 2017$ & $5 / 9 / 2017$ \\
\hline 331.158 & Colusa AC3 & 21 & $3 / 8 / 2017$ & $5 / 9 / 2017$ \\
\hline 318.618 & Colusa AC2 & 1 & $5 / 9 / 2017$ & $5 / 9 / 2017$ \\
\hline 296.278 & Colusa BC2 & 7 & $3 / 8 / 2017$ & $5 / 10 / 2017$ \\
\hline 287.208 & Colusa BC3 & 1 & $5 / 10 / 2017$ & $5 / 10 / 2017$ \\
\hline 269.238 & AbvTisdale & 1 & $5 / 10 / 2017$ & $5 / 10 / 2017$ \\
\hline 222.050 & Knights_RST & 16 & $4 / 3 / 2017$ & $5 / 2 / 2017$ \\
\hline 215.180 & Abv_FremontWeir & 19 & $3 / 21 / 2017$ & $5 / 2 / 2017$ \\
\hline 210.360 & Blw_FremontWeir & 15 & $3 / 5 / 2017$ & $5 / 2 / 2017$ \\
\hline 206.480 & Butte6 & 2 & $4 / 25 / 2017$ & $4 / 26 / 2017$ \\
\hline 203.468 & Blw_FRConf & 6 & $4 / 3 / 2017$ & $4 / 26 / 2017$ \\
\hline 170.748 & I80_Br & 3 & $3 / 16 / 2017$ & $4 / 13 / 2017$ \\
\hline 167.008 & SacTrawl1 & 2 & $3 / 12 / 2017$ & $3 / 22 / 2017$ \\
\hline 166.637 & SacTrawl2 & 4 & $3 / 9 / 2017$ & $4 / 7 / 2017$ \\
\hline 152.438 & Freeport & 9 & $3 / 5 / 2017$ & $4 / 26 / 2017$ \\
\hline 138.228 & Hood & 4 & $3 / 16 / 2017$ & $4 / 13 / 2017$ \\
\hline 131.508 & Blw_Sutter & 8 & $3 / 9 / 2017$ & $5 / 3 / 2017$ \\
\hline 131.018 & SutterSlough & 2 & $3 / 13 / 2017$ & $4 / 4 / 2017$ \\
\hline 128.608 & Blw_Steamboat & 9 & $3 / 9 / 2017$ & $4 / 19 / 2017$ \\
\hline 127.211 & ToeDrainRST & 2 & $3 / 13 / 2017$ & $4 / 28 / 2017$ \\
\hline 126.230 & Mok_SF_Blw_Hwy 12 & 1 & $3 / 19 / 2017$ & $3 / 19 / 2017$ \\
\hline 124.612 & MinorBlwSutter & 1 & $3 / 13 / 2017$ & $3 / 13 / 2017$ \\
\hline 124.532 & MinerNorth & 1 & $4 / 4 / 2017$ & $4 / 4 / 2017$ \\
\hline 120.167 & ToeDrainBase & 5 & $3 / 13 / 2017$ & $4 / 30 / 2017$ \\
\hline 119.058 & BlwGeorgiana & 2 & $3 / 5 / 2017$ & $3 / 10 / 2017$ \\
\hline 114.377 & SouthofBW & 2 & $3 / 13 / 2017$ & $3 / 23 / 2017$ \\
\hline 111.833 & BaseSutterSteam & 1 & $3 / 14 / 2017$ & $3 / 14 / 2017$ \\
\hline 111.730 & YB_LibertyIsBase & 19 & $2 / 28 / 2017$ & $4 / 30 / 2017$ \\
\hline 107.512 & Hwy84Ferry & 19 & 2/28/2017 & 4/30/2017 \\
\hline
\end{tabular}




\begin{tabular}{clcll}
\hline River kilometer & \multicolumn{1}{c}{ Location } & $\begin{array}{c}\text { Number of fish } \\
\text { detected }\end{array}$ & Minimum date & Maximum date \\
\hline 101.468 & SR_Mouth & 6 & $3 / 9 / 2017$ & $5 / 3 / 2017$ \\
100.489 & GeorgeMok & 4 & $3 / 13 / 2017$ & $4 / 14 / 2017$ \\
97.910 & RioVistaBr & 18 & $2 / 25 / 2017$ & $4 / 28 / 2017$ \\
94.449 & ThreeMile & 2 & $3 / 14 / 2017$ & $4 / 29 / 2017$ \\
86.948 & AntiochBridge & 3 & $3 / 22 / 2017$ & $4 / 14 / 2017$ \\
86.078 & DeckerIsland & 15 & $3 / 2 / 2017$ & $4 / 28 / 2017$ \\
71.766 & ChippsW & 8 & $3 / 9 / 2017$ & $4 / 30 / 2017$ \\
1.710 & GoldenGateE & 1 & $5 / 5 / 2017$ & $5 / 5 / 2017$ \\
0.800 & GoldenGateW & 2 & $5 / 3 / 2017$ & $5 / 4 / 2017$ \\
0.172 & TowerBridge & 8 & $3 / 14 / 2017$ & $5 / 3 / 2017$ \\
\hline
\end{tabular}


Publishing support provided by the U.S. Geological Survey

Science Publishing Network, Tacoma Publishing Service Center

For more information concerning the research in this report, contact the Director, Western Fisheries Research Center

U.S. Geological Survey

6505 NE 65th Street

Seattle, Washington 98115

https://wfrc.usgs.gov/ 
